(B. S. Sup. Vol. 2 pp. 360, Sec. 749)

GEOLOGICAL SURVEY CIRCULAR 693

\title{
Remote Sensing Platforms
}

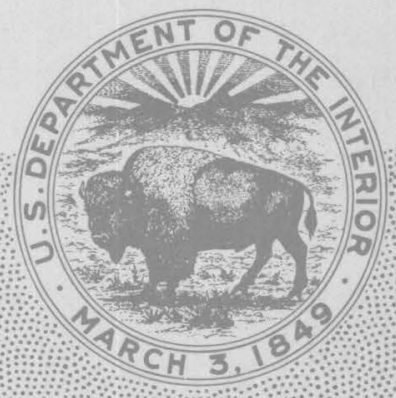





\title{
Remote Sensing Platforms
}

\author{
By Alden P. Colvocoresses
}

GEOLOGICAL SURVEY CIRCULAR 693 
United States Department of the Interior ROGERS C. B. MORTON, Secretary

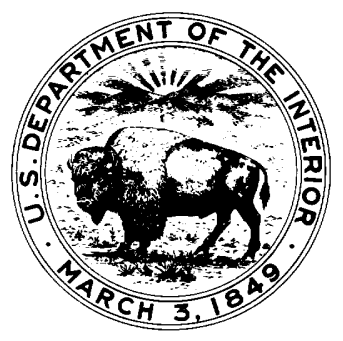

Geological Survey

V. E. McKelvey, Director 


\section{CONTENTS}

Airborne platforms

Balloons

General considerations

Free balloons

Payload-altitude capabilities

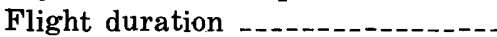

Cost

Stability -..-_-

Some meteorological considerations for free balloon flights

Project Stratoscope

Powered balloons

Tethered ballowns

Descriptions and capabilities

Winches

Tethers

Tethered balloons for archeological studies

Tethered and free balloon

manufacturers

Aircraft

General considerations

Platform stability

Descriptions of aireraft

Low altitude, up to $9 \mathrm{~km}(29,500$

ft) service ceiling, propeller

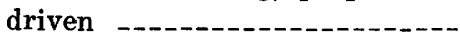

Cessna 180 Skywagon -......

Beecheraft Bonanza -...-..--

Cessna Super Skymaster -...

Beecheraft Queen Air -...-.-

Grumman Mohawk ......-.-. 10

Lockheed YO-3A _..-_-_-_-_ 10

Medium altitude, 9 to $15 \mathrm{~km}$

$(29,500-49,000 \mathrm{ft})$ service ceil-

ing, propeller or jet

Rockwell Standard Jet Commander 1121

Gates Learjet

Fairchild Hiller Porter -.--.-

Lockheed NP3A Orion -....--

Douglas Skywarrior RA-3B -.

Lockheed NC130B (RC130) --

Boeing Stratolifter (RC135A)

E-Systems (formerly LTV)

L450F reconnaissance aircraft

High altitude, service ceiling above

$15 \mathrm{~km}(49,000 \mathrm{ft})$

North American Rockwell X15.

General Dynamics/Martin

RB57F (WB57F) .......-

McDonnell Douglas RF-4C --

Lockheed U-2
Page

1

1

1

2

2

2

2

2

3

4

4

4

5

5

6

6

7

7

8

9

9

9

9

9

10

10

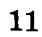

11

11

11

12

12

12

13
Airborne platforms-Continued

Aircraft-Continued

Descriptions of aircraft-Continued

High altitude, service ceiling above $15 \mathrm{~km}(49,000 \mathrm{ft})$ - Continued Lockheed SR71 (YF-12) ---- 16

Bell helicopter 47G-3B-1 ......- 16

Northrop Falconer drone -.....- 16

Goodyear blimps -...-- 17

Schweizer sailplane SGS 2-32 -_-_ $\quad 17$

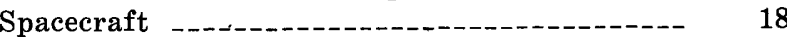

General considerations -

Data transmission -

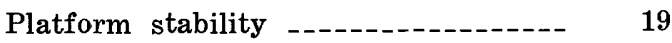

Descriptions of spacecraft -._-_-_-_- 19

Experimental, unmanned, Earth viewing

Film return -

Electronic data transmission, generally sun synchronous _-..--- 20

Nimbus _- 21

TIROS _.

Earth Resources Technology

Satellite (ERTS) _._._. 22

Electronic data transmission, geosynchronous _._._. 23

Application Technology

Satellite (ATS)

Synchronous Meteorological

Satellite (SMS) _...-..-

Proposed high-resolution geosynchronous systems ---

Experimental, unmanned, extraterrestrial

Ranger _-_...- 25

Lunar Orbiter _..._. 25

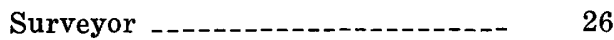

Mariner (flyby) -

Mariner 71 (Mars Orbiter) _...- $\quad 26$

Mariner Venus/Mercury _-_._-_ 27

Viking -

Pioneer (Jupiter) _-_._-_._-_.- 28

Experimental, manned space flight _-_ $\quad 28$

Mercury _... 29

Gemini _...

Apollo _-_._- 29

Lunar Rover Vehicle _._._... 30

Skylab _-_._-_-_ 31

Space Shuttle -.-_._- 31

Operational-NOAA _._._. 32

ESSA-TOS _.

ITOS

ITOS-D _._._. 33

GOES

Bibliography _._. 33 .

.

5

5

6

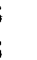

7

7

8

9

9

9

0

1

32

2

3

33




\section{ILLUSTRATIONS}

FIGURE 1. Graph showing payload-altitude capabilities of polyethylene free balloons

2. Graph showing payload-altitude capabilities of scrim free balloons

3. Photograph of sunrise inflation of a $23,000-\mathrm{m}^{3}$ polyethylene balloon_

4. Photograph of a tandem balloon system being reeled up in preparation for launch

5. Graph showing cost estimates for polyethylene and scrim free balloons

6. Map showing typical stratospheric wind flow at $37 \mathrm{~km}(120,000 \mathrm{ft})$ during midsummer

7. Map showing first approximation of areas in the northern hemisphere where balloon hovering and boomerang drifts are feasible during summer within the altitude range $14 \mathrm{~km}$ to $22 \mathrm{~km}$

8. Diagram of hovering balloon flight C70-18

9-12. Photographs:

9. Project Stratoscope II carrying a 3-ton optical telescope to an altitude of $24,400 \mathrm{~m}(80,000 \mathrm{ft})$

10. The Stratoscope II telescope with guidance package and high-resolution camera equipment _......-.

11. A $710-\mathrm{m}^{3}$ spherical tethered balloon being prepared for launch at the White Sands Missile Range, N. Mex. ----

12. Single-hull British A-shape kite balloon with a volume of $2,800 \mathrm{~m}^{3}$

13. Graph showing payload versus altitude for British barrage balloons. 14-24. Photographs:

14. Walking the balloon and aerial camera to the target area.-

15. The radio-controlled Hasselblad EL 500 camera hung in its gimbal as seen from below

16. Cessna 180 Skywagon

17. Beecheraft Bonanza A36 _.........

18. Cessna 337 Turbo-System Super Skymaster

19. Beecheraft Queen Air B80

20. Grumman OV-1 Mohawk observation aircraft

21. Lockheed YO-3A quiet reconnaissance aircraft

22. Rockwell Standard Jet Commander 1121

23. Gates Learjet 24

24. Fairchild Hiller Porter

25. Diagram of NASA 927 Lockheed NP3A Orion flight con-

26-28. Photographs: figuration

26. Douglas Skywarrior RA-3B

27. Lockheed NC130B (RC130) Earth Resources Aircraft (NASA 929)

28. Boeing RC135A

29. Diagram of isometric view of Boeing RC135A showing the USQ-28 aerial electrophotomapping system

30. Photograph of E-Systems L450F reconnaissance aircraft in piloted configuration

31. Photograph of North American Rockwell X15 research aircraft - -

32. Diagram of General Dynamics/Martin RB57F _...

33. Photograph of MeDonnell Douglas (Phantom II) RF-4C

34. Diagram of McDonnell Douglas (Phantom II) RF-4C flight configuration

35. Photograph of Lockheed U-2

36. Photograph of Lockheed SR71A strategic reconnaissance aircraft_-

37. Diagram of USDA Forest Service helicopter fire spotter, Bell $47 \mathrm{G}-$ 3B-1

Page

38

39

40

40

41

42

42

43

44

44

45

45

46

47

47

48

48

48

49

49

50

51

51

51

52

52

53

53

53

54

54

54

55

55

56

56

57 
38-41. Photographs:

38. Northrop Falconer surveillance drone -

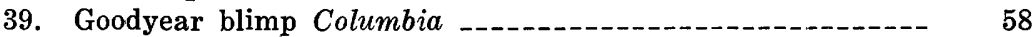

40. Television camera mounted on blimp Mayflower -...-.-. 58

41. Schweizer sailplane SGS 2-32

42. Diagram of proposed film return Earth-sensing space vehicle

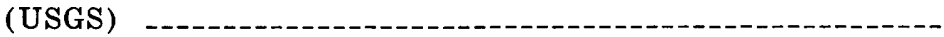

43. Photograph of aircraft recovering a capsule such as might contain film from an Earth-sensing spacecraft _....... 59

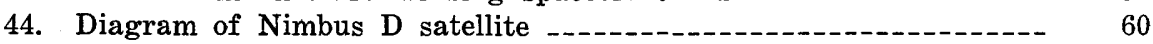

45. Diagram of TIROS M spacecraft _-_-_-_-_-_- 60

46. Artist's conception of Earth Resources Technology Satellite (ERTS)

47-49. Diagrams:

47. ERTS system -

48. ATS-B systems and interior experiments - 62

49. ATS-B exterior experiments - 62

50. Artist's conception of ATS-F and ATS-G _-_-

51. Artist's conception of Synchronous Meteorological Satellite (SMS) 63

52. Diagram of a 6-satellite high-resolution geosynchronous Earth-

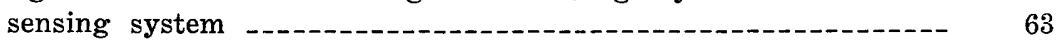

53. Photograph of Ranger lunar probe -

54. Artist's conception of Lunar Orbiter spacecraft -._-_-_-_-_-_- 64

55. Photograph of Lunar Orbiter E, showing camera lens -_...-_- 64

56. Diagram of Surveyor lunar lander -

57. Photograph of Mariner 4 spacecraft (flyby version) ---_---- 65

58. Artist's conception of Mariner 9 spacecraft (Mars Orbiter) ---_-- 65

59. Diagram of Viking spacecraft _._- 66

60. Artist's conception of Pioneer spacecraft

61. Artist's conception of Mercury, Gemini, and Apollo spacecraft ---- 67

62. Photograph of Apollo service module, showing Scientific Instrument Module (SIM)

63-66. Diagrams:

63. Sketch of instruments carried in Apollo SIM bay -...-- 68

64. Sketch of Lunar Rover Vehicle, showing instruments --- 68

65. Skylab-A -..- 69

66. Skylab-A, activation and operation-periods of occupancy-- $\quad 70$

67. Artist's conception of Space Shuttle -.-_-_-_-_-_-_-_-_- 71

68. Diagram of evolution of TIROS, TOS, ESSA satellites

69. Photograph of TIROS Operational Satellites (TOS) -

70. Photograph of interior of the Environmental Survey Satellite, ESSA 3 -

71. Artist's conception of NOAA Satellite ITOS -

72. Diagram of NOAA Satellite ITOS-D - 


\section{ABBREVIATIONS AND ACRONYMS}

$\begin{array}{ll}\text { AFCRL } & \text { Air Force Cambridge Research Laboratories } \\ \text { APT } & \text { Automatic Picture Transmission } \\ \text { ARPA } & \text { Advanced Research Projects Agency } \\ \text { ATS } & \text { Application Technology Satellite } \\ \text { AVCS } & \text { Advanced Vidicon Camera System } \\ \text { bps } & \text { Bits per second } \\ \text { dm } & \text { Cubic decimeter } \\ \text { EREP } & \text { Earth Resources Experiment Package } \\ \text { ERTS } & \text { Earth Resources Technology Satellite } \\ \text { FAA } & \text { Federal Aviation Agency } \\ \text { f.l. } & \text { Focal length } \\ \text { FM } & \text { Frequency Modulation } \\ \text { GOES } & \text { Geostationary Operational Environmental } \\ & \text { Satellite } \\ \text { Hz } & \text { Hertz } \\ \text { inm } & \text { International nautical mile } \\ \text { ITOS } & \text { Improved TIROS Operational System } \\ \text { kbps } & \text { Kilobits per second } \\ \text { kn } & \text { Knot } \\ \text { LST } & \text { Large Space Telescope } \\ \text { MAC } & \text { Military Airlift Command }\end{array}$

MATS Military Air Transport Service Mbps Megabits per second

$\mathrm{MHz}$ Megahertz

NASA National Aeronautics and Space Administration

NOAA National Oceanographic and Atmospheric Administration

PCM Pulse Code Modulation

PM Phase Modulation

SAMOS Satellite and Missile Observation System SEOS Synchronous Earth Observation Satellite SIM Scientific Instrument Module

SLAR Side-looking Airborne Radar

SMS Synchronous Meteorological Satellite

SPM Solar Proton Monitor

TIROS Television Infrared Observation Satellite TOS TIROS Operational Satellite

TV Television

VHF Very High Frequency

VTPR Vertical Temperature Profile Radiometer 


\title{
Remote Sensing Platforms
}

\author{
By Alden P. Colvocoresses
}

The author of this report is actually the author-editor with major contributions by others as follows: George Nolan of AFCRL (balloons), David Landen of USGS (aircraft), Stanley Addess of USGS (NASA spacecraft), and Arthur Schwalb and Lewis J. Allison of NOAA (NOAA spacecraft).

This report was initiated by the American Society of Photogrammetry as a chapter in the forthcoming "Manual of Remote Sensing." A preliminary version titled "Platforms," dated January 1972, has already been given limited distribution for reviewing purposes.

Typical vehicles which carry remote sensors into the atmosphere or beyond into space are described and illustrated, and their performance characteristics are listed. No attempt is made to completely catalog or to cover the history of remote-sensing vehicles. Airborne platforms and spacecraft in use or defined as of 1971-73 were selected from the vehicles which have gained widest acceptance, demonstrated a unique capability, or have been defined for future remote-sensing missions. A wide variety of nonorbiting rockets have carried cameras and other sensors into space, but since current United States remote-sensing programs do not include rockets, except for astronomic observations, rockets are not included. However, as of 1972, British industry was building a variety of rockets specifically designed as remote-sensing platforms. Except for a unique British kite balloon, only American platforms are covered, and, therefore, this circular could be viewed as a contribution to any international effort to cover the subject.

Remote sensing of the Earth is the prime consideration, but sensing of the other planets and moons is also considered. Astronomy, except to the extent indicated above, is not included nor is the measurement of the force fields such as gravity or magnetics.

\section{AIRBORNE PLATFORMS}

\section{BALLOONS \\ GENERAL CONSIDERATIONS}

The objective of this section on free and tethered balloon platforms is to provide sufficient technical and descriptive information to the experimenter so that he can judge whether a balloon is an appropriate platform for his sensor. He can obtain an indepth understanding of balloon capabilities, limitations, and new developments by referring to the literature in the bibliography and contacting the organizations involved in balloon activities.

Although balloons were used as camera platforms during the Civil War, it was not until the late 1950's that a serious program was initiated to utilize balloons for a wide variety of remotesensing experiments. By 1972, balloons had risen to above $49 \mathrm{~km}(160,000 \mathrm{ft})$ and carried a wide variety of sensors that looked at the Earth's surface, the atmosphere, and celestial bodies. Practically all remote-sensing balloon flights are unmanned, but manned balloon flights, particularly by astronomers, have also been successful (Stehling, 1971).

The balloon is a remote-sensing platform which permits the experiment or operation to define the shape, size, and performance required of the carrier; however, the use of balloons is restricted by meteorological factors, especially by wind influences. 


\section{FREE BALLOONS}

PAYLOAD-ALTITUDE CAPABILITIES

The current range of altitude and associated payload capabilities for free balloons are shown in figures 1 and 2 . In figure 1, each curve represents a single, flight-proven balloon made from a superior quality, lightweight polyethylene film. (Not all of the existing balloon designs are included on the charts.) Scrim balloons are made from Mylar film laminated with a reinforcing scrim, or mesh, of Dacron thread. The high-strength scrim materials are used for carrying payloads much heavier than is possible with polyethylene balloons. Figure 2 indicates the range of payload-altitude capabilities for designated volumes of scrim balloons.

Although it is convenient to designate the balloons shown by their volumes, it is important to note that each curve represents an individual design and may be very different from the others in gore pattern, material thickness, type and placement of reinforcements, and location of ducts, valves, etc.

In addition to the weight of the sensor, the payload includes the weight of parachute, instrumentation for balloon command and control, tracking beacons or radar reflectors, ballast and rigging, and other structures.

A gas valve located at the top of the balloon is a highly desirable component of a balloon platform. It gives the operator the flexibility of controlling ascent and descent rates to conform to a desired flight profile, or of changing altitude to take advantage of more favorable wind conditions. Furthermore, a valve provides an added means of bringing the balloon to Earth after payload separation.

Figure 3 shows the inflation of a $23,000-\mathrm{m}^{3}$ polyethylene balloon shortly after sunrise-the time of day when surface winds are normally most favorable for launches.

Operational requirements sometimes will necessitate the use of a tandem balloon system as shown in figure 4 . In this system all of the lifting gas is contained in the top or launch balloon before release. As the system ascends, the expanding gas transfers into the main or bottom balloon.

\section{FLIGHT DURATION}

Zero-pressure balloons usually carry ballast, which may be released either to increase the ascent rate or to compensate for a descent caused by thermal effects. The quantity of ballast that can be carried determines the flight duration of a zero-pressure balloon. This weight factor is an important consideration in selecting the proper balloon to meet special flight-profile requirements or to achieve a flight longer than 1 day.

In contrast to the zero-pressure balloons, superpressure balloons are completely sealed and require no ballast. They float at a constantdensity altitude and are capable of flight durations of many months. The superpressure balloons, however, can carry payloads of less than $40 \mathrm{~kg}$ and are relatively expensive. Therefore, their use is generally restricted to special applications that involve long duration flights with lightweight sensors.

$\operatorname{cosT}$

Rough estimates of the costs of free balloon platforms made of polyethylene or scrim material may be made from figure 5. Costs for items such as helium, operations, flight-control instrumentation, and travel are not included. For payloads greater than $1,000 \mathrm{~kg}$, polyethylene balloons are normally reinforced with load tapes and a cap on the top.

STABILITY

The inherent stability of the free-floating balloon is one of its most attractive assets for scientific applications. If reasonable care is taken in mounting and packaging the instruments, camera systems, spectrometers, magnetometers, telescopes, and interferometers can be flown without difficulty.

The motion of the payload is dependent upon the mechanical properties of the payload suspension system. As the partially inflated balloon ascends through the atmosphere, the loadline tends to wind and unwind in random fashion, causing the payload to rotate at rates that are usually much less than $2 \mathrm{r} / \mathrm{min}$. At the same time, the payload may behave as a simple or compound pendulum. Angular displacements 
from the vertical of $2^{\circ}$ or less are generally observed. After the system has reached float equilibrium, however, payload motions need not be considered for most types of experiments. Gradual changes in payload orientations do occur. Torsional rotation rates are generally a few revolutions per hour with a maximum rate of 12 $\mathrm{r} / \mathrm{h}$ having been observed. Displacements from the vertical due to pendulum motion have been reported to be no greater than $0.5^{\circ}$ or a horizontal displacement of the payload about $1.4 \times 10^{-3}$ times the length of the loadline.

\section{SOME METEOROLOGICAL CONSIDERATIONS FOR FREE BALLOON FLIGHTS}

The horizontal trajectory of a free balloon is primarily determined by the winds it encounters while airborne. However, a considerable degree of trajectory control is possible by selecting periods of the year, as determined from climatology, when repeatable wind patterns exist and by controlling the balloon's altitude using ballast drops and gas valving.

Three basic flight profiles may have application to the use of balloons as platforms for remote sensing of the Earth's surface: precision ballooning, station-keeping, and boomerang. Fundamental to these profiles is the occurrence during the summer of stratospheric easterlies, that is, winds blowing from the east. This phenomenon occurs annually and thus can be safely used for planning flight operations. A typical example of the summertime stratospheric easterlies is given in figure 6 , which shows streamline analysis of rocketsonde wind observations at the $5 \mathrm{mb}$ surface (approximately $36.6 \mathrm{~km}$ or $120,000 \mathrm{ft}$ ) on July 22,1964 . The lower boundary of these easterlies is approximately $18.3 \mathrm{~km}(60,000 \mathrm{ft})$, and they extend upward with their strength increasing with altitude and also toward lower latitudes at the same altitude. Peak values occur during the latter part of July with minimum values at the beginning and end of summer.

The stratospheric easterlies have been used for precision ballooning-operations in which a balloon overflies a specific geographical location, such as an instrumented area on a test range. One might also envision the utilization of this wind phenomenon for cross-country traverses of balloons carrying remote sensors.
Station-keeping and boomerang balloon flight profiles are also associated with the summertime occurrence of the stratospheric easterlies. However, to achieve these profiles a layer of westerlies (winds blowing from the west) must exist below the stratospheric easterlies. In this situation there are opposite flows of air in adjacent layers of the atmosphere, providing the setting for a balloon to drift back and forth across an area of interest merely by changing altitude. Between these layers of easterlies and westerlies a minimum wind layer exists, which provides the opportunity to hover or station keep a balloon over a relatively small area for an extended period. Figure 7 gives information on locations in the Northern Hemisphere where balloon station-keeping and boomerang profiles can be flown. Figure 8 shows the horizontal and vertical trajectories of a station-keeping balloon flight which remained over an area having a radius of approximately $75 \mathrm{~km}$ (40 international nautical miles) for 72 hours.

\section{PROJECT STRATOSCOPE}

By the late 1950's, astronomic experimenters found that when only one or two functions in the balloon were to be performed it was cheaper and more convenient to launch a variety of unmanned balloons rather than a more complex manned flight. Simple experiments could be sent aloft unmanned, with radio signals used to point the equipment, control the flight, and record the data.

An unmanned project, Stratoscope, achieved a series of outstanding successes. Stratoscope I, proposed by Martin Schwarzchild, an astronomer at Princeton University, and funded by the Office of Naval Research was originally launched in 1957 and was quickly followed by several flights. The results included a series of very detailed pictures of solar surface granulations. By 1963, a double-balloon system had taken a 3,150 $\mathrm{kg}(7,000 \mathrm{lb})$ payload to an altitude of about $24,400 \mathrm{~m}(80,000 \mathrm{ft})$. That year new infrared spectra were obtained of the Moon, Jupiter, and seven stars.

Stratoscope II was sponsored by the National Science Foundation, the Office of Naval Research, and NASA. In 1970, this balloon lifted a radio-controlled $92-\mathrm{cm}(36-\mathrm{in}$.$) diameter tele-$ 
scope and brought back extremely high resolution photographs of Jupiter, Uranus, two kinds of nebulas, and Seyfert galaxies whose bright nuclei resemble quasars (figs. 9 and 10).

The performance characteristics of Stratoscope II were as follows:

Ceiling: $24,400 \mathrm{~m}(80,000 \mathrm{ft})$.

Size: Length, $200 \mathrm{~m}$ (660 ft) ; volume, $148,600 \mathrm{~m}^{3}$.

Payload: $3,150 \mathrm{~kg}(7,000 \mathrm{lb})$.

Special equipment: A 64-channel radio telemetry system provided a high degree of remote control. A guidance system for the remotely controlled telescope made by RCA Laboratories, Princeton, N.J., provided a pointing accuracy of 0.02 second of arc. A key element of Stratoscope II was a precise optical system with a 180-kg (400-lb), 92-cm (36-in.) diameter primary mirror. The Stratoscope telescope was designed by Perkin-Elmer Corp., Norwalk, Conn. It had a 5.5-m (18-ft) main tube assembly with a 3.3m (11-ft) side arm forming an L-shaped telescope. The side arm held the guidance equipment, the camera equipment, and the high-resolution TV camera. A lowresolution TV camera was boresighted with the main telescope. After each flight, the system and the exposed film were returned to Earth.

\section{POWERED BALLOONS}

During 1972 the U.S. Air Force launched at least one powered balloon, Pobal, which has been reported by "Aviation Week and Space Technology" (1973). The balloon of $20,200 \mathrm{~m}^{3}$ $\left(710,000 \mathrm{ft}^{3}\right)$ rose to a height of $18,300 \mathrm{~m}$ $(60,000 \mathrm{ft})$ and was powered by a batterydriven slowly rotating propeller of $9 \mathrm{~m}(30 \mathrm{ft})$ diameter. The experiment had a successful duration of 3 hours after which the rudder became dislodged due to winds. A powered balloon as compared with the passive type has the advantage of being remotely controlled and, within limitations, being guided along a path or hovering over a given area. If successfully developed, this mode has considerable potential application as a remote-sensing platform.

\section{TETHERED BALLOONS}

The basic sources of the material that follows are listed in the references. Particular attention is directed to the "Tethered Balloon Handbook" prepared for the AFCRL by Myers (1968). This work is an authoritative compilation of the history, development, applications, and listings of available modern equipment for tethered balloon activities. A paper by Young (1968) presents an excellent overview of tethered balloon technology and offers predictions for future capabilities. A report by Battelle Columbus Laboratories (1971) sponsored by ARPA provides both a survey and technical assessment of tethered balloon systems.

When considering the use of tethered balloons, it is essential that the initial planning be concerned with the atmosphere and the air space in which the balloon will be flying. Are wind conditions and other meteorological factors favorable, and are there air-safety constraints imposed on the location of the desired operation? The restrictions imposed by meteorological factors will depend in large part upon the type of tethered balloon system being considered. The use of air space must be coordinated with the controlling agency. In the United States this is either the FAA or the responsible agency in the case of use of a restricted air space. FAA regulations pertaining to tethered balloons can be found in "Federal Aviation Regulations," pt. 101, v. 6.

Although tethered balloons have been associated historically with wartime, serving as both a passive means of defense against aerial attacks and as observation platforms for artillery spotters, present-day usage is much broader, encompassing a variety of scientific disciplines. Tethered balloons are being used to carry aloft various types of sensors, meteorological measuring equipment, communication relays, and antennas.

\section{DESCRIPTIONS AND CAPABILITIES}

Tethered balloon systems are usually custom tailored for a particular operation. The three main types of tethered balloons in use are the sphere, the natural shape, and the single-hull aerodynamic or streamlined shapes in a variety 
of fineness ratios and fin designs. The hull design chosen for a system depends on such requirements as downwind displacement, altitude, payload, windspeed, flight duration, and anticipated life. The sphere has been used since the inception of tethered balloons and is far from obsolete. Although spheres are generally limited to winds below $55 \mathrm{~km} / \mathrm{h}(30 \mathrm{kn})$, there are several areas of the world where tethered systems utilizing a spherical balloon could be used several months per year to fly at altitudes up to 3,000 $\mathrm{m}(10,000 \mathrm{ft})$ above sea level. The principal advantage of the sphere is its relatively low cost compared with the streamlined shapes.

Figure 11 shows a $710-\mathrm{m}^{3}$ spherical balloon readied for launch. This system employed three tether lines to assure control of the balloon in maintaining its position over a relatively small area. This particular balloon has been used repeatedly as a platform for a variety of experiments. It has, among other combinations of payload and altitude, the capability of carrying a 200-kg (440-lb) payload to $1 \mathrm{~km}(3,300 \mathrm{ft})$ with a maximum wind of $35 \mathrm{~km} / \mathrm{h}(20 \mathrm{kn})$.

The natural shape, mainstay of free ballooning, also provides a suitable tethered balloon. Its principal advantage is relatively low cost. However, its use is limited to winds of less than 30 $\mathrm{km} / \mathrm{h}$ (15 kn).

Streamlined balloons have much higher windspeed limitations. They also tend to fly nearer to the tether point than spheres in the same wind fields on a single tether. Figure 12 is a picture of a $2,800 \mathrm{~m}^{3}$ single-hull A-shape kite balloon, designed and manufactured by Airborne Industries, Ltd., Leigh-on-the-Sea, Essex, England, previously called Lea Bridge Industries. This type of balloon was used in World War II.

Figure 13 is a payload-altitude graph for the three most popular models. These curves were developed for $135 \mathrm{~kg}$ winch tension on the tether cable, $30^{\circ} \mathrm{F}$ superheat temperature of the balloon gas above ambient standard temperature, and a cable weight of $134 \mathrm{~kg} / \mathrm{km}$. Costs range from $\$ 15,000$ to $\$ 35,000$ and are subject to change. The envelopes of these balloons have safely withstood windspeeds in excess of 110 $\mathrm{km} / \mathrm{h}(60 \mathrm{kn})$.

Modern tools, both theoretical (computerized models) (Myers and Vorachek, 1971; Doyle and
Vorachek, 1971; and Doyle and others, 1973) and experimental (instrumented flights) are being utilized to improve tethered balloons and also to provide accurate stability data for existing systems. The recently developed ARPA Family 2 balloons, for example, fly in $140-\mathrm{km} / \mathrm{h}$ (75-kn) winds. Measurements directly applicable to sensors have been obtained by cinetheodolite and telemetry at the U.S. Air Force tethered balloon facility in New Mexico. The data include position, velocity, accelerations,

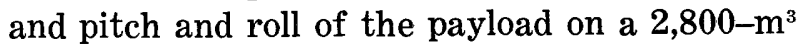
(100,000- $\mathrm{ft}^{3}$ ) A-shape (modified BJ barrage) balloon with cable lengths up to $2,750 \mathrm{~m}(9,000$ $\mathrm{ft})$ in winds to $50 \mathrm{~km} / \mathrm{h}(27 \mathrm{kn})$. Similar data were obtained using an $800-\mathrm{m}^{3}\left(28,000-\mathrm{ft}^{3}\right)$ natural-shaped balloon on a tri-tether at altitudes up to $610 \mathrm{~m}(2,000 \mathrm{ft})$ in winds to 25 $\mathrm{km} / \mathrm{h}(13 \mathrm{kn})$.

\section{WINCHES}

Winches for tethered balloon operations are used to raise and lower balloons to the desired altitude and to make the necessary operational adjustments of the balloon altitude during flight operations. Relatively inexpensive hand-operated winches, or even fishing reels, may be used for small, low-altitude balloons. Power-driven winches come with a multitude of available features and can range in price from several hundred dollars to several hundred thousand dollars. Some of the features of power-driven winches for tethered balloon applications, which add significantly to the cost of the winch, are variable speed drives, capstan or traction drives, level wind mechanisms, and various line speed, tension, and footage-measuring instruments. The winch system installation may be permanent, mobile, or portable.

Tethered balloon winches are rarely off-theshelf items and are usually custom tailored for a specific application. Many winch manufacturers have standard components from which special winches can be assembled, thereby eliminating much of the design time and expense which would otherwise be required.

\section{TETHERS}

All tethers require a suitably high tensile strength, a high strength-to-weight ratio, low 
drag, low stretch, torque stability, high flexibility, abrasion resistance, and easy splicing. Typical balloon-tethering configurations are the single, dual, or tri-tether arrangements. The different configurations offer the various degrees of freedom which are dictated by the intended balloon operations. In many instances the tether line is designed to serve additional purposes: to carry the antenna, to encase the power line running from ground to sensors, to support an array of sensors along its length or the tubing for transferring helium to the balloon, etc. Tapered or stepped-diameter tethers may be desired for high-altitude flights where the weight of a constant-diameter tether cannot be safely borne. Most tether manufacturers have the capabilities for producing a unique tether to fit a specific need.

\section{TETHERED BALLOONS FOR ARCHEOLOGICAL STUDIES}

Tethered balloons have been used successfully by Julian $\mathrm{H}$. Whittlesey to support aerial cameras for recording and mapping archeological sites (figs. 14 and 15) in Turkey, Greece, Italy, and Cyprus. Camera altitudes ranged from 10 to $610 \mathrm{~m}$ (30 to $2,000 \mathrm{ft}$ ), with Linhof, Graflex, and Hasselblad cameras in single and multiple (multiband) form. Aerodynamic airfoil balloons were also utilized in the presence of high winds. Various schemes were used to obtain stereoscopic coverage. Some of the sites photographed were in shallow water. The performance of the tethered balloons used by Whittlesey was as follows:

Ceiling: From 10 to $610 \mathrm{~m}$ (30 to $2,000 \mathrm{ft}$ ). Windspeed: With parafoil or ovoid shape, flown in winds from 25 to $40 \mathrm{~km} / \mathrm{h}$ (15 to $20 \mathrm{kn})$. Spherical balloons were tethered in relatively calm winds up to $10 \mathrm{~km} / \mathrm{h}$ $5 \mathrm{kn}$ ).

Size: Up to $20 \mathrm{~m}^{3}\left(700 \mathrm{ft}^{3}\right)$.

Payload: From $1.4 \mathrm{~kg}$ to $2.8 \mathrm{~kg}$ ( 3 to $6 \mathrm{lb}$ ).

In one arrangement, an electrically advanced, radio-controlled Hasselblad EL 500 camera was hung in a gimbal from the tethered balloon by means of four lines (Whittlesey, 1970). This arrangement provided for an unusual degree of platform stability. The balloon was filled with hydrogen. The weight of the entire payload, consisting of calibrated camera, lens motor, power- pack, radio receiver, antenna, and magnesium gimbal mount, was $2.8 \mathrm{~kg}(6 \mathrm{lb})$. The gross weight of the balloon and payload was $10 \mathrm{~kg}$ (23 lb) plus tether lines that weighed several kilograms. Remote-sensing equipment included a variety of small photographic cameras, which were either pneumatically or radio controlled from the ground.

As a result of Whittlesey's work, the U.S. Geological Survey is investigating the use of tethered airfoil balloons as platforms for photographically recording paneled control points in support of photogrammetric mapping.

TETHERED AND FREE BALLOON MANUFACTURERS

The names and addresses of manufacturers of tethered and free balloons are listed below for the reader who wishes to obtain more current information, including the cost of a particular balloon. (This list may include companies no longer in the business and may omit new companies.)

Airborne Industries Ltd.

Airborne Works

Arteriai Road

Leigh-on-the-Sea

Essex, England

E. Bollay and Assoc., Inc.

Boulder, Colorado 80302

Dewey \& Almy Chemical Division

62 Whittemore Avenue

Cambridge, Massachusetts 02140

Robert Fulton Company

Old Ridgebury Road

Danbury, Connecticut 06810

Goodyear Aerospace Corp.

1210 Massillon Road

Akron, Ohio 44315

ILC Industries, Inc.

350 Pear Street

Dover, Delaware 19901

Jalbert Aerology Laboratory 170 N.W. 20th Street

Boca Raton, Florida 33432

Raven Industries, Inc. Box 1007, 205 E. 6th Street

Sioux Falls, South Dakota 57101 
G. T. Schjeldahl Company

P.O. Box 170

Northfield, Minnesota 55057

Semco Balloons

2002 N. 11th Street

Coeur d'Alene, Idaho 83814

Winzen Research, Inc.

401 W. 84th Street

Minneapolis, Minnesota 55420

Some of these manufacturers provide complete operational balloon planning and field support. The National Center for Atmospheric Research, Boulder, Colorado 80302, is an excellent source of information on all phases of balloon operations. This organization also furnishes complete flight services. The balloon group at the Air Force Cambridge Research Laboratories, Bedford, Massachusetts 01730, provides complete balloon services for U.S. Air Force and Department of Defense relevant activities.

\section{AIRCRAFT}

\section{GENERAL CONSIDERATIONS}

Practically every type of aircraft built has been used, at one time or another, as a remote-sensor platform. From the aircraft types listed in "Jane's All the World's Aircraft" (Taylor) and others, a representative selection has been made from those currently utilized as remote-sensor platforms. A sizable number of conventionally powered aircraft are described, whereas only single examples have been selected for unconventional types, which include helicopters, drones (unmanned aircraft), blimps, and sailplanes. Selected aircraft are described in abbreviated terms and additional data are available from Jane's, the aircraft manufacturer, or the organization using the aircraft.

Conventional aircraft currently used for remote sensing vary in size from small singleengine piston-powered craft to the sophisticated 4-engine jet military version of the Boeing 707 (RC135) and the Lockheed SR71. The remotesensing application of widest use is in obtaining mapping photographs. Figures 16 to 19 illustrate some of the smaller aircraft frequently used by private aerial mapping contractors in the United States. Small aircraft of this class are used for most of the aerial photography in the United States for private and governmental organizations. Such planes are adequate for lower altitude aerial photography and other types of remote sensing where instrumentation is light and simple.

A single-engine or light twin-engine aircraft is generally more economical and maneuverable than a large 2- or 4-motored aircraft; however, the selection of the aircraft should be based on the operator's intended use, the geography and meteorology of the operating area, the capital and operating cost, maneuverability, safety, performance, and ease with which the aircraft can be converted to remote-sensing operations.

Planes used for remote sensing are usually either commercial or military types that are modified. Modification can be very expensive, and it is generally more economical to select an aircraft that requires minimum change. Technical details relative to the problems associated with selection and modification of aircraft for aerial photography can be found in the "Manual of Photogrammetry," (1966); the "Manual of Photographic Interpretation," (1960) ; and the "Manual of Color Aerial Photography," (1968), all published by the American Society of Photogrammetry. Adapting aircraft for any other type of remote sensing is generally a highly specialized operation which must be considered on a case-by-case basis. However, many nonphotographic sensors are designed to fit standard mapping-camera ports, and thus aircraft designed for mapping operations may be suitable, with minimum modification, for other remote-sensing operations. Remote sensors of the active, wave propagating form require considerable power, which may be a major consideration in the choice of aircraft.

Jet aircraft have a high potential for remote sensing because of their excellent rate of climb, high operating ceiling, and maximum speed, but the cost of acquisition and conversion from commercial or military types restrict their wider use. High-altitude jet photography is being used increasingly for making photomaps and orthophotomaps where a single exposure may cover an entire map quadrangle. Most jet aircraft applications to remote sensing, however, are still limited to NASA experimental 
flights, government operations, and a few commercial firms.

Very high altitude remote-sensing aircraft have to some extent become available to the civilian community. The X15 (fig. 31), which was strictly a research platform, demonstrated remote sensing (photography) from an altitude of more than $107 \mathrm{~km}(354,000 \mathrm{ft})$. The X15 was a hybrid aircraft/spacecraft since its flight trajectory carried it well above the atmosphere. Two other high-altitude aircraft types, the RB57F (fig. 32) and the U-2 (fig. 35), are now available for nonmilitary remote-sensing applications. These provide platforms at service ceilings of $18.3 \mathrm{~km}(60,000 \mathrm{ft})$ and 21.3 $\mathrm{km}(70,000 \mathrm{ft})$. Military reconnaissance aircraft, such as the RF4C (fig. 33) and the SR71 (fig. 36) have reported service ceilings of 15.2 $\mathrm{km}(50,000 \mathrm{ft})$ and over $24.4 \mathrm{~km}(80,000 \mathrm{ft})$, but as yet they have not been used for civilian projects.

Another consideration is the role of man in the aircraft. With balloons and spacecraft, man may or may not be aboard the platform, but aircraft are generally manned. However, remote-control systems are rapidly being developed to the point where unmanned aircraft may become practical. Completely automated aircraft have monitored atomic explosion tests, and drones are an accepted form of military reconnaissance. Even if the aircraft is manned with a pilot, the number of other people that actually fly is a prime consideration relative to the type of aircraft and cost of the flight. As operational systems are defined, they tend to become more automated; there appears to be no real reason why remote-sensing missions, once defined and tested, need a flight crew of more than one or two. The opposite extreme is to perform maximum onboard processing and evaluation with a sizable crew; however, this approach has not yet been shown to be practical.

\section{PLATFORM STABILITY}

In addition to the fundamental consideration of having an aircraft at the right place at the right time, the problem of platform stability is paramount. In general, a highly stable platform, free of both vibrations and long-period oscillations, is desired. Constant motion of the platform relative to the scene is an expected condition and is, in fact, required for many remote-sensing missions. Compensation for the resulting image motion, if needed, is normally included in the design of a sensor system or its mount rather than the platform. Vibration, oscillation, or any other anomalies in the predetermined relative motion of the platform to the scene result in instability which has an overall degrading effect.

Aircraft in the atmosphere are inevitably subject to two types of instability: (1) vibrations created by the engines or other parts of the aircraft, and (2) rotations (pitch, roll, and yaw) which occur principally because both the aircraft and the atmosphere are dynamic. There are two basic ways of eliminating or at least reducing instability. The first is to provide a mount which isolates the sensor from the aircraft vibration and, by gyros or similar devices, maintains the sensor attitudes with respect to the scene independent of aircraft rotations. Mounts of this type have been designed for general-purpose use by the U.S. Air Force, but they are normally coupled to a specific sensor, such as a mapping camera. The second approach to reducing instability is in the selection and design of equipment and the aircraft itself. A reciprocating engine creates considerable vibration, a turbine somewhat less, and a jet still less. Propellers and reciprocating engines create torque as well as vibrations, but torque is normally neutralized by differentially adjusting wing lift and rudder, or it may be eliminated by the use of counterrotating pairs of engines. Vibration is reduced and isolated by the use of appropriate engine mounts. If the remote sensing can be limited to specific relatively small areas, propellers may be feathered or the engines even shut down for the critical periods of time if the aircraft is so designed. A high-lift aircraft, such as the Porter (fig. 24), with the engine shut off can actually hover or glide over a given scene for at least half an hour provided that there is a $75 \mathrm{~km} / \mathrm{h}(40 \mathrm{kn})$ wind in which to head. The craft will, of course, be constantly losing altitude while the engine is shut down. Thus stability is affected by the type, number, and use of engines. The design of the airframe itself as well as the sensor location with respect to 
the aircraft center of gravity are other parameters that affect stability. Equipping the plane with autopilots, damping, and self-leveling devices may also reduce the amplitude as well as the rates of rotational motion. Heavily loaded, a plane flies at a steeper pitch than when the load is reduced; thus the sensor, if fixed to the aircraft, will change in attitude with the use of fuel. A cross wind will cause an aircraft to drift, and if the sensor is not adjusted accordingly, the pertinent sensor axis and the ground path of the aircraft will not be alined.

A most important factor affecting aircraft stability is the local atmosphere. Winds, turbulence, and other aspects of atmospheric dynamics cause most platform instability. At any given point atmospheric dynamics will vary hourly and daily as well as seasonally. As a general rule the atmosphere becomes more stable with height, and at the operational altitudes of U-2's and SR71's atmospheric dynamic effects are almost negligible. Obviously the stability of a twin-engine jet at 20 or $25 \mathrm{~km}$ altitude is far better than that of a single-reciprocating engine aircraft at $5 \mathrm{~km}$ altitude.

\section{DESCRIPTIONS OF AIRCRAFT}

LOW ALTITUdE, UP TO 9 KM (29,500 FT) SERVICE

CEILING, PROPELLER DRIVEN

Cessna 180 Skywagon.-The Cessna 180 Skywagon (fig. 16) is a single-engine $(230 \mathrm{hp})$, propeller-driven, high-wing aircraft capable of carrying as many as six passengers or equivalent. Gross weight is $1,270 \mathrm{~kg}(2,800 \mathrm{lb})$. First marketed in 1968, it has had considerable use as a mapping camera platform and is well adapted for sensor equipment up to $180 \mathrm{~kg}$ $(400 \mathrm{lb})$ in weight.

Performance:

Service ceiling: $5,940 \mathrm{~m}(19,500 \mathrm{ft})$.

Speed : Maximum cruising ( $75 \%$ power) at $1,980 \mathrm{~m}(6,500 \mathrm{ft})$ is $260 \mathrm{~km} / \mathrm{h}$ $(160 \mathrm{mi} / \mathrm{h})$. Minimum or stalling is $93 \mathrm{~km} / \mathrm{h}(58 \mathrm{mi} / \mathrm{h})$.

Range: From 1,120 to $1,920 \mathrm{~km} \mathrm{(700} \mathrm{to}$ $1,200 \mathrm{mi}$ ) with long-range tanks.

Special equipment: Optional electronics for aerial survey projects include navigation aids, blind-flying instruments, autopilot, wing-leveling stability augmentation, and turn coordinator.
Beechcraft Bonanza.-The Beechcraft Bonanza (fig. 17) in the standard Model A36 is a single-engine, propeller-driven, low-wing aircraft with retractable landing gear. It is powered by a 285-hp Continental engine. The Model A36, marketed in 1968, was developed from the Model 35, which was introduced in 1946. Maximum gross weight of the A36 is $1,620 \mathrm{~kg}(3,600$ lb). Sensor (payload) capacity is estimated at $360 \mathrm{~kg}(800 \mathrm{lb})$.

\section{Performance:}

Service ceiling: $4,870 \mathrm{~m}(16,000 \mathrm{ft})$.

Speed: Maximum cruising ( $75 \%$ power) at $1,980 \mathrm{~m}(6,500 \mathrm{ft})$ is $315 \mathrm{~km} / \mathrm{h}$ $(195 \mathrm{mi} / \mathrm{h})$. Minimum or stalling, gear down, flaps $30^{\circ}$ is $103 \mathrm{~km} / \mathrm{h}(64$ $\mathrm{mi} / \mathrm{h})$; gear and flaps up is $120 \mathrm{~km} / \mathrm{h}$ $(75 \mathrm{mi} / \mathrm{h})$.

Range: From 1,290 km (800 mi) (75\% power) at $1,980 \mathrm{~m}(6,500 \mathrm{ft})$ to 1,430 $\mathrm{km}(890 \mathrm{mi})(55 \%$ power $)$ at $3,050 \mathrm{~m}$ $(10,000 \mathrm{ft})$.

Special equipment: Optional equipment includes autopilot, dual controls, and marker beacon receiver.

Cessna Super Skymaster.-The Cessna Super Skymaster (fig. 18) is a twin (tandem) turboprop, high-wing craft with twin tail booms, capable of carrying up to six passengers or equivalent. Gross weight is $2,000 \mathrm{~kg}(4,400 \mathrm{lb})$. The aircraft, marketed in 1965, has been adapted for mapping and remote-sensing missions. Remote Sensing, Inc., Houston, Tex., reports carrying the following load of remote sensors on this aircraft: a Texas Instruments RS-310 infrared scanner, an RC-8 or RC-9 mapping camera, and four gang-mounted Hasselblad 500 EL multispectral cameras. The 4-seat version of the aircraft has space for equipment weighing $165 \mathrm{~kg}$ (365 lb).

Performance :

Service ceiling: 8,930 m (29,300 ft).

Speed: Maximum cruising ( $75 \%$ power) is $305 \mathrm{~km} / \mathrm{h}(190 \mathrm{mi} / \mathrm{h})$. Minimum or stalling is $113 \mathrm{~km} / \mathrm{h}(70 \mathrm{mi} / \mathrm{h})$.

Range: At maximum cruising speed from 1,900 to $2,500 \mathrm{~km}(1,190$ to $1,550 \mathrm{mi})$ with long-range tanks.

Special equipment: Optional avionics include blind-flying instruments, autopilot, navigation instruments, and an oxygen system. 
Beechcraft Queen Air.-The Beechcraft Queen Air B80 (fig. 19) is a twin-engine, light executive or business transport of conventional low-wing monoplane configuration. The cabin accommodates 6 to 11 passengers or a crew of two on the flight deck with space for sensor and electronic equipment. Gross weight is 4,000 $\mathrm{kg}(8,800 \mathrm{lb})$. It is powered by two $380-\mathrm{hp}$ Lycoming 6-cylinder horizontally opposed aircooled and supercharged engines. Sensor capacity is $820 \mathrm{~kg}(1,800 \mathrm{lb})$.

Performance :

Service ceiling: $8,170 \mathrm{~m}(26,800 \mathrm{ft})$.

Speed: Maximum cruising ( $70 \%$ power) is $360 \mathrm{~km} / \mathrm{h}(225 \mathrm{mi} / \mathrm{h})$ at $4,570 \mathrm{~m}$ $(15,000 \mathrm{ft})$.

Range: With maximum fuel and 45-min fuel reserve, $2,500 \mathrm{~km}(1,500 \mathrm{mi})$.

Special equipment: The aircraft has a deicing system on the leading edge of the wings, optional auxiliary fuel tanks, a pressurization system, and full ground and in-flight air conditioning.

All Beechcrafts may be equipped with a full range of avionics, including dual VHF, radio, and elaborate positioning and navigation aids, and they may be fitted with vertical mapping camera installations. The twin-engine Beechcrafts carry weather-avoidance radar. The King Air and Queen Air models may be equipped with a wide variety of remote sensors; in 1972 Beech announced the RS99 ("Aviation Week and Space Technology," 1972) which is a remote-sensing version of the B99 series.

Grumman Mohawk.-The Grumman OV-1 Mohawk (fig. 20) is a high-performance 2-seat observation and surveillance aircraft developed by Grumman for the U.S. Army. More than 365 Mohawks have been placed in service in five models. The principal difference in the models is in the navigation and remote-sensing equipment that has been installed. Some models carry a variety of advanced remote-sensing equipment, such as the KA-30 high-resolution optical photographic system (in model OV1A) and integrated flight systems for day and night reconnaissance.

The aircraft is powered by two $1,160-\mathrm{hp}$ Lycoming turboprop engines. Gross weight for the $\mathrm{OV}-1 \mathrm{~A}$ is $6,820 \mathrm{~kg}(15,000 \mathrm{lb})$. Maximum load available for equipment is $2,250 \mathrm{~kg}(5,000$ lb).

In 1971 the U.S. Geological Survey obtained a Mohawk Model OV-1 for research concerning the quality of water and the environment. The sensing equipment includes SLAR, a thermal scanner, a 230-mm (9-in.) focal-length camera, and a cluster of Hasselblad cameras for multispectral photography. This model has a ceiling of about $7,620 \mathrm{~m}(25,000 \mathrm{ft})$.

Performance:

Service ceiling: (OV-1C) 9,000 m $(29,500 \mathrm{ft})$.

Speed: Maximum cruising (OV-1A) is $490 \mathrm{~km} / \mathrm{h}(305 \mathrm{mi} / \mathrm{h})$. Minimum or stalling $(\mathrm{OV}-1 \mathrm{~A})$ is $110 \mathrm{~km} / \mathrm{h}(68$ $\mathrm{mi} / \mathrm{h}$.)

Range: (OV-1A) 2,260 km (1,400 mi) with external tanks, $10 \%$ reserve.

Special equipment: Mohawk models OV$1 \mathrm{~B}, \mathrm{OV}-1 \mathrm{C}$, and $\mathrm{OV}-1 \mathrm{D}$ carry interchangeable equipment, which includes SLAR and an in-flight processor. One model, the $O V-1 D$, can be converted from infrared reconnaisasnce to SLAR surveillance in about 1 hour.

Lockheed YO-3A.-Lockheed began studies and development on quiet aircraft late in 1966. The first Lockheed quiet aircraft was the QT2 (Quiet Thruster, 2 seat). The first two prototypes were fitted with night sensors. It is reported that reconnaissance flights as low as

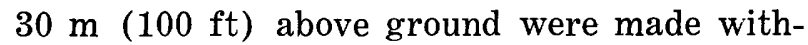
out detection.

Potential of the quiet reconnaissance type of aircraft was recognized, and the U.S. Army Aviation Systems Command undertook further development with Lockheed in July 1968. This resulted in a more refined quiet reconnaissance aircraft, designated YO-3A (fig. 21).

Basis of the design is the Schweizer SGS 232 sailplane, but the new aicraft has a lowwing configuration. The fuselage has been modified extensively.

Perhaps the greatest single reduction in noise has come from using specially developed propellers with three, four, or six blades that rotate at speeds as low as $500 \mathrm{r} / \mathrm{min}$. A modified 210hp air-cooled Continental 6-cylinder engine provides power. 
Infrared equipment is carried in the $\mathrm{YO}_{-}$ $3 \mathrm{~A}$ for night reconnaissance operations. No details on performance are available.

\section{MEDIUM ALTITUDE, 9 TO 15 KM $(29,500-49,000$ FT) SERVICE CEILING, PROPELLER OR JET}

\section{Rockwell Standard Jet Commander 1121.-} This plane (fig. 22) is a high-speed twin-jet executive transport with standard accommodation for a pilot and as many as eight passengers. It is powered by two General Electric turbojet engines. Gross weight is $7,640 \mathrm{~kg}(16,800$ lb). A stretched version of the Commander is known as the Commodore. Production rights were taken over by Israeli Aircraft Industries in 1967 . Sensor capacity is $725 \mathrm{~kg}(1,600 \mathrm{lb})$.

Performance :

Service ceiling : $13,700 \mathrm{~m}(45,000 \mathrm{ft})$.

Speed: Maximum cruising is $805 \mathrm{~km} /$ h $(500 \mathrm{mi} / \mathrm{h})$ at $10,670 \mathrm{~m}(35,000$ ft.) Minimum or stalling is $160 \mathrm{~km}$ ! h $(100 \mathrm{mi} / \mathrm{h})$.

Range: $2,965 \mathrm{~km}(1,840 \mathrm{mi})$ with maximum fuel and maximum payload at economy cruising speed $760 \mathrm{~km} / \mathrm{h}$ $(470 \mathrm{mi} / \mathrm{h})$ at $11,900 \mathrm{~m}(39,000 \mathrm{ft})$, no reserve.

Special equipment: Blind-flying instrumentation is standard. Provision is made for full range of radio and radar communications, navigation, storm warning, glideslope and localizer, and Automatic Direction Finding equipment.

Gates Learjet.-This twin-engine business jet (fig. 23) is powered by two General Electric CJ610 turbine engines. Designed to carry eight passengers, the jet has a gross takeoff weight of $5,900 \mathrm{~kg}(13,000 \mathrm{lb})$. The business jet has been modified into a remote-sensing aircraft operating for altitudes well above $12,200 \mathrm{~m}$ $(40,000 \mathrm{ft})$. Sensor capacity is $1,250 \mathrm{~kg}(2,760$ lb).

First marketed in 1966, the Learjet 24 replaced the earlier Model 23.

Performance (Gates Learjet 24) :

Service ceiling: 13,700 m (45,000 ft).

Speed: Maximum airspeed, Mach 0.81 at $9,450 \mathrm{~m}(31,000 \mathrm{ft})$ or $885 \mathrm{~km} /$ h $(550 \mathrm{mi} / \mathrm{h})$. Normal cruise speed,
Mach 0.77 at $12,500 \mathrm{~m}(41,000 \mathrm{ft})$ or $820 \mathrm{~km} / \mathrm{h}(510 \mathrm{mi} / \mathrm{h})$. Stalling speed at sea level with $4,090 \mathrm{~kg}(9,000 \mathrm{lb})$, landing configuration, is $155 \mathrm{~km} / \mathrm{h}$ $(96 \mathrm{mi} / \mathrm{h})$.

Range: $2,400 \mathrm{~km}(1,500 \mathrm{mi})$ with 8 passengers, 45-min fuel reserve.

Special equipment: Figure 23 shows a Gates Learjet 24, the model most extensively used in remote sensing, with the special door open to show the camera installation.

Several domestic and foreign companies have built modifications to the Learjet door to allow cameras inside the pressurized cabin to photograph through an optical glass plate in the floor of the special door. A quick-change modification to the door allows the jet to be taken off charter service for camera work and returned to passenger hauling. The conversion takes about 3 hours.

An earlier Learjet Model 23 was used by astronomers of Rice University, Houston, Tex., in the research project "Flying Infrared Telescope," operating on top of the troposphere, at altitudes of $15,200 \mathrm{~m}(50,000 \mathrm{ft})$ to photograph the stars, planets, and planetary nebulas. The Learjet was provided by NASA Ames Research Center (Hudson, 1968 and 1971).

Fairchild Hiller Porter.-This is a versatile airplane (fig. 24) designed to fill a wide variety of aerial sensing needs. It has an extremely

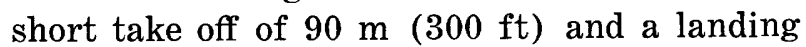
distance of less than $45 \mathrm{~m}(150 \mathrm{ft})$. The Porter carries as many as 11 passengers, or it can carry a remote-sensor package weighing 910 $\mathrm{kg}(2,000 \mathrm{lb})$. It has a small but powerful turbine engine and reversible propeller. Additional fuel may be carried in external wingmounted pylons and would extend the plane's range to a thousand miles. Its gross weight is $2,200 \mathrm{~kg}(4,850 \mathrm{lb})$.

Performance:

Service ceiling : $7,770 \mathrm{~m}(25,500 \mathrm{ft})$.

Speed : Maximum cruising at 3,050-3,650 $\mathrm{m}(10,000-12,000 \mathrm{ft})$ is $280 \mathrm{~km} / \mathrm{h}$ (175 $\mathrm{mi} / \mathrm{h})$.

Range: $970 \mathrm{~km} \mathrm{(600} \mathrm{mi)} \mathrm{with} \mathrm{normal}$ configuration and maximum fuel; $1,600 \mathrm{~km}(1,000 \mathrm{mi})$ with external wing-mounted tanks. 
Special equipment: The Porter can be adapted for aerial photography and other remote sensing. A military version carries a complete radio communications system, a pod containing three P-2 70-mm cameras, and 40 flares of 2 million candlepower for night photographs. It has a floor hatch and large cargo doors for installing special sensing equipment.

Lockheed NP3A Orion.-This aircraft (fig. 25), which was derived from the Electra, is a 4-engine turboprop low-wing plane capable of carrying a sensor payload of as much as 9,000 $\mathrm{kg}(20,000 \mathrm{lb})$. Maximum gross weight is $51,400 \mathrm{~kg}(113,000 \mathrm{lb})$. NASA 927 is such a craft adapted for remote-sensor research. The "Annual Report, 1971," of NASA Manned Spacecraft Center, Earth Observation Aircraft Program, describes this aircraft and the sensors in considerable detail. The total sensorrelated equipment weighs $2,500 \mathrm{~kg} \quad(5,500 \mathrm{lb})$ as configured in this aircraft.

Performance:

Service ceiling : $9,100 \mathrm{~m}(30,000 \mathrm{ft})$.

Speed: Maximum cruising is $610 \mathrm{~km} / \mathrm{h}$ $(330 \mathrm{kn})$. Minimum or stalling is 280 $\mathrm{km} / \mathrm{h}(150 \mathrm{kn})$.

Range: 3,700 to $3,900 \mathrm{~km}(2,300$ to 2,400 $\mathrm{mi}$ ).

Endurance: $7 \mathrm{~h}$.

Stability: Extent of average deviations from prescribed attitude is $\pm 2^{\circ}$ in pitch and roll and $\pm 8^{\circ}$ in yaw.

Special equipment: Precise altimeter, Loran navigation system, inertial navigation unit, gyro-stabilized platform.

Douglas Skywarrior $R A-3 B$.-Production of the twin-jet RA-3B (fig. 26) carrier-based aircraft ended in January 1961, and only four remain in service with the U.S. Navy late in 1973. Nevertheless, they are a major element of the U.S. Navy reconnaissance and mapping effort and are effective, versatile, and durable. The RA-3B photographic reconnaissance aircraft are versions of the standard McDonnell Douglas A-3 airframe. Weight empty is 19,800 $\mathrm{kg}(43,500 \mathrm{lb})$; normal loaded weight is 35,500 $\mathrm{kg}(78,000 \mathrm{lb})$; and overload weight is 37,300 $\mathrm{kg}(82,000 \mathrm{lb})$.

\section{Performance:}

Service ceiling: $13,700 \mathrm{~m}(45,000 \mathrm{ft})$.

Speed: Maximum cruising $1,020 \mathrm{~km} / \mathrm{h}$ $(630 \mathrm{mi} / \mathrm{h})$ at $9,150 \mathrm{~km}(30,000 \mathrm{ft})$ altitude. Landing speed $269 \mathrm{~km} / \mathrm{h}$ $(167 \mathrm{mi} / \mathrm{h})$.

Normal range: More than $4,650 \mathrm{~km}$ (2,880 $\mathrm{mi})$.

Endurance: $5 \mathrm{~h}$, plus $15 \mathrm{~h}$ with in-flight refueling capability.

Special equipment: This aircraft has 16 camera windows and sufficient space and lifting capacity to carry a wide array of sensors (Barton, 1972). As many as 12 cameras ranging from 45 to $910 \mathrm{~mm}$ ( 1.75 to $36 \mathrm{in}$.) are carried simultaneously. Night photography supported by flares, infrared scanning, and radar imaging can also be carried out. A dual viewfinder system also supports the remote-sensing mission.

Additional information on special equipment is given in "RA-3B Photographic Capabilities Handbook," published by the U.S. Navy, Fleet Air Reconnaissance Squadron ONE.

Lockheed NC130B (RC130).-This plane (fig. 27) is used as a NASA sensor system facility, which carries both imaging and nonimaging remote sensors. The data acquisition system includes various onboard remote sensors, signal processing, and a control and recording system. The Lockheed NC130B is an all-metal high-wing long-range land-based monoplane powered by four Allison turboprop constantspeed engines. The fuselage can be pressurized and airconditioned in flight and on the ground. The military photomapping version has the principal mission of executing electronic aerial geodetic surveying and photogrammetric mapping in an integrated system. Gross weight is $61,400 \mathrm{~kg}(135,000 \mathrm{lb})$. Weight available for sensor payload is $9,230 \mathrm{~kg}(20,300 \mathrm{lb})$.

Performance:

Service ceiling : $10,700 \mathrm{~m}(35,000 \mathrm{ft})$.

Speed: Maximum cruising is $590 \mathrm{~km} / \mathrm{h}$ $(320 \mathrm{kn})$.

Range: $4,000 \mathrm{~km}(2,500 \mathrm{mi})$.

Endurance: $9 \mathrm{~h}$.

Stability: Extent of average deviations 
from prescribed attitude is $\pm 21 /^{\circ}$ in pitch, $\pm 7^{\circ}$ in roll, and $\pm 5^{\circ}$ in yaw.

Special equipment: In NASA's version, each of the four camera windows accommodates the field of view of an RC-8 metric camera plus allowance for roll stabilization of up to $\pm 6^{\circ}$. The TV subsystem is used by the pilot in following a ground track. Navigation subsystems include an inertial navigation system, a radar altimeter set, a navigational computer, and remote navigation indicators. Aircraft position in latitude and longitude coordinates is displayed at the navigator's station. SLAR is boresighted with a camera window. Military photomapping versions carry a similar array of special equipment which supports basic mapping functions.

Boeing Stratolifter (RC135A).-This plane is a long-range jet transport developed from the KC135A Stratotanker. The KC135A aircraft were powered by Pratt and Whitney turbojet engines and became the first strategic jet transports in the Military Air Transport Service (MATS). All KC135 aircraft are similar to but smaller than the Boeing 707 airliner, both derived from the 707 prototype (figs. 28, 29).

Four RC135A aircraft were built. They were similar to the KC135A but specially equipped for multiple cameras and electronic equipment for photomapping and electronic surveying of the terrain, using SHIRAN, an electronic system for establishing geodetic control. However, the cost of upkeep for photomapping could not be justified, and the four RC135A photomapping aircraft were converted from photomapping to other uses during 1972. Ten aircraft designated WC135B (same as C135B) were modified for long-range weather reconnaissance missions for the Military Airlift Command (MAC), Air Weather Service. Other Air Force reconnaissance versions include the RC135B and RC135D. Gross weight (C135B) is 125,000 $\mathrm{kg}(275,500 \mathrm{lb})$.

Performance:

Service ceiling: 9,100 to $13,700 \mathrm{~m}$ $(30,000$ to $45,000 \mathrm{ft})$.
Speed: Average cruising speed $855 \mathrm{~km} /$ $\mathrm{h}(530 \mathrm{mi} / \mathrm{h})$ at $10,700 \mathrm{~m}(35,000 \mathrm{ft})$. Maximum level speed $970 \mathrm{~km} / \mathrm{h}(600$ $\mathrm{mi} / \mathrm{h})$.

Range: $7,400 \mathrm{~km}(4,600 \mathrm{mi})$ with 24,500 $\mathrm{kg}(54,000 \mathrm{lb})$ payload. Maximum ferry range is $14,485 \mathrm{~km}(9,000 \mathrm{mi})$.

Special equipment: The RC135A carries special navigation equipment for improved mapping accuracy. The aircraft were assigned to the 1370th Photo Mapping Wing of the MAC. The mapping system was known as the AN/USQ 28 and was probably the most sophisticated ever built.

E-Systems (formerly LTV) L450F reconnaissance aircraft.-This is a motorized version of the Schweizer sailplane built to meet military aircraft requirements for high-altitude and endurance (fig. 30). It is powered by a modified Pratt and Whitney turboprop engine. The new design provides the capability of carrying data-gathering or electronic relay equipment similar to that of a communications satellite. The relay equipment can be carried to an altitude of $13,700 \mathrm{~m}(45,000 \mathrm{ft})$ and could be operated up to $24 \mathrm{~h}$ at a time. Alternatively, the aircraft can be flown unmanned by remote control over a radius of $400 \mathrm{~km}$ (250 $\mathrm{mi})$.

For operation in the unmanned mode, automatic stabilization equipment is installed, and complete ground control and monitoring by telemetry allows control of the aircraft in a variety of modes. Gross weight is $2,140 \mathrm{~kg}$ $(4,700 \mathrm{lb})$. Payload is 160 to $320 \mathrm{~kg}$ (350 to $700 \mathrm{lb})$.

Performance :

Service ceiling: 13,700 to $15,200 \mathrm{~m}$ $(45,000$ to $50,000 \mathrm{ft})$.

Speed: Maximum cruising at $13,700 \mathrm{~m}$ $(45,000 \mathrm{ft})$ is $170 \mathrm{~km} / \mathrm{h}(105 \mathrm{mi} / \mathrm{h})$.

Best glide ratio : $28: 1$.

Range (piloted version): $9,700 \mathrm{~km}$ $(6,000 \mathrm{mi})$.

Endurance : 24 to $30 \mathrm{~h}$.

HIGH ALTITUDE, SERVICE CEILING ABOVE $15 \mathrm{KM}$ $(49,000$ FT $)$

North American Rockwell X15.-This plane (fig. 31) was a highly specialized research ve- 
hicle jointly funded by the Air Force, the Navy, and the National Aeronautics and Space Administration (Aerospace Industries Assoc., 1970). Three aircraft were built, with the first flight on June 8, 1959. Tests conducted on this unique platform contributed to research, particularly in studies related to hypersonic and hyperaltitude flight regimes. It attained speeds greater than Mach 6 and altitudes above 107,$000 \mathrm{~m}(350,000 \mathrm{ft})$. The No. 1 plane, now in the Smithsonian Institution, was used for research in high-altitude aerial photography, ultraviolet stellar photography, atmospheric density measurements, horizon scanning and definition measurements, and advanced integrated data systems. It was also used in research to determine the effects of flight regimes covering a wide range of speeds, altitudes, and environmental conditions on photographic film resolution and distortion. The No. 2 plane, shown in figure 31, was fitted with twin droppable fuel tanks, coated with ablative material, and modified as a ramjet test bed. It was the plane which set an unofficial speed record of Mach 6.7 or $7,290 \mathrm{~km} / \mathrm{h}(4,520 \mathrm{mi} / \mathrm{h})$. The No. 3 aircraft was destroyed in an accident on Nov. 11, 1967, in which Major M. J. Adams lost his life. The three X15's made 197 flights in 10 years.

\section{Performance:}

Maximum altitude: 108,000 m (354,200 $\mathrm{ft}$ or $67.1 \mathrm{mi})$ reached by Joseph Walker, chief test pilot, NASA, on Aug. 22, 1963.

Speed: An official speed record was achieved by Joseph Walker, on June 27,1962 , at $6,620 \mathrm{~km} / \mathrm{h}(4,104 \mathrm{mi} / \mathrm{h})$. An unofficial speed was recorded at $7,290 \mathrm{~km} / \mathrm{h}(4,520 \mathrm{mi} / \mathrm{h})$ on Nov. 18 , 1966, by Major Pete Knight, USAF.

Total flight life of aircraft: Approximately $24 \mathrm{~h}$.

Maximum launching weight: $23,140 \mathrm{~kg}$ $(50,900 \mathrm{lb})$.

Maximum landing weight: $7,780 \mathrm{~kg}$ $(17,120 \mathrm{lb})$.

Payload: Instrumentation payload designed for the X15A was $590 \mathrm{~kg}$ $(1,300 \mathrm{lb})$.
Special equipment: Research was undertaken to determine the effects of highspeed shock waves and friction-heated air turbulence on aerial photographs taken from a camera mounted in the nose of the aircraft. Among the cameras flown was an experimental type $\mathrm{KC}-1$ camera body fitted with a prototype lens, forerunner of the 152 $\mathrm{mm}$ (6-in.) focal length $\mathrm{f} / 5.6$ Geocon I designed by Dr. James Baker. This camera was installed in an ART-15 gyrostabilized mount in the pressurized instrument compartment just aft of the cockpit. A special quartz glass, nearly optically flat and $460 \mathrm{~mm}$ (18 in.) in diameter, was used for the window. Six flights were made to determine geometric image deformations produced by high-altitude supersonic flight.

Another series of flights was conducted to determine image-resolution degradation using an experimental KS-25 camera with a $610-\mathrm{mm}$ (24-in.) focal length lens developed by the Air Force Avionics Laboratory at Wright-Patterson AFB, Ohio. This camera was capable of resolving better than 115 lines per millimeter on fine-grain photographic film. It was installed in the same ART-15 mount that has been used to carry the $\mathrm{KC}-1$ mapping camera. One objective of this test was to obtain photographic images that would, as nearly as possible, simulate those that were expected to be obtained later from space. Photographs obtained with the X15 thus permitted comparative studies and interpretation which paved the way for analysis and evaluation of high-altitude aircraft and space photography which was to follow.

In another experiment, a gimbal-mounted 4camera platform was used for research in ultraviolet steller photography and for photographing the stars from altitudes above $65 \mathrm{~km}$ (40 mi).

A horizon scanner was also used to study the light spectrum of the sky and to obtain data on the accuracy of sensing the horizon. These data were later used to improve attitude and guidance references for Earth-orbiting spacecraft. 
General Dynamics/Martin RB57F (WB57F). -A General Dynamics/Martin WB57F aircraft is flown and maintained for the NASA Earth Observations Aircraft Program Office. The WB57F shown in figure 32 is a midwing 4-engine aircraft powered by two Pratt and Whitney turbofan engines and two auxiliary removable Pratt and Whitney turbojets carried in underwing pods.

The data acquisition system comprises an airborne sensor platform, various sensors, and ancillary control and data-recording equipment. The sensor equipment is described in detail in the "Annual Report, 1971," of the NASA Manned Spacecraft Center, Earth Observation Aircraft Program. Gross weight is $28,600 \mathrm{~kg}$ $(63,000 \mathrm{lb})$. Estimated weight available for remote-sensor payload is $2,160 \mathrm{~kg}(4,750 \mathrm{lb})$.

Performance:

Service ceiling : $18,900 \mathrm{~m}(62,000 \mathrm{ft})$.

Speed: Maximum cruising at $18,300 \mathrm{~m}$ $(60,000 \mathrm{ft})$ is $740 \mathrm{~km} / \mathrm{h}(460 \mathrm{mi} / \mathrm{h})$. Minimum or stalling is $145 \mathrm{~km} / \mathrm{h}(90$ $\mathrm{mi} / \mathrm{h}$ ).

Range: $5,320 \mathrm{~km}(3,300 \mathrm{mi})$.

Endurance: $+4 \mathrm{~h}$ at service ceiling.

Stability: Extent of average deviations from prescribed attitude is approximately $\pm 0.5^{\circ}$ in pitch and roll and $\pm 8^{\circ}$ in yaw.

Special equipment: Considerable special equipment is carried, including weather radar in the fuselage nose, an autopilot, and a navigation system comprising a C-12 Gyrosyn compass, an APN-102 Doppler radar, and an ASN-41A navigator computer. A Litton LTN-51 inertial navigation system was added in 1972 . The system measures the heading, ground speed, and drift angle of the aircraft, and computes present latitude and longitude, distance to destination, ground track, and relative bearing. An APN-159 pulse-type radar altimeter indicates absolute clearance of the aircraft above the terrain. An optical viewfinder enables the equipment operator to view the terrain ahead of the aircraft and to measure drift. A multispectral scanning imaging spec- troradiometer was installed in 1972. McDonnell Douglas $R F-4 C$. - This high-performance fighter-type aircraft (F-4) (figs. 33, 34 ) is modified for multiple-sensor reconnaissance. It incorporates optical, infrared, and electronic sensors for reconnaissance missions day or night and in any kind of weather. Its optical systems include a number of cameras of various focal lengths, forward- and side-looking cameras, and panoramic cameras that scan the terrain from horizon to horizon. Films can be processed in flight and ejected over the ground command station. The RF-4C also carries side-looking radar for mapping on each side of the flight path and a third radar for forward-looking ground mapping. It also carries an infrared sensor for day or night use. Gross weight is $24,800 \mathrm{~kg}(54,600 \mathrm{lb})$.

Performance:

Service ceiling: $15,200 \mathrm{~m}(50,000 \mathrm{ft})$. However, the F-4B version has temporarily reached $30,000 \mathrm{~m}(98,400 \mathrm{ft})$ in a time-to-height test which took slightly over $6 \mathrm{~min}$ to achieve.

Speed: Maximum cruising $2,240 \mathrm{~km} / \mathrm{h}$ $(1,390 \mathrm{mi} / \mathrm{h})$ at $12,200 \mathrm{~m}(40,000 \mathrm{ft})$.

Range: Ferry range, 3,700 km (2,300 $\mathrm{mi}$ ).

Special equipment: Navigation radar including terrain avoidance, central air data computer, navigational computer, and electronic altimeter.

Lockheed U-2.-This unique aircraft (fig. 35 ) is capable of sustained flight at very high altitudes. Although basically a manned aircraft, recent reports ("Aviation Week and Space Technology," 1971) indicate the U-2 has also been converted into a drone. In April 1971, NASA acquired on loan from the U.S. Air Force two U-2 aircraft for high-altitude photography and research. Gross weight is $7,850 \mathrm{~kg}(17,270 \mathrm{lb})$ with external tanks.

The primary job of the NASA U-2 aircraft is to complement two Earth resources research space flights: the Earth Resources Technology Satellite (ERTS) and the manned orbital workshop, Skylab. Test sites were photographed and analyzed before the launch of the spacecraft, and the U-2's photographed sites simultaneously with the passes of both ERTS and Skylab in 1972 and 1973. 


\section{Performance:}

Service ceiling : $21,300 \mathrm{~m}(70,000 \mathrm{ft})$.

Speed: Maximum cruising is $790 \mathrm{~km} / \mathrm{h}$ $(490 \mathrm{mi} / \mathrm{h})$.

Range: Internal fuel only, 100 U.S. gal reserve, $3,550 \mathrm{~km}(2,200 \mathrm{mi})$; with external tanks, 100 U.S. gal reserve, $4,200 \mathrm{~km}(2,600 \mathrm{mi})$.

Endurance: Approximately $5 \mathrm{~h}$.

Stability: The U-2 at high altitude is highly stable as demonstrated by continuous strips of near-vertical mapping photographs which show no signs of vibration or longer term oscillations even though a stabilizing mount was not used.

Special equipment: The Air Force carried a variety of frame and panoramic cameras of up to $610 \mathrm{~mm}$ (24 in.) focal length. These include mapping cameras in gyrostabilized mounts. NASA uses a gang of small multispectral cameras to simulate space imagery and also carries a mapping camera of $152 \mathrm{~mm}$ (6 in.) focal length. A ventral periscopic sight or viewfinder is included, and an autopilot has also been installed on occasions. In late 1973, NASA plans to install at least one inertial guidance system.

Lockheed SR71 (YF-12).-The Lockheed SR71 (fig. 36) is an Air Force long-range advanced strategic reconnaissance aircraft. One of the fastest and highest flying aircraft in the world, it is capable of worldwide reconnaissance operations including aerial photographic missions and multiple forms of remote sensing. It is powered by two Pratt and Whitney J58 turbojets and has a speed of Mach 3, or more than $3,400 \mathrm{~km} / \mathrm{h}(2,100 \mathrm{mi} / \mathrm{h})$. The $\mathrm{SR71}$ is the reconnaissance version of the general YF-12 series of aircraft. However, the reconnaissance version is the only one in operational use today. Gross weight is $76,500 \mathrm{~kg}(170,000 \mathrm{lb})$.

\section{Performance:}

Service ceiling: Over $24,400 \mathrm{~m}(80,000$ $\mathrm{ft})$; maximum ceiling reported at 36 ,$600 \mathrm{~m}(120,000 \mathrm{ft})$.

Speed: Maximum $3,340 \mathrm{~km} / \mathrm{h}(2,070 \mathrm{mi} /$ h) at $24,463 \mathrm{~m}(80,258 \mathrm{ft})$ a world record, May 1, 1965. Minimum or stalling not given.

Range: More than 3,220 km (2,000 mi) ; with aerial refueling it has global range.

Special equipment: Equipment ranges from simple surveillance to multiplesensor high-performance reconnaissance systems.

\section{BELL HELICOPTER 47G-3B-1}

The Bell 47G-3B-1 helicopter is utilized by the U.S. Department of Agriculture, Forest Service, Northern Forest Fire Laboratory, Missoula, Mont., as a platform for a simple infrared line scanner. The Forest Service Fire Spotter can be used to locate forest fires that are too small to be readily visible to optical detection system. Nominal altitude is $610 \mathrm{~m}(2,000$ $\mathrm{ft}$. Gross weight for the model $47 \mathrm{G}-3 \mathrm{~B}-1$ shown in figure 37 is $1,340 \mathrm{~kg}(2,950 \mathrm{lb})$. This model is a 3 -seater with high-altitude performance over a wide range of temperatures. This helicopter is powered by a supercharged Lycoming engine uprated to $280 \mathrm{hp}$.

During 1973, the Forest Service was experimenting with a telemetry near-real-time system as compared with the conventional infrared line scanner from which the data must be physically returned and processed before evaluation. With the telemetry system the imagery data are transmitted from the helicopter to the ground station where evaluation can start immediately.

Performance:

Service ceiling : 4,270 m (14,000 ft).

Speed: Maximum $170 \mathrm{~km} / \mathrm{h}(105 \mathrm{mi} / \mathrm{h})$ at sea level. Cruising $135 \mathrm{~km} / \mathrm{h}(83$ $\mathrm{mi} / \mathrm{h})$ at $1,520 \mathrm{~m}(5,000 \mathrm{ft})$.

Range : $400 \mathrm{~km}$ ( $250 \mathrm{mi}$ ) with maximum fuel at $1,520 \mathrm{~m}(5,000 \mathrm{ft})$ and no reserves.

Endurance: Approximately $3 \mathrm{~h}$. Maximum payload: $540 \mathrm{~kg}(1,190 \mathrm{lb})$.

\section{NORTHROP FALCONER DRONE}

This surveillance drone (see also E-Systems, p. 13) (fig. 38) was developed originally for the U.S. Army Signal Corps. Launched from a zerolength launcher, it is controlled remotely by 
radio and tracked by radar. It carries still or TV cameras for surveillance over hostile territory. On reaching a predetermined recovery area the controller commands parachute recovery. The camera is removed, the film is processed, and the prints are delivered within minutes after recovery. Models are available for day or night photointelligence and reconnaissance duties. The cameras can be replaced by other sensor systems. This propeller-driven platform is powered by a $\mathbf{9 2 - h p ~ M c C u l l o c h ~ a i r - ~}$ cooled engine. Maximum launching weight is $200 \mathrm{~kg}$ (440 lb). Empty weight is $160 \mathrm{~kg}$ ( 350 lb).

\section{Performance:}

Service ceiling : 4,570 m (15,000 ft).

Speed: Maximum level speed at sea level is $320 \mathrm{~km} / \mathrm{h}(201 \mathrm{mi} / \mathrm{h})$.

Endurance at sea level: $35 \mathrm{~min}$.

Special equipment: Recovery is by a

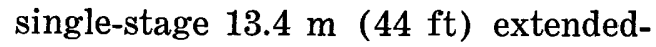
skirt parachute deployed on command or automatically. The radio-command flight-control system includes a receiver autopilot. Special equipment includes two $75-\mathrm{mm}$ cameras, a flare ejector, a radar beacon or passive radar reflector pods, and a night light identification system. Flares are carried for night photography.

\section{GOODYEAR BLIMPS}

The blimps Columbia, America, and Mayflower, owned and operated by the Goodyear Tire and Rubber Company, Akron, Ohio, are the only lighter-than-air craft known to be operating in the U.S. today. They were built during the period 1968-1971. The three aircraft are the 297th, 298th, and 299th blimps that the company has built since 1917, mostly for the U.S. Army or Navy. Power is supplied by twin 6-cylinder pusher-type 210-hp Continental engines (figs. 39, 40).

The three blimps are in demand by the news media, particularly television networks, for use as aerial and television camera platforms for viewing special events. Their aerial photographs have appeared in virtually every newspaper and magazine.

Performance:

Service ceiling: Maximum 2,290 m
$(7,500 \mathrm{ft})$. Normal operational altitude 300 to $910 \mathrm{~m}(1,000$ to $3,000 \mathrm{ft})$.

Speed: Maximum $80 \mathrm{~km} / \mathrm{h}(50 \mathrm{mi} / \mathrm{h})$. Cruising $55 \mathrm{~km} / \mathrm{h}(35 \mathrm{mi} / \mathrm{h})$.

Size: Columbia $58.5 \mathrm{~m}$ (192 ft) long, 18 $\mathrm{m}(59.5 \mathrm{ft})$ high, $15 \mathrm{~m}(50 \mathrm{ft})$ wide.

Volume: Columbia, 5,800 $\mathrm{m}^{3} \quad(202,700$ $\left.\mathrm{ft}^{3}\right)$.

Weight: Maximum gross $5,600 \quad \mathbf{~ k g}$ $(12,320 \mathrm{lb})$; empty $4,100 \mathrm{~kg}(9,040$ lb).

Maximum lift or payload: $1,490 \mathrm{~kg}$ $(3,280 \mathrm{lb})$ or six passengers plus pilot. Range: $805 \mathrm{~km}$ (500 $\mathrm{mi})$.

Endurance: $20 \mathrm{~h}$.

Special equipment: The blimp carries special TV orthicon viewing cameras for aerial scenes and transmits the data to a ground-crew bus which serves as radio headquarters. It also carries frame and movie cameras and broadcasting equipment for reporting special events.

A recent report by the Aero-Mechanical Programs of the Goodyear Aerospace Corp. (1971) describes the use of airborne sensing equipment flown aboard a Goodyear blimp, including isolated nose-probe acoustic sensor, steerable acoustic sensor, stereo acoustic sensors, directional acoustic sensor, remotely controlled TV camera, infrared covert illuminator, acoustic gradient array, low-light-level and daytime TV, remote trailing sensor, and an aft-looking sensor.

Test equipment can be located virtually anywhere on the airship. Acoustic and infrared sensors can be isolated from engine noise and heat. Sensors can be lowered or dunked from the airship into hard-to-reach places.

Acceleration in the cabin of the aircraft during powered flight is less than $1 / 40$ th $g$ (acceleration of gravity) with a vibration frequency range of 10 to $1,000 \mathrm{~Hz}$.

There is no indication that blimps are being used for remote sensing except for their news media role.

\section{SCHWEIZFR SAILPLANE SGS 2-32}

The Schweizer sailplane SGS 2-32 has an unusually large airplane-type cabin capable of 
carrying two average-sized passengers in addition to the pilot (fig. 41). It has an all-metal monocoque structure, and the airframe has been used as a basis for several powered aircraft. The SGS 2-32 was chosen by Lockheed Missiles and Space Company to form the basic airframe of its YO-3A quiet reconnaissance aircraft and by Ling-Temco-Vought (now E-Systems) for its $\mathrm{L} 450 \mathrm{~F}$. The sailplane's maximum takeoff gross weight is $610 \mathrm{~kg}(1,340 \mathrm{lb})$.

Performance:

Speed: Maximum (smooth air) $225 \mathrm{~km} /$ h $(140 \mathrm{mi} / \mathrm{h})$. Minimum or stalling $77 \mathrm{~km} / \mathrm{h}(48 \mathrm{mi} / \mathrm{h})$. Minimum sinking speed $0.7 \mathrm{~m} / \mathrm{s}(2.4 \mathrm{ft} / \mathrm{s})$ at $80 \mathrm{~km} / \mathrm{h}$ $(50 \mathrm{mi} / \mathrm{h})$.

Best glide ratio: $34: 1$ at $97 \mathrm{~km} / \mathrm{h} \quad(60$ $\mathrm{mi} / \mathrm{h})$.

Maximum aero-tow speed: $180 \mathrm{~km} / \mathrm{h}$ $(110 \mathrm{mi} / \mathrm{h})$.

Special equipment: Optional equipment includes electrical and oxygen systems, radio communications, and such special instrumentation as might be specified, including provisions for aerial cameras or other remote sensors.

\section{SPACECRAFT}

With the advent of space systems, a new dimension has been added to remote sensing. Platforms are no longer limited by the atmosphere, and orbits can be defined which provide the following: (1) Any altitude desired as long as it is effectively above that of atmospheric drag effects (about $150 \mathrm{~km}$ ) and still within the dominant gravity field of the Earth. (2) Configuration so that the entire Earth or any designated portion can be covered at specified intervals. (3) Constant position relative to the Earth's surface through the geostationary mode, thus permitting continuous sensing of a given section of the Earth's surface. (4) Remote sensing at relatively close range of extraterrestrial bodies such as the Moon and planets and without the interference of the Earth's atmosphere.

Remote sensing of the entire Earth on a periodic basis and sizable sections on a continuous basis thus becomes feasible. Lighting and atmospheric conditions will limit the effective- ness of the system particularly where sensing of the actual surface with reflected solar energy is involved. The meteorological satellites demonstrate the Earth-sensing electronic transmission space modes even though they do not carry sensors that resolve the surface to the extent desired for many applications associated with Earth studies.

Satellites designed for remote sensing on an operational basis are generally unmanned though manned space stations provide similar capabilities. Manned extraterrestrial missions, such as Apollo, can provide opportunities for remote sensing of the Moon or planet concerned; however, to date manned missions have not been defined with remote sensing as their primary objective.

\section{GENERAL CONSIDERATIONS}

No attempt is made to cover either the theory or the state-of-the-art of space flights. The problems of achieving and maintaining the proper orbit and providing the power and environment for remote sensing are beyond the scope of this circular. However, the problems of data transmission and spacecraft platform stability are unique to remote-sensing missions and are therefore briefly covered. Information in this section has been obtained from "Jane's All the World's Aircraft" unless otherwise noted.

\section{DATA TRANSMISSION}

All space flights require a network of ground control stations for data transmission and command of the spacecraft. These networks vary with the type of mission. The NASA network for Earth and lunar missions is described in the "Space Tracking and Data Acquisition Network Manual" (NASA, 1967). The transmission and control network for planetary flights is described in "The Deep Space Network" (Calif. Inst. of Tech., Jet Propulsion Laboratory, 1971).

The NOAA system for its operational meteorological satellites is described in the "Instructions and Operating Handbook for the Improved TIROS Operational System (ITOS) and the TIROS Operational System (TOS), Part 4." 
Except for the film return mode, as exemplified by manned missions, sensor response must be in electronic signal form and transmitted to Earth. If this is to be done globally on a realtime basis, from Earth-sensing systems such as the meteorological satellites, there must be a ground station network capable of continuously receiving from the satellite. Since the wavelengths involved require line-of-sight transmission, several ground stations, depending on the orbit, are needed to acquire the data. The use of geostationary communications satellites as relay stations is a recent development which promises to simplify the data-transmission problem and reduce the number of ground stations required. Three U.S. ground stations are employed for the Earth Resources Technology Satellite (ERTS-1) data acquisition. Canadians installed a ground station prior to launch, Brazil installed a ground station during 1973; and other countries have asked for advice in setting up similar installations. For areas outside the ground stations' range, a wide-band video tape recorder is included on ERTS-1 which stores the data on board and then plays it back when the flight is within range of a ground station. This procedure precludes realtime transmission, but the delay involved in transmission will generally be less than 1 hour. It is important to note, however, that data processing of ERTS is centralized, and therefore additional delay generally occurs prior to actual receipt of the data by the processing center at Greenbelt, Md. Early in 1973, ERTS-1 lost part of the use of its second tape recorder (the first failed shortly after launch), thus reducing its coverage beyond the range of the ground stations. The problem of recovering hard copy, such as film, is discussed briefly under film return (p. 20). During 1973 this mode was being demonstrated by Skylab.

\section{PLATFORM STABILITY}

In theory, a spacecraft might be free of all relative motion except for its designed orbital vector, and thus be a perfectly stabilized platform. In practice, spacecraft must be controlled to maintain proper attitude and to dampen inevitable oscillations, including vibrations that may develop from onboard mechanisms. Attitude must be sensed and determined before it can be adjusted. Horizon sensors, particularly in the infrared region, can relate spacecraft attitude to the Earth or another planet as a whole, but there are limits to this procedure, which is accurate only to the order of a tenth of a degree. Truly precise attitude can be obtained by stellar observations. This approach is used on extraterrestrial flights and has also been defined for film-return Earth-sensing missions. The control of attitude can be accomplished by reaction jets, gimbaled inertial systems (including gyros), torquing with respect to the Earth's magnetic field, or even a gravity gradient boom which works on the principle that a linear-shaped mass will aline itself in a gravitational field. To keep from constantly correcting for attitude, some limits or deadbands are imposed before corrective action is introduced. The fewer the corrections, the more stable and longer lived the platform's attitude control system, and thus reduction of rotational rates (damping) is a desirable objective. Some figures relative to deadbands and rotational rates are quoted for described spacecraft.

Station keeping, which involves adjustment by jet thrusters, is another source of instability. On remote-sensing missions it is more desirable to allow the orbit to change somewhat rather than pay the price of constant station keeping. Although there is no such thing as a fully stable Earth orbit, some spacecraft have remained in the same nominal Earth orbit for several years without station-keeping adjustment.

\section{DESCRIPTIONS OF SPACECRAFT}

The spacecraft section is divided into two parts. The first covers experimental spacecraft, which are flown by NASA, and the second covers operational remote-sensing spacecraft, which are flown by NOAA.

\section{EXPERIMENTAL, UNMANNED, EARTH VIEWING}

Three basic unmanned space modes for sensing the Earth have been defined :

(1) Film return, short-lived, $150-500 \mathrm{~km}$ altitude, sun-synchronous.

(2) Electronic data transmission, long-lived, $300-1,500 \mathrm{~km}$ altitude, sun-synchronous, except 
for TIROS 1-8: (TIROS, ITOS, Nimbus, ERTS-A\&B) ${ }^{1}$

(3) Electronic data transmission, long-lived, $36,000 \mathrm{~km}$ altitude, geostationary or geosynchronous: Advanced Technology Satellite (ATS), Synchronous Meteorological Satellite (SMS), and the proposed Synchronous Earth Observation Satellite (SEOS).

\section{FILM RETURN}

The NASA manned spacecraft program has repeatedly returned exposed film to Earth; however, an unmanned film-return mission has not been flown by NASA except as incident to the manned program (Apollo 6). Unmanned film-return missions have been defined and requested of NASA by the U.S. Department of the Interior (1970).

Newspapers, periodicals such as "Space Business Daily" (1971) and "Science News" (Driscoll, 1971), and a recent book by Klass (1971) refer to so-called reconnaissance/surveillance satellites of the film-return type. Jane's describes United States SAMOS and U.S.S.R. COSMOS surveillance satellites in general terms, but official information relative to the remote-sensing capabilities of such satellites is not available. The "Aeronautics and Space Report of the President for 1970" (1971) tabulates basic data on all United States space flights. The semiannual publication "Rockets and Satellites Catalogue of Data" by the World Data Center A (1971) tabulates worldwide data on space flights. Surveillance space flights would be tabulated in these publications.

Although no unmanned platform designed for film return is specially described, figure 42 illustrates the configuration that such a vehicle might take. General Electric Company (1967b) and Lockheed Missiles and Space Co. (1967 and 1969) have both described film-return missions.

The U.S. Department of the Interior proposal (1970) of such a mission to NASA did not designate the vehicle but did include the following specifications :

Target date: 1972.

Orbit: $232 \mathrm{~km}$ altitude, circular, $83^{\circ}$ inclina-

\footnotetext{
${ }^{1}$ Designation of NASA programs that exemplify the mode.
}

tion to Equator, sun synchronous, 10:00 a.m. local time for photographic limb.

Design life: 30 to $\mathbf{4 0}$ days.

Cameras : 2 metric, 305-mm focal length with 240-mm (9.5-in.) film width.

A pair of stellar cameras are included for attitude determination, and the entire payload weight would be in the order of $1,000 \mathrm{~kg}$. NASA has sponsored the design of a laser altimeter for such a satellite, and Doppler transponders which would provide precise location are currently used on navigation satellites such as the Navy's Tranet.

On film-return flights, exposed film is stored on board, and at a prescribed interval or at the end of the mission a reentry vehicle, with the film, is detached on a signaled command. A propulsion unit reduces the velocity of the reentry vehicle so that it reenters the atmosphere, where a parachute further reduces its rate of fall. Aircraft with grappling lines snag the chute lines, and the reentry vehicle is brought on board the aircraft. NASA has demonstrated this procedure by recovery of its biosatellite (TRW, 1969). The recovery operation is illustrated in figure 43.

For such remote-sensing missions, onboard data recording to correlate images with precise time, and thus position, is essential. Attitude controls and determination are also needed. The cameras must be command controlled, with flexibility such as exposure variations being highly desirable. Since film will fog due to radiation, it must be shielded. Indications are that the practical lifetime is something less than a year. Obviously the film-return mode involves high cost since cameras are not recovered from their limited-life mission, as now defined, and the film recovery operation requires elaborate logistical support.

\section{ELECTRONIC DATA TRANSMISSION, GENERALLY SUN SYNCHRONOUS}

This mode includes NASA and NOAA meteorological satellites and also the first Earth Resources Technology Satellite (ERTS-1), which was launched July 23, 1972. The relationship of experimental to operational meteorological satellites is shown in figures 68,69 . Such 
spacecraft, except for the early TIROS (1-8), are launched into near-polar circular orbits, which retain a fixed relationship with respect to the Sun-Earth axis. At any given position on the orbit, local Sun time will be the same, thus creating the sun-synchronous condition. As the Sun latitude changes with the seasons the Sun elevation on any given earth surface scene will also change, but the Sun longitude (time) will be basically fixed whenever the spacecraft passes over the same scene.

Altitudes of such orbits are in the order to 300 to $1,500 \mathrm{~km}$. Since the flight is long lived, the orbit must be completely above atmospheric drag effects. The field of view of the sensors and the density and capability of the ground stations to which all data must be transmitted further define the orbit. Meteorological spacecraft, in near polar orbit, can effectively sense the entire Earth every 24 hours during daylight and every 12 hours when equipped with both day and night sensors. In a high-resolution system, such as ERTS, the field of view of the sensor is small and even at its $920-\mathrm{km}$ altitude it will take 18 days to completely image the Earth during daylight hours, except for the poles, which are not covered due to the orbital inclination. To date, 5 Nimbus, 10 TIROS, 9 TOS, 1 ITOS, and 1 ERTS have been successfully orbited. These are described in chronological order, and TOS and ITOS are described as operational (NOAA) satellites.

Nimbus.-The Nimbus program, started in 1958 and still continuing, was conceived as a test bed for spaceborne remote-sensing instrumentation. Six launches have been made; five were successful. Although primarily meteorological, Nimbus has been utilized successfully to test application of instrumentation on a broad scale of Earth-observing usage, and a further launch is scheduled for 1974 (fig. 44).

Description (Nimbus D) :

Size (overall in-orbit dimensions) $2.9 \mathrm{~m}$ $(9.5 \mathrm{ft})$ high, $2.9 \mathrm{~m}(9.5 \mathrm{ft})$ wide, sensor ring $1.47 \mathrm{~m}(4.82 \mathrm{ft}) \times 0.33 \mathrm{~m}$ $(1.08 \mathrm{ft})$.

Weight: $570 \mathrm{~kg}(1,260 \mathrm{lb})$.

Typical payload: Infrared interferometer spectrometer, temperature/humidi- ty infrared radiometer, image-dissector camera system, filter wedge spectrometer, selective chopper radiometer, satellite infrared spectrometer, backscatter ultraviolet spectrometer, cloud-top altitude radiometer, monitor of ultraviolet solar energy, and interrogation, recording, and location system.

Payload capacity: $135 \mathrm{~kg} \quad\left(\begin{array}{lll}300 & \mathrm{lb}\end{array}\right)$ weight; $100 \mathrm{~W}$ available power, $1 \mathrm{~m}^{3}$ (35 $\left.\mathrm{ft}^{3}\right)$ volume.

Stabilization: Three-axis active control utilizing flywheels, rate gyros, horizon scanners, and reaction jets; to $\pm 1^{\circ}$ all axes. Active control is augmented by gravity gradient torquing.

Nominal orbit: Circular, high noon, sun synchronous, $80^{\circ}$ retrograde, $1,110 \mathrm{~km}$ altitude, 107-min period.

Design life: $1 \mathrm{yr}$.

Onboard storage: High data-rate storage on two 5-channel tape recorders.

Transmission: S-band communication, narrow bands; PCM 4 kbps real time, $128 \mathrm{kbps}$ playback.

Launch vehicle: Thorad/Agena-D

TIROS.-Ten spacecraft in the TIROS series of satellites (fig. 45), launched between 1960 and 1965, were the precursors of the TOS (TIROS Operational Satellite) system. The spacecraft were utilized to test instrumentation and operational system concepts. TIROS design proved successful and formed the basis for the TOS configuration, which was used until replaced by the ITOS system. TIROS satellites returned $650,000 \mathrm{TV}$ images during the program, which ended during 1973.

Description :

Size: Pillbox shape, 18-sided polygon, $56 \mathrm{~cm}$ (22 in.) high, $107 \mathrm{~cm}$ (42 in.) diameter.

Weight: In orbit, 122-152 kg (270-338 lb).

Typical payload (not all instruments were carried on all flights) : Narrowangle TV, 5-channel scanning radiometer, $40^{\circ}$ Hanel radiometer, University of Wisconsin bolometers, and au- 
tomatic picture transmission (APT) system.

Payload capacity: $6.9 \mathrm{dm}^{3}$ (11.9 $\left.\mathrm{ft}^{3}\right)$ volume, $75 \mathrm{~W}$ total spacecraft power.

Stabilization: TIROS 1-8 spin stabilization maintained by solid fueled spinup rockets. Mechanical nutation damper provided $14^{\circ}$ damping. TIROS 9 10 had liquid dampers providing damping to $<0.1^{\circ}$. Horizon infrared sensors provided input for attitude control maintained to $\pm 1^{\circ}$ in pitch, roll, and yaw.

Orbit: TIROS 1-8 were programed for $740-1,300 \mathrm{~km}$ altitude, circular orbits with a $48^{\circ}-60^{\circ}$ inclination. TIROS 910 were programed for sun-synchronous polar circular orbits.

Design life: $3 \mathrm{mo}$.

Onboard storage: Video tape recorders capable of storing 32 images/orbit.

Transmission: PCM telemetry system; data rate for TV, $0.5 \mathrm{Mbps}$, for APT, 2 kbps.

Launch vehicle: Thor Delta.

Earth Resources Technology Satellite (ERTS).-The Earth Resources Technology Satellite (ERTS) is designed to demonstrate the feasibility of mapping and monitoring Earth surface features from space. It therefore carries multispectral imaging systems as well as auxiliary equipment to collect information needed to utilize data returned from these instruments. At least two spacecraft are planned in this series with the first one being launched into a near-polar circular orbit on July 23, 1972. During its first year of operation, performance of the ERTS spacecraft was literally flawless. Although the vidicons were used for only a relatively short period, the multispectral scanner was in continuous use, and the ERTS system in 1 year accomplished the following: (1) complete cloud-free coverage of the United States; (2) cloud-free coverage of a sizable percentage of the remaining land surface, polar, and coastal areas of the Earth; and (3) repetitive coverage, based on the 18-day coverage cycle of ERTS, which shows significant temporal changes in the United States and other land areas of the world.
Due to the spacecraft stability, scanner performance and system corrections made by NASA in processing the initial coverage, the imagery had the following characteristics: (1) multispectral (4-band) response with high radiometric fidelity, (2) high geometric fidelity in the form of a defined continuous map projection thus providing the potential for an automated mapping system, and (3) spatial frequency (resolution) based on picture elements of $80-\mathrm{m}$ side dimension at ground scale (figs. $46,47)$.

Description (ERTS-1) :

Size: $3 \mathrm{~m}(10 \mathrm{ft})$ high x $4 \mathrm{~m}(13 \mathrm{ft})$ wide with solar panels extended; sensor ring, $1.5 \mathrm{~m}(5 \mathrm{ft}) \times 0.3 \mathrm{~m}$ (1 ft).

Weight: $815 \mathrm{~kg}(1,800 \mathrm{lb})$.

Payload: Three return-beam vidicon cameras, 2 data-collection system receivers, 1 multispectral scanner (4 bands), 2 video tape recorders. By late 1973, the ERTS-1 return-beam vidicon cameras had had very limited use, and tape recording was only a fraction of original capability.

Payload capacity: $240 \mathrm{~kg} \quad(530 \mathrm{lb})$ weight, between 350 and $400 \mathrm{~W}$ available power, and $1 \mathrm{~m}^{3}\left(35 \mathrm{ft}^{3}\right)$ volume.

Stabilization: Three-axis active control utilizing flywheels, rate gyros, horizon scanners, and reaction jets; to $\pm 0.4^{\circ}$ in pitch and roll and $\pm 0.6^{\circ}$ in yaw.

Nominal orbit: Near circular, sun synchronous with local sun time of 0942 at descending mode, $99^{\circ}$ inclination, 900 to $950 \mathrm{~km}$ altitude. This orbit gives full Earth coverage except for polar regions every 18 days.

Design life: 1 yr, but ERTS-1 may be operational for more than 2 yrs.

Onboard storage: Two wide-band video tape recorders each having 30 -min capacity at $15 \mathrm{Mbps} \mathrm{PCM}$ or $3.5 \mathrm{MH}_{\mathrm{z}}$ video recording rate. Command storage for 30 commands.

Transmission: S-band communication, wide band (video) $20 \mathrm{MH}_{\mathrm{z}}$ bandwidth; narrow band PBM $1 \mathrm{kbps}$ real time or 24 kbps playback.

Other: Capability exists for orbit adjustment with onboard propulsion, 
attitude determination system accuracies $0.07^{\circ}$ in pitch and roll and $0.5^{\circ}$ yaw.

Launch vehicle: Long-tank Delta.

ELECTRONIC DATA TRANSMISSION, GEOSYNCHRONOUS

This mode has been well demonstrated by NASA's Advanced Technology Satellite (ATS) with remote sensors used for meteorological research. The next scheduled effort in this mode is the Synchronous Meteorological Satellite (SMS) which will combine technology research by NASA with meteorological operations and research by NOAA and is scheduled for launch in 1974. These two types of satellites, though utilized for meteorological purposes, can also resolve the Earth's surface to a limited extent. For terrain observations a much higher resolution camera, coupled to a tracking telescope, is probably required. Such a system has been proposed to NASA by the U.S. Department of the Interior (1969), and NASA is supporting studies of this and related concepts. As indicated on page 31 , a very large telescope launched by the Space Shuttle could be placed in geosynchronous orbit for Earth viewing.

Application Technology Satellite (ATS).The Application Technology Satellite (ATS) is a multipurpose platform used to test various types of space systems, including remote sensing, from geosynchronous altitude (figs. 48, 49, 50 ). Through data obtained from this platform, concepts for such spacecraft as the SMS were formulated.

Description :

Size: Cylindrical, $142 \mathrm{~cm}$ (56 in.) diameter, 135-182 cm (53-72 in.) length.

Weight: 295-355 kg (650-780 lb).

Typical payload: Multicolor spin-scan camera, image dissector camera, communications experiments, and space environment experiments. Total spacecraft power, $190 \mathrm{~W}$ from solar panels, 6 Ah batteries.

Stabilization: Spin stabilized with 4 monopropellant thrusters, each with $2.2 \mathrm{~kg}$ (5 lb) thrust; also magnetic torquing and gravity gradient stabilization.

Nominal orbit: Geosynchronous altitude
$36,000 \mathrm{~km}(19,400 \mathrm{inm})$.

Design life: 1 yr.

Onboard storage: None.

Transmission: PCM.

Launch vehicle: Atlas Agena or Atlas Centaur.

Synchronous Meteorological Satellite (SMS). -The Synchronous Meteorological Satellite (SMS), scheduled to be launched in 1974, is the prototype spacecraft to be used by NOAA in implementing the Global Atmospheric Research Program, a key step in the international World Weather Watch. It is the first spacecraft designed for this purpose to fly in geosynchronous orbit and thus will also be known as the Geostationary Operational Environmental Satellite (GOES). Aside from taking cloud-cover imagery, it will monitor the space environment and provide a data relay to aid in speeding up meteorological data collection (fig. 51).

Description :

Size: Pillbox shape, $190 \mathrm{~cm}$ (75 in.) diameter, $122 \mathrm{~cm}$ (48 in.) length.

Weight: $225 \mathrm{~kg}(500 \mathrm{lb})$ in orbit.

Payload: Visible and infrared spin-scan camera system, Space Environment Monitoring System, and data-collection system.

Payload capacity : $75 \mathrm{~kg}$ (165 lb) weight and $1.26 \mathrm{~m}^{3}\left(35 \mathrm{ft}^{3}\right)$ volume; $160 \mathrm{~W}$ available power.

Stabilization: Spin stabilized by Delta launch vehicle and cold gas system; contains nutation dampers.

Orbit: Geosynchronous altitude 36,000 km $(19,400 \mathrm{inm})$.

Design life: 3 yr.

Onboard storage: None.

Transmission: PCM 194-bps S-band communications.

Launch vehicle: Thrust-augmented Delta.

Proposed High-Resolution Geosynchronous Systems.-In 1969, the Department of the Interior proposed that a high-resolution Earthviewing tracking telescope be flown in geosynchronous orbit as part of the ATS program. Although not feasible for ATS, the concept of monitoring the Earth's surface from geosynchronous altitude has been considered by NASA and others. Interior recommended that an 
operational system be developed by 1980 . During 1972 and 1973, NASA supported studies of the Synchronous Earth Observation Satellite (SEOS) that involve the detailed study of the Earth from geosynchronous orbit (fig. 52).

Description (Interior proposal) :

Orbit: Circular, geosynchronous on plane of the ecliptic with first satellite at about longitude $95^{\circ} \mathrm{W}$., altitude $36,000 \mathrm{~km}(19,400 \mathrm{inm})$.

Design life : 5 to $10 \mathrm{yr}$.

Sensor: Tracking telescope capable of resolving $20-50 \mathrm{~m}$ elements on the Earth's surface in at least three spectral bands. Instantaneous field of view to cover $40-80 \mathrm{~km}$ (on a side) of the Earth's surface. Primary optic would be of about $1 \mathrm{~m}$ diameter.

Transmission: Capable of transmitting one 3-band scene per minute.

Operation: Sensor directable to any section of a sizable part of the Earth's surface at any time, subject only to conditions of visibility. Six satellites could monitor all but the polar regions of the Earth on a continuing basis and in stereo mode, which provides high spatial precision.

EXPERIMENTAL, UNMANNED, EXTRATERRESTRIAL

Prior to the space age, remote sensing of the Moon and planets had been limited to Earthbased optical and radio telescopes. Telescopes have been carried in aircraft and balloons, but space systems that can escape the Earth's atmosphere and gravitational field have completely revolutionized the concepts of extraterrestrial exploration. Remote sensing of the Moon and planets is now feasible in any one of a variety of modes, which may be categorized as follows:

1. Lander.-Either crash (probes) or soft landing. The latter may or may not be capable of returning to Earth. Remote sensing may be achieved during the approach, while on the body, or possibly during the return flight (if there is one). The U.S.S.R. has placed two landers on the Moon which collected samples and TV photos and then returned to EarthLUNA 16 in 1970 and LUNA 20 in 1972.
2. Orbiter.-Orbits the body indefinitely. An orbiter of defined life which returns to Earth with hard-copy film is feasible and has been accomplished by the U.S.S.R. with the ZOND satellite during 1969 and 1970.

3. Flyby.-The spacecraft passes close to but does not go into orbit about the body of interest. This mode is applicable to the more distant planets.

The first NASA extraterrestrial remote-sensing program involved the exploration of the Moon in support of the manned Apollo program. Ranger, Lunar Orbiter, and Surveyor were the three groups of missions which provided imagery and other data of the Moon essential to the lunar landings of Apollo. In addition to the lunar program, NASA has an extensive program of planetary exploration based on the Mariner spacecraft. Mars has been sensed by flyby missions, and the first Mars orbital mission occurred during 1971. In October 1973, Mariner 10 was launched on a flyby mission of Venus and Mercury. In 1972 and 1973, Pioneer missions to Jupiter were launched as precursors of further outer planet missions. Although plans for the Grand Tour flyby of up to five planets has been dropped by NASA, at least one Pioneer mission past Venus is scheduled for 1978 , including instrumented probes as well as spacecraft sensing from orbit. Russian extraterrestrial remote-sensing programs are generally parallel to those of the United States.

Unmanned extraterrestrial missions depend on electronic transmission of remote-sensored signals back to Earth. Transmission from the distant planets can be achieved although the amount of data is limited by the power, time, and equipment available. As with Earth-sensing missions, ground stations use line-of-sight radio signals to control the spacecraft, monitor its performance, and receive the sensor signals. On the more distant missions, transmission of signals back to Earth becomes a limiting factor. Power generally comes from solar panels, and since their generating capacity is limited, the rate of signal transmission is also limited.

As spacecraft are defined for distant planetary missions, the problems of communication, orbit and attitude adjustment, and thermal control become increasingly difficult. Power is the 
key to the problems, and solar panels have their limitations. Mariner flybys of Mars and Venus took days to transmit the contents of an image which took only a few milliseconds to acquire. The use of some form of nuclear power source appears to be the most promising answer to the basic problem for distant planetary explorations (Corliss, 1966). Radioisotope thermoelectric generators will be used to power the Pioneer and probably later outer planetary missions. Attitude reference on such missions depends heavily on the stars, but reference to the horizon of the body itself can also be applied to an orbiter. Durability and dependability become increasingly critical.

The following programs are described: Ranger, Lunar Orbiter, Surveyor, Mariner flyby, Mariner Mars Orbiter, Mariner Venus/Mercury, Viking, and Pioneer mission to Jupiter.

\section{RANGER}

The Ranger lunar probes were first attempts by the United States to obtain closeup imagery of an extraterrestrial body. The series consisted of nine spacecraft; the first two, which failed at launching were designed to be tested in Earth orbit. Of the remaining seven, only Rangers 7, 8, and 9 successfully completed their missions of taking TV imagery before crashing on the Moon. The program ended when Ranger 9 crashed on March 24, 1965 (fig. 53).

Description:

Shape: A truncated cone mounted on a hexagonal base $152 \mathrm{~cm} \mathrm{(60} \mathrm{in.)} \mathrm{in}$ diameter.

Typical payload: Six slow-scan vidicons with narrow- and wide-angle lenses of $76 \mathrm{~mm}$ and $25 \mathrm{~mm}$ focal length.

Payload capacity: $164 \mathrm{~kg}$ (362 lb); power from batteries, $40 \mathrm{Ah}$.

Stabilization: Three-axis stabilization with gyros for inertial reference, Earth and Sun sensors for celestial reference, and cold gas active control.

Orbit: Orbital planes as defined by the trajectories were inclined $15^{\circ}$ to the lunar equator.

Design life: 30 days.

Onboard storage: None.
Transmission: Two $960 \mathrm{MH}_{\mathrm{z}}$ transmitters, $60 \mathrm{~W}$ power each; two $960 \mathrm{MH}_{\mathrm{z}}$ transponders, $3 \mathrm{~W}$ power each.

Other: Midcourse correction thruster of $28 \mathrm{~kg}(62 \mathrm{lb})$. Imagery taken during final $10-20$ min of flight.

Launch vehicle: Atlas Agena.

LUNAR ORBITER

The five Lunar Orbiter spacecraft were launched during 1966 and 1967 to photograph the Moon for selection of potential Apollo landing sites. The Orbiter series obtained data on lunar size, shape, and gravitational properties. The spacecraft carried instruments for sampling the near-lunar micrometeoroid and radiation environments (figs. 54 and 55).

Description :

Size (exclusive of solar panels and antennas): $152 \mathrm{~cm} \mathrm{(60} \mathrm{in.)} \mathrm{diameter,}$ $168 \mathrm{~cm}$ (66 in.) high.

Weight: $388 \mathrm{~kg}$ (855 lb).

Typical payload: Two film cameras, film processors, scanner, and transmitters; pressure-type micrometeoroid detectors and two cesium iodide dosimeters.

Payload capacity: $72.5 \mathrm{~kg}(160 \mathrm{lb})$; power, $110 \mathrm{~W}$.

Stabilization: Primary, three axis referenced to Sun and Canopus; backup, three axis inertial. Control accuracy - pitch, roll, and yaw to $\pm 0.1^{\circ}$ with cold gas system.

Nominal orbit: For Orbiters I, II, and III, selenocentric - perilune $50 \mathrm{~km}$, apolune, $1,850 \mathrm{~km}$, inclination $12^{\circ}$, period $3.5 \mathrm{hr}$. Orbiters IV and V had different, and varying orbits.

Design life: About 2 mo.

Onboard storage: Command of 128 21bit words; Bimat film.

Transmission: PCM 50 bps, S-band communication.

Other: Onboard film processing, Bimat process. Optical-mechanical-electronic video scanner of developed film generates signal for transmission to Earth.

Launch vehicle: Atlas Agena. 
SURVEYOR

The Surveyor program was designed to demonstrate the ability to soft land on the moon as well as to transmit scientific and engineering information about the lunar surface (fig. 56). Of 7 spacecraft, 5 were successful and 2 had inflight failures prior to landing.

Description :

Size: Pyramidal open-frame structure 3 $\mathrm{m}$ (10 ft) high. With landing gear extended, can fit in a $4.25 \mathrm{~m} \mathrm{(14} \mathrm{ft)}$ diameter space.

Weight: 995-1,080 kg (2,200-2,380 lb).

Typical payload: Survey TV camera and auxiliary mirrors, alpha-scattering instruments, and soil magnets.

Payload capacity: Weight $40 \mathrm{~kg}$ (89 lb) ; power from $90 \mathrm{~W}$ solar panels and 230-Ah rated batteries.

Stabilization: Three-axis gyro referenced to Sun and Canopus with active control by cold gas jets. During landing an automated closed-loop system was used with radar altimeter and Doppler velocity sensors providing reference data.

Orbit: Not applicable as Surveyor soft landed at several Apollo landing sites.

Design life: 90 days including flight and lunar surface operation.

Onboard storage: None.

Transmission: Two transmitters, 2 receivers, 2 omnidirectional antennas, and 1 high-gain planar-array antenna for transmitting 600-TV-line data. Tracking and engineering data were transmitted on a 2,295 $\mathrm{MH}_{\mathrm{z}}$ band at $10 \mathrm{~W}$ power.

Launch vehicle: Atlas Centaur.

\section{MARINER (FLYBY)}

The Mariner spacecraft were designed to provide imagery and environmental information of the planets Venus and Mars. Because of the dense Venusian cloud cover, imaging systems were not included on missions to this planet. The spacecraft were designed to fly by the planets and then proceed into solar orbit (fig. 57 ). In addition to the planetary measurements, the spacecraft provided useful data on the interplanetary environment. Of the seven spacecraft in this series, two failed at launch. Flights occurred between 1962 and 1969 .

Description :

Size: Octagonal $127 \mathrm{~cm}$ (50 in.) across flats, $66 \mathrm{~cm} \mathrm{(26} \mathrm{in.)} \mathrm{thick.} \mathrm{In} \mathrm{flight,}$

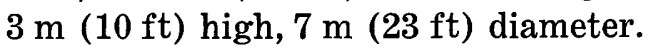
Weight: $260 \mathrm{~kg}$ (575 lb).

Payload: Mariner 4 to Mars-TV attached to Cassegrainian telescope, helium magnetometer, cosmic-ray detectors, and cosmic-dust detectors. Mariner 7 to Mars-two vidicon cameras, infrared spectrometer, infrared radiometer, ultraviolet spectrometer, conical radiometer. Mariner 5 to Venus -Faraday-cup detector, energetic-particles detectors, helium triaxial magnetometer, and ultraviolet photometers.

Payload capacity: $48.5 \mathrm{~kg}$ (107 lb) ; 50 W power.

Stabilization: Three axis referenced to Sun and Canopus, cold gas system, pitch and yaw controlled to $\pm 1 / 2^{\circ}$, roll $\pm 1 / 4^{\circ}$.

Orbit: Heliocentric epoch 07/16/65 period 567 days, apogee 1.58 astronomical units radius, perigee 1.1 astronomical units radius, and inclination $0^{\circ}$.

Design life: $1 \mathrm{yr}$.

Onboard storage: Tape recorded $7.83 \mathrm{x}$ $10^{8}$ bits storage.

Transmission: PCM 33.3 bps near Earth, 8.33 bps near Mars.

Other: Capability for in-flight trajectory adjustment.

Launch vehicle: Atlas Agena.

MARINER 71 (MARS ORBITER)

The Mariner 71 (Mars Orbiter) project is a direct continuation of Mariner 69 missions. The two spacecraft for this mission were modifications of the Mars flyby configuration, with the main change being a larger propulsion system needed to place the spacecraft in orbit. The two missions were designed to map 70 percent of the Martian surface and make environmental 
measurements but also were to look for seasonal changes and their relationship to surface phenomena. The two spacecraft were Mariner 8 and 9. Mariner 8 failed at launch, but Mariner 9 flew successfully in 1971 (fig. 58).

Description:

Size: Octagonal $127 \mathrm{~cm}$ (50 in.) across flats, $230 \mathrm{~cm}$ (90 in.) high. In flight, $690 \mathrm{~cm}$ (272 in.) span including solar panels.

Weight: $544 \mathrm{~kg}(1,200 \mathrm{lb})$ not including propellants.

Payload: Two TV cameras, ultraviolet spectrometer, infrared interferometer spectrometer, and infrared radiometer.

Payload capacity: Weight $20 \mathrm{~kg}$ (44 lb) ; power $450 \mathrm{~W}$, degrading to $330 \mathrm{~W}$.

Stabilization: Three-axis stabilized using inertial as well as Sun and Canopus sensors. Cold gas system pointing accuracy is in the order of $\pm 1^{\circ}$.

Nominal (mapping) orbit:

$\begin{array}{lr}\text { Apoapsis } & 16,900 \mathrm{~km} \\ \text { Periapsis } & 1,610 \mathrm{~km} \\ \text { Period } & 12 \mathrm{~h} \\ \text { Inclination } & 50^{\circ}-80^{\circ}\end{array}$

Design life: At least 90 days in Mars orbit.

Onboard storage: $168 \mathrm{~m}(550 \mathrm{ft}) \mathrm{mag}$ netic tape, $1.8 \times 10^{8}$ bits capacity.

Transmission: All-digital system with variable rate, engineering data at $33 \frac{1}{3}$ or $8 \frac{1}{3}$ bps and science data at realtime $50 \mathrm{bps}$. Block-coded real time, 16 or $8 \mathrm{kbps}$. Block-coded stored 16,8 , 4,2 , or $1 \mathrm{kbps}$.

Other: Onboard computer flight programable with 512-word memory. Ground commandable two degrees of freedom. Scan platform for holding and pointing instruments.

Launch vehicle: Atlas SLV-3C first stage. Centaur second stage.

\section{MARINER VENUS/MERCURY}

A modified version of the original Mariner spacecraft designed to fly by both Venus and Mercury, Mariner 10 was launched in October 1973 and is scheduled to fly by Venus during February 1974, Mercury during March 1974.
It may fly by Mercury again in September 1974 . Imagery of Venus will be limited to the cloud blanket and ultraviolet clouds that appear to circle the planet every 5 days. The imagery of Mercury should be equivalent to that of the best Earth-based imagery of the Moon.

The spacecraft weighs $500 \mathrm{~kg}(1,100 \mathrm{lb})$; otherwise the description and payload are generally those of Mariner 9. The difference in weight is due to the elimination of two solar panels.

\section{VIKING}

Viking, the latest in NASA's series of unmanned planetary explorers, is scheduled for a 1975 mission to Mars. The program calls for insertion of two spacecraft into Mars orbit, each spacecraft sending a separate landing craft to the surface. Viking's primary purpose is to determine if life once existed, is present, or might develop on Mars (NASA, Langley Research Center, 1970).

The Viking spacecraft will travel some 460 million miles through space on its journey of about 1 year (fig. 59). Once in Mars orbit, the spacecraft will separate into an orbiter and a lander. While the orbiter performs remotesensing and water-vapor mapping, the lander will take panoramic color pictures of the surroundings and obtain geophysical and meteorological data.

Description :

Size: Total length of Titan III/Centaur spacecraft $48.8 \mathrm{~m}$ (160 ft). Lander capsule, $4.3 \mathrm{~m}$ (14 ft) diameter x 4.9 m (16 ft) height (in flight). Orbiter spread $10.7 \mathrm{~m} \mathrm{(35} \mathrm{ft)} \mathrm{including} \mathrm{solar}$ panels.

Weight: Total launch weight of orbiter/ lander $3,175 \mathrm{~kg}(7,000 \mathrm{lb})$ of which the orbital insertion engine and fuel will be $1,815 \mathrm{~kg}(4,000 \mathrm{lb})$.

Payload: Two TV cameras for imaging, infrared spectrometer for water-vapor mapping, infrared radiometer for thermal mapping, and a radio subsystem.

Payload capacity of Orbiter: $68 \mathrm{~kg}$ (150 lb) for scientific experiments to record and relay data. 
Stabilization: Three-axis, using inertial as well as Sun and Canopus sensors. Cold gas system pointing accuracy is in the order of $\pm 1^{\circ}$.

Nominal orbit:

$\begin{array}{ll}\text { Apoapsis } & 32,550 \mathrm{~km} \\ \text { Periapsis } & 14,964 \mathrm{~km} \\ \text { Period } & 24.6 \mathrm{~h}\end{array}$

Inclination (has not been selected)

Design life of Orbiter: 140 days after Mars orbit insertion, consisting of 50 days before lander separation and 90 days after landing. Either orbiter can support either lander for the lander's lifetime, which is 90 days after landing.

Onboard storage: Similar to but somewhat larger than Mariner 9.

Launch vehicle: Titan III/Centaur.

\section{PIONEER (JUPITER)}

The purpose of the Pioneer F and G missions is to extend interplanetary measurements farther out into the solar system. Specifically, the mission is to provide information on the asteroid belt that lies between Mars and Jupiter and to fly by and gather data on Jupiter itself (fig. 60). Pioneer F (now Pioneer 10) was launched March 2, 1972; Pioneer G (now Pioneer 11), April 5, 1973. Interplanetary travel time is expected to be 600 and 700 days.

During 1973, a Pioneer Venus flight for 1978 was under study by NASA but was not yet defined or approved.

Description (Pioneer/Jupiter) :

Size : $2.4 \mathrm{~m}(8 \mathrm{ft})$ length, $5.5 \mathrm{~m}$ (18 ft) diameter.

Weight: $254 \mathrm{~kg}$ (560 lb).

Typical payload: Meteoroid detector, asteroid/meteoroid detector, plasma analyzer, helium vector magnetometer, charged-particle detectors, cosmic-ray telescope, Geiger-tube telescope, trapped-radiation telescope, ultraviolet photometer, infrared radiometer, and imaging photopolarimeter.

Payload capacity: Weight $28 \mathrm{~kg}$ (62 lb) ; power $23 \mathrm{~W}$ supplied by radioisotope thermonuclear generator.
Stabilization: Spin-stabilized at $4-5 \mathrm{r} /$ min, with fine adjustment by hydrazine-fueled thrusters. Attitude reference by Sun and star sensors.

Orbit: Trajectory to carry spacecraft within $160,000 \mathrm{~km}$ of Jupiter and then out of solar system.

Design life: About 2 yr.

Onboard storage: Tape recorder.

Transmission: S-band communications, maximum data rate from vicinity of Jupiter, 1,024 bps. Data can be transmitted at eight different rates and formats. S-band command system capable of 255 discrete commands.

Launch vehicle: Atlas Centaur.

\section{EXPERIMENTAL, MANNED SPACE FLIGHT}

To date, no manned space flights have been defined with remote sensing as the prime objective. The Manned Orbiting Laboratory, an Air Force project that was canceled, was probably the closest U.S. approach to the remote-sensing concept. However, the Manned Orbiting Laboratory had numerous other objectives in addition to remote sensing. NASA's Mercury, Gemini, and most Apollo flights were concerned with getting man to the Moon, and remote sensing, as typified by hand-held snapshots, was incidental. Apollo 9 carried a well-defined multispectral Earth-viewing experiment, SO-65; starting with Apollo 13, a variety of fixed and mobile cameras were carried in an effort to obtain systematic photo coverage of selected portions of the Moon.

The Apollo program also involved photography and other sensing of the lunar surface. Hand-held and mounted cameras (film and TV) were used on all missions that landed on the Moon, and starting with Apollo 15, the Lunar Rover Vehicle provided a moving platform for sensors on the Moon's surface.

Skylab, launched in May 1973, carries a battery of Earth-sensing experiments although astronomic observations of the Sun and the various experiments aimed at defining man's abilities and limitations in the space environment have a higher priority. The Space Shuttle has been defined, but other post-Skylab manned space programs cannot be evaluated as remotesensor platforms now. 
Russian manned space flights to date have been limited to Earth orbits, but otherwise they are parallel to the United States efforts, except that their flights emphasize the development of manned space stations, which do have a sizable remote-sensing potential.

Vehicles of the following programs are described: Mercury, Gemini, Apollo, Skylab, and Space Shuttle.

\section{MERCURY}

Project Mercury was the first series of manned space flights conducted by the United States. The capsule was designed for one man and carried many experiments, including terrain photography. The experiment was extremely successful and led to further experimentation in later manned programs. There were four orbital missions in this series (fig. 61).

Description :

Size: Cone, $189 \mathrm{~cm}$ (74 in.) diameter, $335 \mathrm{~cm}$ (132 in.) long.

Weight: $1,360 \mathrm{~kg}(3,000 \mathrm{lb})$.

Typical camera payload: $70-\mathrm{mm}$ modified Hasselblad camera, 35-mm zodical light camera, and 16-mm Maurer camera.

Payload capacity: Size and weight not available. Total spacecraft power from 500-Ah batteries. Window-viewing capabilities.

Stabilization: Three-axis attitude control by jet reaction thrusters with automatic and manual modes.

Orbit: Apogee $266 \mathrm{~km}$ (144 inm), perigee $161 \mathrm{~km}(87 \mathrm{inm})$, inclination $\approx 32^{\circ}$ to Equator.

Design life: 3 days.

Onboard storage: Film.

Transmission: Not applicable.

Launch vehicle: Atlas.

\section{GEMINI}

Project Gemini was a continuation of Mercury. A new design spacecraft enabled two men to remain in orbit for an extended period and thus allowed for more sophisticated and selective experimentation. There were 10 missions in the Gemini program.
Description:

Size: Truncated cone, $305 \mathrm{~cm}$ (10 ft) diameter, $574 \mathrm{~cm}$ (18.8 ft) long.

Weight: $3,175 \mathrm{~kg}(7,000 \mathrm{lb})$.

Typical camera payload: $70-\mathrm{mm}$ modified Hasselblad and 70-mm and 16-mm Maurer cameras.

Payload capacity : $125 \mathrm{~kg}$ (275 lb), total spacecraft power from 160-Ah batteries and 6,570 Ah-fuel cells. Viewing through two windows or with hatches open.

Stabilization: Three-axis jet-reaction attitude control system with automatic and manual modes.

Orbit: Up to $1,370 \mathrm{~km}$ (740 inm) apogee, inclination $\approx 30^{\circ}$ to Equator.

Design life: 2 wks.

Onboard storage: Film.

Transmission: Not applicable.

Launch vehicle: Titan II.

\section{APOLLO}

The Apollo program followed Gemini in extending manned space activities. In addition to providing a mechanism for lunar exploration, Apollo again demonstrated the useful application of Earth-orbital photography. Apollo 6 flew in unmanned mode, but considerable photography of the Earth was obtained on that mission. The SO-65 multispectral photographic experiment (Apollo 9) provided the basis for definition of such dedicated remote-sensing missions as ERTS.

On the early lunar missions, Apollo 8 through 14 , the only remote sensors were cameras, primarily the $70-\mathrm{mm}$ Hasselblad with interchangeable lenses. On Apollo 15, 16, and 17, much larger camera systems and other orbital remote sensors were mounted in the service module. These three missions produced high-quality mapping photographs for about 25 percent of the Moon's surface, while other sensors which could also operate on the dark side increased the total coverage to about 35 percent.

Description :

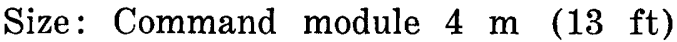
diameter, $3.5 \mathrm{~m}$ (11.5 ft) long. Service

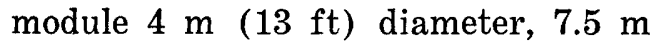


(25 ft) long. Lunar excursion module

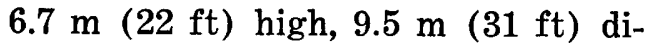
agonal across lunar landing pads.

Weight: Command module $5,760 \mathrm{~kg}$ $(12,700 \mathrm{lb})$, service module $23,500 \mathrm{~kg}$ $(51,700 \mathrm{lb})$, lunar excursion module $15,300 \mathrm{~kg}(33,700 \mathrm{lb})$.

Typical sensor payloads: 70-mm Hasselblad, 16-mm Millikon, 35-mm Maurer, 460-mm (18-in.) Hycon, and color TV in command and lunar modules. Starting with Apollo 15, lunar-sensing devices were carried in a bay of the service module and designated the Scientific Instrument Module (SIM). On Apollo 15 and 16 these devices included: 76-mm (3-in.) mapping camera, 76-mm (3-in.) stellar-attitude camera, 610-mm (24-in.) optical-bar panoramic camera, laser altimeter, mass spectrometer, gamma-ray spectrometer, and X-ray and alpha particle spectrometer. On Apollo 17, the spectrometers were replaced by the lunar sounder (side-looking radar) and infrared scanning radiometer. The SIM in lunar orbit is shown in figure 62. A diagram indicating the various sensors is shown in figure 63. The Lunar Rover Vehicle, also carried on Apollo 15, is described separately.

Payload capacity: Size and weight not available; total spacecraft power from 1,250-Ah batteries and 19,300-Ah fuel cells.

Camera viewing: Through windows at various attitudes or as exposed in the SIM.

Stabilization: Three-axis, jet-reaction attitude control with automatic rate and manual modes operating liquid propellant thrusters.

Orbit: Earth, lunar, lunar trajectory. Earth orbits had an inclination of about $30^{\circ}$ to Equator.

Design life: About 2 wks.

Onboard storage: Film.

Transmission: TV in real time.

Launch vehicle: Saturn 1 or 5.
LUNAR ROVER VEHIGLE

The Lunar Rover Vehicle (LRV), which was used on the Moon by the Apollo 15, 16, and 17 astronauts, has been called by NASA "a manned spacecraft on wheels." It is undoubtedly the most advanced and highly specialized motor vehicle ever built. Since it carried an array of remote sensors and had a unique application, it is included here even though it is a groundbased platform. The whole vehicle weighed 220 $\mathrm{kg}(480 \mathrm{lb})$ on Earth and carried a payload of about $450 \mathrm{~kg}(1,000 \mathrm{lb})$ consisting of the two astronauts and their life-supporting equipment weighing $360 \mathrm{~kg}(800 \mathrm{lb})$. The remaining 90 $\mathrm{kg}(200 \mathrm{lb})$ of payload included cameras, scientific experiments, and rock samples on the return to the service module (fig. 64).

\section{Performance:}

Speed: Maximum $15 \mathrm{~km} / \mathrm{h}(9 \mathrm{mi} / \mathrm{h})$. Cruising $8 \mathrm{~km} / \mathrm{h}(5 \mathrm{mi} / \mathrm{h})$ forward or backward.

Climb: LRV can climb a $20^{\circ}$ slope and stop on a $30^{\circ}$ slope. It can climb obstructions up to $0.3 \mathrm{~m}$ ( $1 \mathrm{ft}$ ) high and cross crevasses $70 \mathrm{~cm}$ (28 in.) wide.

Weight: Empty $220 \mathrm{~kg}$ (480 lb) ; with payload $450 \mathrm{~kg}(1,000 \mathrm{lb})$.

Size: Length $3.1 \mathrm{~m}$ (10.2 ft), width 1.8 $\mathrm{m}$ (6 ft), wheelbase $2.3 \mathrm{~m} \mathrm{(90} \mathrm{in.),}$ and clearance $36 \mathrm{~cm}$ (14 in.).

Range: $65 \mathrm{~km}$ (40 $\mathrm{mi}$ ) total distance.

Power: Two nonrechargeable $36-\mathrm{V}$ silver-zinc batteries.

Engines: Each wheel powered by a 185W (0.25-hp) electric motor. Power steering by two 75-W (0.1-hp) electric motors, one for each axle.

Special equipment: The LRV carried a dead-reckoning navigation system which reported speed, total distance traveled, and direction and distance to the lunar excursion module throughout the entire traverse.

A lunar communications relay unit transmitted directly to Earth the radio signals of the astronauts' voices, biomedical data, and color TV images from a TV camera mounted near the front of the vehicle. The vehicle carried a 16$\mathrm{mm}$ movie camera, and a 70-mm Hasselblad 
camera with interchangeable lenses. A handheld unit for drilling cores of lunar geologic material as deep as $3 \mathrm{~m}$ (10 ft) was carried along with rakes and tongs for collecting samples. A magnetometer and traverse gravimeter were also included.

\section{SKYLAB}

Skylab-A, which was launched in May 1973, is aimed at increasing man's role as an experimenter in space. Skylab utilizes the empty tank of a Saturn IVB as a semipermanent space base, which was visited three times during the program for long-duration experimentation. The program ended early in 1974 . The data obtained during each visit were returned with the crew for analysis on the ground. The particular instrument cluster pertinent to this circular is the Earth Resources Experiment Package (EREP), a module located physically in the docking adapter. Extensive observations of the Sun were also carried out with special solar sensors (figs. 65 and 66 ).

Description (Apollo-derived spacecraft designed for intermittent manned occupancy for a wide variety of experiments, including remote sensing of the Earth) :

Size: Not applicable.

Weight: Not applicable.

Remote-sensor payload: Multispectral photographic assembly consisting of six bore-sighted cameras of $152-\mathrm{mm}$ (6-in.) focal length, 460-mm (18-in.) focal length Earth Terrain Camera (ETC), infrared spectrometer, 13-band multispectral scanner, microwave radiometer/scatterometer and altimeter, and L-band radiometer.

Payload capacity (not including control units, film storage, etc.) : $1.3 \mathrm{~m}^{3}$ (45 $\left.\mathrm{ft}^{3}\right)$ volume, $340 \mathrm{~kg}(745 \mathrm{lb})$ weight, and special viewing windows.

Stabilization: Three-axis stabilization control mainly by jet reaction engines. Desired attitude determination to $\pm 0.1^{\circ}$. Desired attitude rate to be known to $\pm 0.005^{\circ} / \mathrm{s}$.

Nominal orbit: $435 \mathrm{~km}$ (235 inm) altitude and $50^{\circ}$ inclination to Equator.
Design life: 28 to 56 or 85 days per visit, three visits, nearly 1 year overall.

Onboard storage: Film in film vaults; magnetic tape, voice annotation and digital.

Other: Special mounts provided for instruments.

Launch vehicle: Saturn.

SPACE SHUTTLE

Early in 1972 the Space Shuttle was defined and development started (NASA, 1972). The shuttle is scheduled to be operational by 1980 and involves the concept of a reusable manned space vehicle. The shuttle is scheduled to launch, service, and retrieve unmanned satellites but has also been defined for manned missions (sorties) which include remote sensing of the Earth (fig. 67).

Description (Winged orbiter, capable of reentry and reuse, attached to large propellant containers for launching) :

Size: Wingspan $24 \mathrm{~m}$ (80 ft), length 38 $\mathrm{m}$ (124 ft), with a payload bay $4.5 \mathrm{~m}$ (15 ft) in diameter by $18 \mathrm{~m}(60 \mathrm{ft})$ in length.

Weight: Payload weight is $29,500 \mathrm{~kg}$ $(65,000 \mathrm{lb})$ for takeoff and $18,000 \mathrm{~kg}$ (40,000 lb) for landing.

Remote-sensor payload: Not defined to date, but sortie configuration would permit the use of a very large assortment of remote sensors, including the Large Space Telescope (LST) with 3-m (10-ft) diameter primary optics. The LST is designed for astronomic observations but might be adapted for Earth observations, particularly from a geosynchronous orbit.

Stabilization: Not defined.

Nominal orbit: $200 \mathrm{~km}$ (108 inm) altitude at various inclinations, including polar. With a secondary propulsive vehicle called the "Space Tug," geosynchronous orbits or trajectories to the Moon or planets are feasible.

Design life: Life of an unmanned satellite which may be launched by the shuttle is indefinite. The manned sortie mode is nominally of 7 days dura- 
tion but can be extended to 30 days when required. The orbiter, being reusable, has an extended life.

\section{OPERATIONAL-NOAA}

Remote sensing from space has reached the operational stage only in meteorology. The National Oceanographic and Atmospheric Administration (NOAA) is the United States agency charged with such operations. NOAA absorbed the Environmental Science Services Administration (ESSA) which controlled the original operational meteorological satellite. The first operational weather satellites were the ESSATOS series with the first launch in 1966. Since that date at least one weather satellite has been in operation continuously. In 1970 , the ITOS series was introduced. The latest, ITOS-D, was launched in 1971. Both TOS and ITOS satellites fly in near-polar sun-synchronous orbits and image the globe every 12 hours. The SMS, which will be geostationary, has been described under NASA spacecraft, but it will also perform an operational role as the GOES satellite. ESSATOS, ITOS-A, $-\mathrm{B},-\mathrm{C}$, and $-\mathrm{D}$ are described here.

The evolution of the meteorological satellites, including the experimental NASA and the operational systems, is outlined in figure 68 , in which the actual missions are tabulated.

\section{ESSA-TOS}

The ESSA-TOS spacecraft were the first of the operational meteorological satellite system. They were used to provide cloud imagery for operational as well as research usage. Specifically designed to provide a platform for the instrumentation developed to meet mission requirements, these spacecraft can be considered as a group of separate but coordinated subsystems operating as part of an overall datagathering system. This type of spacecraft has been superseded by the ITOS system. Two versions of the ESSA spacecraft were operated. One version carried an Advanced Vidicon Camera System (AVCS), which stores the sensor signal on board and then transmits to a designated receiver in a short period. The other version carried an Automatic Picture Transmission (APT), which transmits in real time to any station within range (basically line-of- sight) of the satellite. APT receivers numbering in the hundreds are relatively simple to construct, and therefore the APT system is available on a worldwide basis (figs. 69 and 70).

Description:

Size: Pillbox 18-sided polygon, $56 \mathrm{~cm}$ (22 in.) high, $107 \mathrm{~cm}$ (42 in.) diameter.

Weight: $148 \mathrm{~kg}$ (327 lb) in orbit.

Typical payload: AVCS version carried redundant 800-line vidicon cameras with tape recorders and low-resolution flatplate radiometer. APT version carried tape recorders replaced with APT transmission equipment.

Payload capacity: $6.9 \mathrm{dm}^{3}\left(420 \mathrm{in} .^{3}\right)$ volume, $75 \mathrm{~W}$ total spacecraft power.

Stabilization: Spin stabilized with magnetic torquing attitude control, liquid dampers provide short-term nutation. Attitude controlled to $\pm 1^{\circ}$ in roll and yaw, attitude determination accuracy $\pm 0.1^{\circ}$, short-term nutation controlled to $\pm 0.2^{\circ}$.

Nominal orbit: Circular, $1,460 \mathrm{~km}(790$ inm) altitude; inclination $101.6^{\circ}\left(78.4^{\circ}\right.$ to Equator) ; period $115.1 \mathrm{~min}$; AVCS version sun synchronous at 1500 local solar time, APT version sun synchronous at 0900 local solar time.

Design life: $6 \mathrm{mo}$.

Onboard storage: Video tape recorders.

Transmission: PCM TV 0.5 Mbps, APT 2 kbps.

Other: Cameras are mounted on the spacecraft as spokes on a wheel so that they point directly down once during each spin of the spacecraft as it rolls along its orbit.

Launch vehicle: Thrust-augmented Delta.

ITOS

The ITOS (A, B, C), an improved TOS satellite, represented a newer development in the meteorological system. Its configuration included a larger payload with redundant APT and AVCS systems (fig. 71).

Description:

Size: $100 \mathrm{~cm} \times 100 \mathrm{~cm} \times 122 \mathrm{~cm} \mathrm{(39} \mathrm{in.}$ 
x 39 in. $x 48$ in.), excluding solar arrays.

Weight: $308 \mathrm{~kg}(680 \mathrm{lb})$.

Payload: Two scanning radiometers, 2 AVCS, 2 APT systems, 1 flatplate radiometer, and 1 solar proton monitor (SPM).

Payload capacity: Weight $59 \mathrm{~kg}$ (130 lb) ; available power $32 \mathrm{~W}$.

Stabilization: Three-axis stabilized utilizing momentum wheel with passive attitude control provided by magnetic torquing. Liquid dampers used to control short-term nutation. Stabilization is to $\pm 1^{\circ}$. Short-term nutation is to $\pm 0.3^{\circ}$ with short-term rate less than $0.05^{\circ} / \mathrm{s}$. Attitude determination accuracy $\pm 0.1^{\circ}$.

Nominal orbit: Circular, $1,460 \mathrm{~km}(790$ inm) altitude, sun synchronous at 1500 local solar time, inclination $101.6^{\circ}$ (78.4 ${ }^{\circ}$ to Equator), period $115.1 \mathrm{~min}$.

Design life: 6 mo.

Onboard storage: 44-min incremented video tape recorder.

Transmission: Redundant FM transmitter for APT, redundant PM transmitter for SPM, redundant S-band transmitter for wide-band data.

Launch vehicle: Delta.

\section{ITOS-D}

The ITOS-D satellite was specifically designed to provide a platform for instrumentation developed to meet NOAA's mission requirements. The configuration enabled stabilization permitting the sensors continually to face the Earth. It has the capability to view the globe twice each day, once during daylight, once at night (fig. 72).

Description :

Size : $100 \mathrm{~cm} \times 100 \mathrm{~cm} \times 108 \mathrm{~cm} \mathrm{(39} \mathrm{in.}$ $x 39$ in. $x 42$ in.).

Weight: $355 \mathrm{~kg}(785 \mathrm{lb})$.

Payload: Two-channel scanning radiometer, 2-channel very-high-resolution radiometer, vertical temperature profile radiometer, and SPM.

Payload capacity: Weight $57 \mathrm{~kg}$ (125 Ib), available power $89 \mathrm{~W}$.
Stabilization: Three-axis stabilization utilizing momentum wheel. Attitude controlled to $\pm 1^{\circ}$ with reference to Earth's magnetic field. Attitude determination accuracy $0.1^{\circ}$. Short-term nutation controlled to $\pm 0.3^{\circ}$ by liquid dampers. Attitude rate less than 0.05 dampers. Attitude rate less than $0.05^{\circ} / \mathrm{s}$.

Nominal orbit: Circular, $1,460 \mathrm{~km}(790$ inm) altitude, sun synchronous at 0900 local solar time, inclination $101.6^{\circ}\left(78.4^{\circ}\right.$ to Equator), period $115.1 \mathrm{~min}$.

Design life: 6 mo to $1 \mathrm{yr}$.

Onboard storage: 44-min incremental video tape recorder.

Transmission: Redundant PM transmitter for SPM data, redundant S-band transmitters for wide-band data.

Launch vehicle: Delta.

GOES

(See Synchronous Meteorological Satellite, page 23.)

\section{BIBLIOGRAPHY}

Aerospace Industries Assoc., 1970, The 1970 aerospace yearbook, 48th ed.: Washington, D.C., p. R-99.

Allied Research Assoc., Inc., 1965, Nimbus I users' catalog: AVCS and APT: Prepared for Nat'l Aeronautics and Space Adm. under contract NAS53253.

American Society of Photogrammetry, 1960, Manual of photographic interpretation.

1966, Manual of photogrammetry, $3 \mathrm{~d}$ ed. 1968, Manual of color aerial photography.

Aviation Week and Space Technology, Nov. 29, 1971, Nov. 13, 1972, and Aug. 13, 1973.

Barton, J. H., 1972, U.S. Navy cartography: Am. Soc. of Photogramm.. Photogramm. Eng., v. 38, no. 2, p. 147-154.

Boeing Co., 1967a, Lunar Orbiter 1, extended mission spacecraft subsystem performance. Nat'l. Aeronautics and Space Adm., CR-870.

- 1967b, Lunar Orbiter 2, mission system performance. Nat'l. Aeronautics and Space Adm., CR66437.

Briggs, D. E., Scanlon, J. G., Golden, R. R., and Kaeding, D. A., 1969, TOS Evaluation Center (TEC) post-operational test results for ESSA 3: Nat'l. Aeronautics and Space Adm., Goddard Space Flight Center, X-481-69-457. 
California Institute of Technology, Jet Propulsion Laboratory, 1965, From project inception through midcourse maneuver, v. 1 of Mariner Mars 1964 project report, mission and spacecraft development: Calif. Inst. of Tech., Jet Propulsion Lab. Tech. Rept. 32-740.

1966a, Mission description and performance, pt. 1 of Ranger 8 and 9: Calif. Inst. of Tech., Jet Propulsion Lab. Tech. Rept. 32-800.

- 1966b, PDP Mariner Mars 1969: Calif. Inst. of Tech., Jet Propulsion Lab. Proj. Doc. 69.

- 1967, Mariner Mars '69 project: Calif. Inst. of Tech., Jet Propulsion Lab. Rept. 13.

1969a, Mission plan, pt. 2 of Mariner Mars 1969 mission plan and requirements: Calif. Inst. of Tech., Jet Propulsion Lab. PD91.

1969b, PDP Mariner Mars 1969 project: Calif. Inst. of Tech., Jet Propulsion Lab. Proj. Management Rept. 41.

1969c, Surveyor project final report: Calif. Inst. of Tech., Jet Propulsion Lab. Tech. Rept. 32-1265. 1971, The deep space network: Calif. Inst. of Tech., Jet Propulsion Lab. Tech. Rept. 32-1526, v. 1.

Corliss, W. R., 1966, SNAP nuclear space reactors: U.S. Atomic Energy Comm.

Doyle, G., Jr. and Vorachek, J., 1971, Investigation of stability characteristics of tethered balloon systems: U.S. Air Force Cambridge Research Labs., AFCRL-71-0406. Prepared by Goodyear Aerospace Corp.

Doyle, G., Jr., Vorachek, J., and Block, D., 1973, Stability and dynamic behavior of two tethered balloon systems: U.S. Air Force Cambridge Research Labs., AFCRL-TR-73-0396. Prepared by Goodyear Aerospace Corp.

Driscoll, Everly, 1971, The bureaucratic odyssey of a space mapping camera: Sci. News, v. 100, no. 22, p. 362 .

Electro-Optical Systems Design, 1970, Up-up-and-away in balloon launch, Stratoscope photographs, planets, galaxies (Project Stratoscope): Electro-Optical Systems Design 5/70.

Fordyce, D. C., 1969, PDP Applications Technology Satellites ATS-A through E. Nat'l. Aeronautics and Space Adm., Goddard Space Flight Center Proj. Devel. Plan (PDP).

General Electric Co., 1967a, Percheron suitability, application "A", payloads: Gen. Elec. Co. Doc. No. 67SD4287. Prepared for Nat'l. Aeronautics and Space Adm., Off. Space Sci. and Applications.

$1967 \mathrm{~b}$, Summary report covering an analysis of spacecraft systems with physical recovery capability to perform earth oriented applications experiments: Prepared for Nat'l. Aeronautics and Space Adm. under contract NAS-W-1691, 3v.

- 1971, ERTS data users handbook: Gen. Elec. Co. Doc. No. 71SD4249. Prepared for Nat'l. Aeronautics and Space Adm., Goddard Space Flight Center under contract NAS 5-11320.
Gerwin, H. L., ed., 1967, ATS-4 GSFC concept design study: Nat'l. Aeronautics and Space Adm., Goddard Space Flight Center, X-730-67-10.

Goodyear Aerospace Corp., Aero-Mechanical Programs, 1971, Airborne sensor platform: Goodyear Inf. Circ. 8330-9/71.

Heacock, R. L., Kuiper, G. P., and Shoemaker, E. M., 1966, Experimenters analysis and interpretations, pt. 2 of Ranger 8 and 9: Calif. Inst. of Tech., Jet Propulsion Lab. Tech. Rept. 32-800.

Hudson, J. F., 1968, Research role for the Learjet: Wichita, Kans., Learjet Contrails.

1971, Aircraft performance, Gates Learjet 24: Wichita, Kans., gates Learjet Corp.

Klass, P. J., 1971, Secret sentries in space: New York, Random House.

Kollsman Instrument Corp., n.d., U.S. Air Force AN/ USQ-28 aerial electro-photo mapping system: Elmhurst, N.Y., Standard Kollsman Industries.

Kosofsky. L. J., 1964, Mission description and performance, pt. 1 of Ranger 7: Calif. Inst. of Tech., Jet Propulsion Lab. Tech. Rept. 32-700.

Lockheed Missiles and Space Co., Space Systems Division, 1967, NASA-AGENA: Sunnyvale, Calif., Lockheed Missiles and Space Co., NAP-E1 2-4-67.

Lockheed Missiles and Space Co., 1969, Earth Resources Technology Satellite film recovery system, a complementary approach to the recovery of earth resources data: Lockheed Missiles and Space Co. with Mark Systems, Inc.

Mattill, J. I., ed., 1971, The lunar rover: Mass. Inst. of Tech. Technology Rev., v. 73, no. 9.

Morris, A L., and Stefan, K. H., 1969, High altitude balloons as scientific platforms: Boulder, Colo. Nat'l. Center for Atmospheric Research.

Myers, P. F., 1968, Tethered balloon handbook: U.S. Air Force Cambridge Research Labs., AFCRL-690017. Prepared by Goodyear Aerospace Corp.

Myers, P., and Vorachek, J., 1971, Definition of tethered balloon systems: U.S. Air Force Cambridge Research Labs., AFCRL-71-0213. Prepared by Goodyear Aerospace Corp.

National Aerospace Education Council, 1970, 1970 United States aircraft, missiles and spacecraft: Wash., D.C.

Oelila, R. G., Brown, I. H., Jr., and Minckler, R. D., 1971, A survey and technical assessment of lowaltitude tethered balloon systems: Columbus, Ohio, Battelle Columbus Labs., Tactical Tech Center.

Quick, J. R., 1964, Eye in the sky: Dayton, Ohio.

Radio Corporation of America, 1969, Instructions and operating handbook for the Improved TIROS Operational System (ITOS) and the TIROS Operational System (TOS), pt. 4.

Remote Sensing, Inc., 1971, Brochure of remote sensing. Schnapf, A., 1963-64, TIROS, the television and infrared observation satellite: British Interplanetary Soc. Journal, v. 19, p. 386-409.

Schultz, F. L., 1966, Mariner-Mars science subsystem: Nat'l. Aeronautics and Space Adm., TN 32-813. 
Science, 1962, Mission of Mariner 2, preliminary abservations: Science, v. 138. p. 1095-1099.

Science News, 1971, Scientific spy eyes for NASA: Sci. News, v. 99, no. 15, p. 240.

Sloan, R. K., 1968, Mariner Mars 1964 project report, scientific experiments: Calif. Inst. of Tech., Jet Propulsion Lab. Tech. Rept. 32-883.

Space Business Daily, 1971, v. 56, no. 21.

Stampfl, R. A., 1963, Nimbus spacecraft and its communication system as of Sept. 1961: Nat'l. Aeronautics and Space Adm., TN D-1422.

Stehling, K. R., 1971, A case for more balloon astronomy: Smithsonian, v. 2, no. 3, p. 28-33.

Stoldt, N. W., and Havanac, P. J., 1973, Compendium of meteorological satellites and instrumentation: Nat'l. Aeronautics and Space Adm. Nat'l. Space Science Data Center, NSSDC 73-02. Prepared by U.S. Air Force Environmental Tech. Applications Center.

Taylor, J. W. R., ed., v. d., Jane's all the world's aircraft: London, Jane's Yearbook, 1961-62, 1962-63, 1963-64, 1966-67, 1967-68, 1969-70, 1970-71, 197172, and 1972-73. Also distributed through McGrawHill Book Co., N.Y. and McGraw-Hill Co. of Canada, Scarborough, Ontario.

TRW, 1969, TRW space-log: Redondo Beach, Calif.

U.S. Air Force, 1970, Standard aircraft characteristics.

U.S. Air Force Cambridge Research Laboratories, 1963, AFCRL balloon symposium proceedings: U.S. Air Force Cambridge Research Labs., AFCRL-63-919. 1965, AFCRL scientific balloon symposium, 1964, proceedings: U.S. Air Force Cambridge Research Labs., AFCRL-65-486.

1966, AFCRL scientific balloon workshop, 1965, proceedings: U.S. Air Force Cambridge Research Labs., AFCRL-66-309.

1967, Fourth AFCRL scientific balloon symposium proceedings: U.S. Air Force Cambridge Research Labs., AFCRL-67-0075.

1968a, AFCRL tethered balloon workshop, 1967, proceedings: U.S. Air Force Cambridge Research Labs., AFCRL-68-0097.

- 1968b, Fifth AFCRL scientific balloon symposium proceedings: U.S. Air Force Cambridge Research Labs., AFCRL-68-0661.

1970, Sixth AFCRL scientific balloon symposium proceedings: U.S. Air Force Cambridge Research Labs., AFCRL-70-0543.

U.S. Dept. of the Interior, 1969, Proposal to NASA for a high-resolution earth sensing experiment from geostationary (geosynchronous) orbit.

1970, Proposal to NASA for a film-return earth sensing experiment.
U.S. Federal Aviation Agency. n.d., Moored balloons, kites, unmanned rockets and unmanned free balloons, pt. 101, v. 6 of Federal Aviation Regulations.

U.S. National Aeronautics and Space Administration, 1965, Mariner-Venus 1962, final project report: Nat'l. Aeronautics and Space Adm. SP-59.

1966, Manned space flight experiments, interim report Gemini 9 mission.

1971, The Pioneer mission to Jupiter: Nat'l. Aeronautics and Space Adm., SP-268.

1972, Space Shuttle: Washington, D.C., 23p.

U.S. National Aeronautics and Space Administration, Goddard Space Flight Center, 1967a, ATS-D (S/ G1) spacecraft and telemetry measurements list: Nat'l. Aeronautics and Space Adm., Goddard Space Flight Center, S-460-ATS-15.

1967b, Operations plan 1967 Applications Technology Satellite (ATS-C) : Nat'l. Aeronautics and Space Adm., Goddard Space Flight Center, X513-67-457.

- 1967c, Space tracking and data acquisition network manual: Nat'l. Aeronautics and Space Adm., Goddard Space Flight Center, X-350-67-304.

U.S. National Aeronautics and Space Administration, Langley Research Center, 1970, NASA 75 project, Viking mission definition: Nat'l. Aeronautics and Space Adm., Langley Research Center, M75-123-1, app. D.

U.S. National Aeronautics and Space Administration, Manned Spacecraft Center, 1963, Mercury project summary: Nat'l. Aeronautics and Space Adm., Manned Spacecraft Center, SP-45. 1971, EREP users handbook.

U.S. National Aeronautics and Space Administration, Manned Spacecraft Center, Earth Observations Aircraft Facility, 1970, Aircraft sensor systems facility: Nat'l. Aeronautics and Space Adm., Manned Spacecraft Center, 3v.

U.S. National Aeronautics and Space Administration, Manned Spacecraft Center, Earth Observations Aircraft Program, 1971, FY 1971, 1st annual report: Nat'l. Aeronautics and Space Adm., Manned Spacecraft Center, Off. Space Sci. and Applications.

Whittlesey, J. H., 1970, Tethered balloon for archaeological photos: Am. Soc. of Photogramm., Photogramm. Eng., v. 36, no. 2.

World Data Center A, 1971, Rockets and satellites catalogue of data: Nat'l. Acad. of Sci.

Wyckoff, R. C., 1962, Scientific experiments for Mariner R-1 and 4-2: Calif. Inst. of Tech., Jet Propulsion Lab. Tech. Rept. 32-315.

Young, E. F., 1968, Tethered balloons: present and future: Am. Inst. of Aeronautics and Astronautics, AIAA Paper 68-941. 


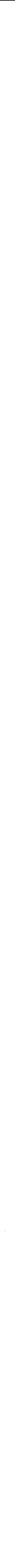




\section{ILLUSTRATIONS}




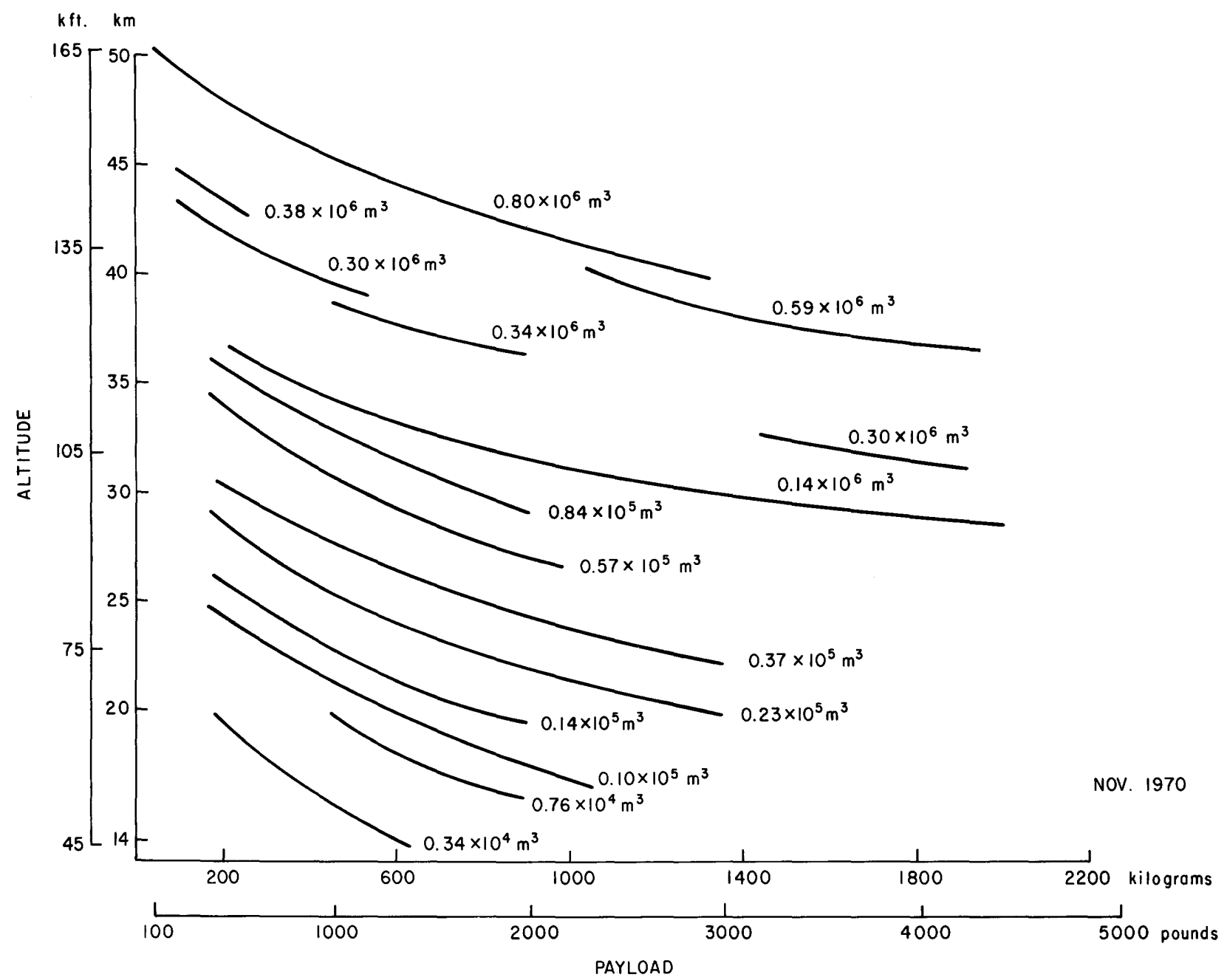

FIGURE 1.-Payload-altitude capabilities of polyethylene free balloons. 


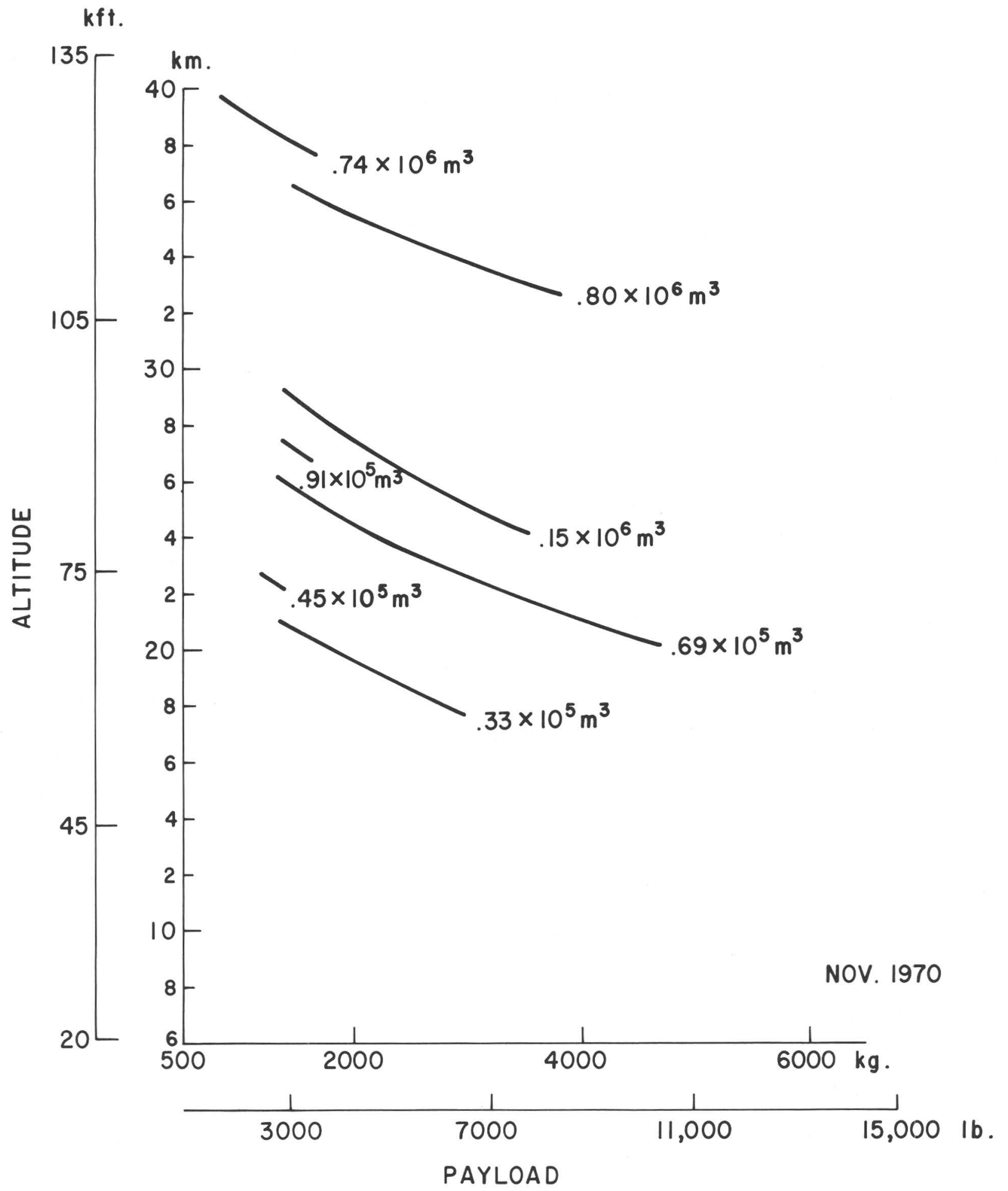

FIGURE 2.-Payload-altitude capabilities of scrim free balloons. 


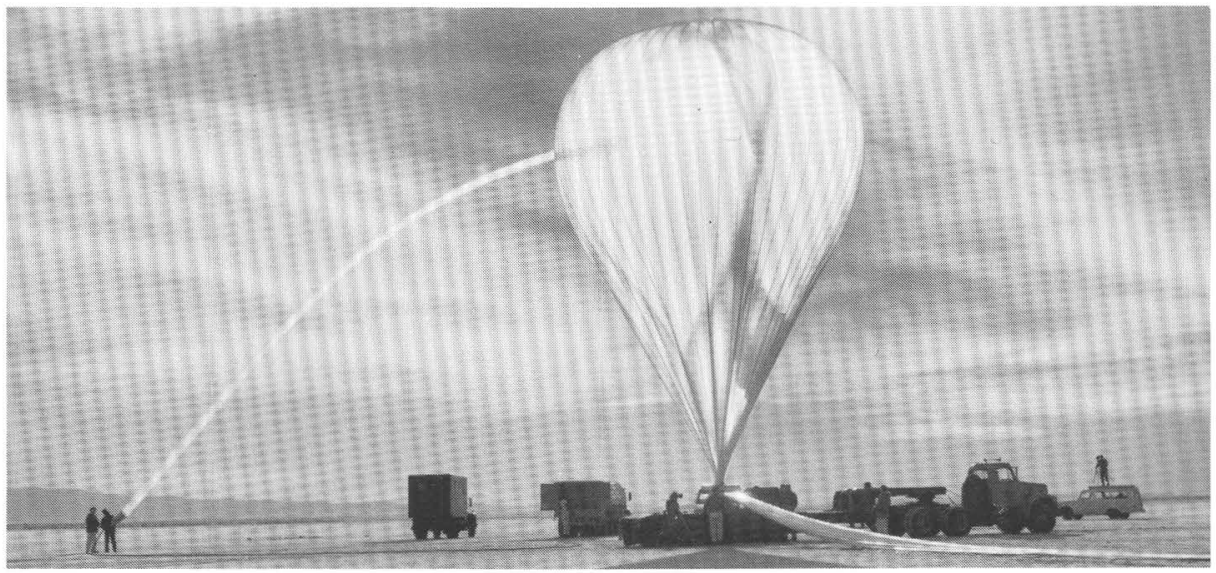

FIGURE 3.-Sunrise inflation of a $23,000-\mathrm{m}^{3}$ polyethylene balloon.

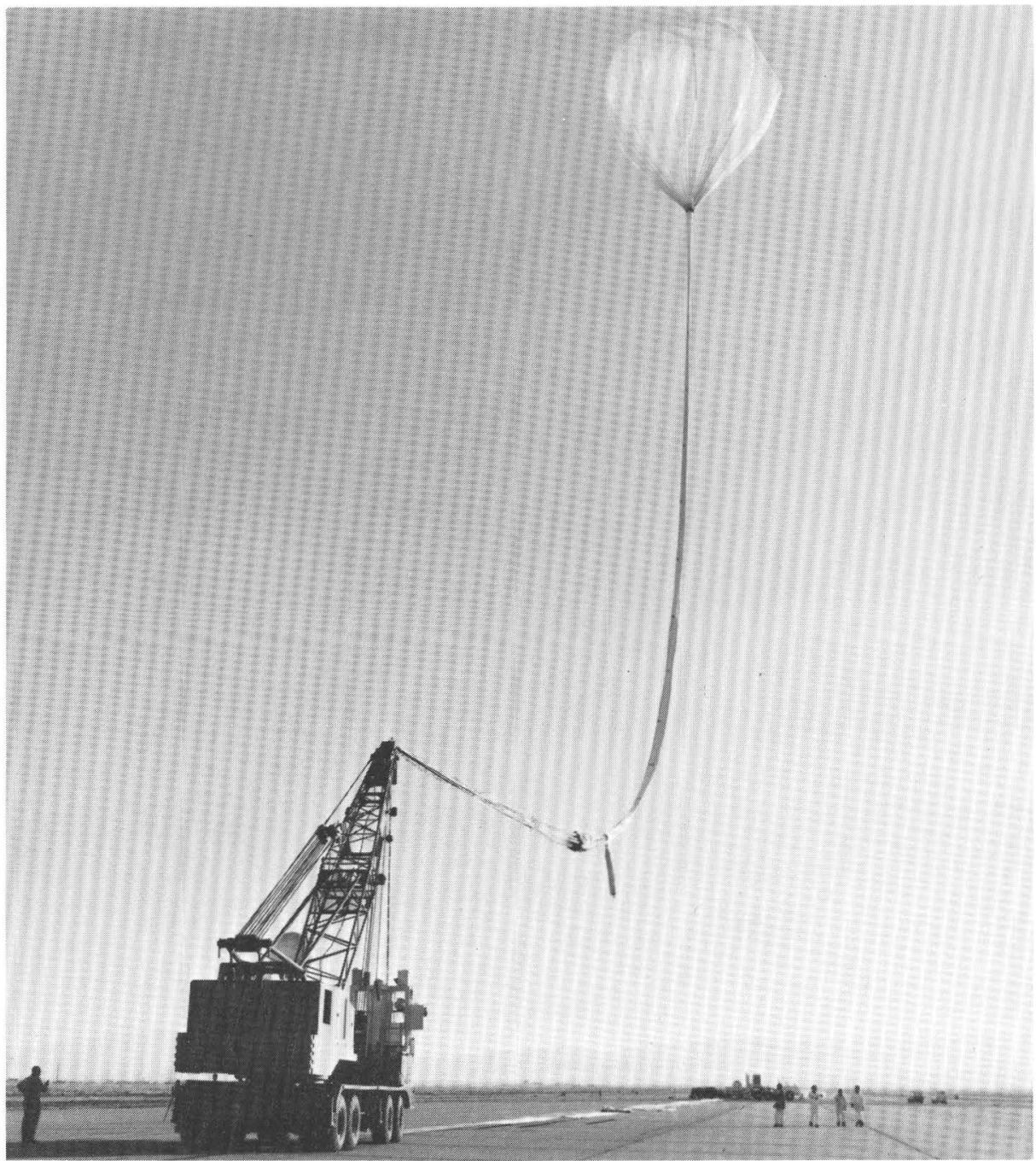

FIGURE 4.-A tandem balloon system reeled up in preparation for launch. 


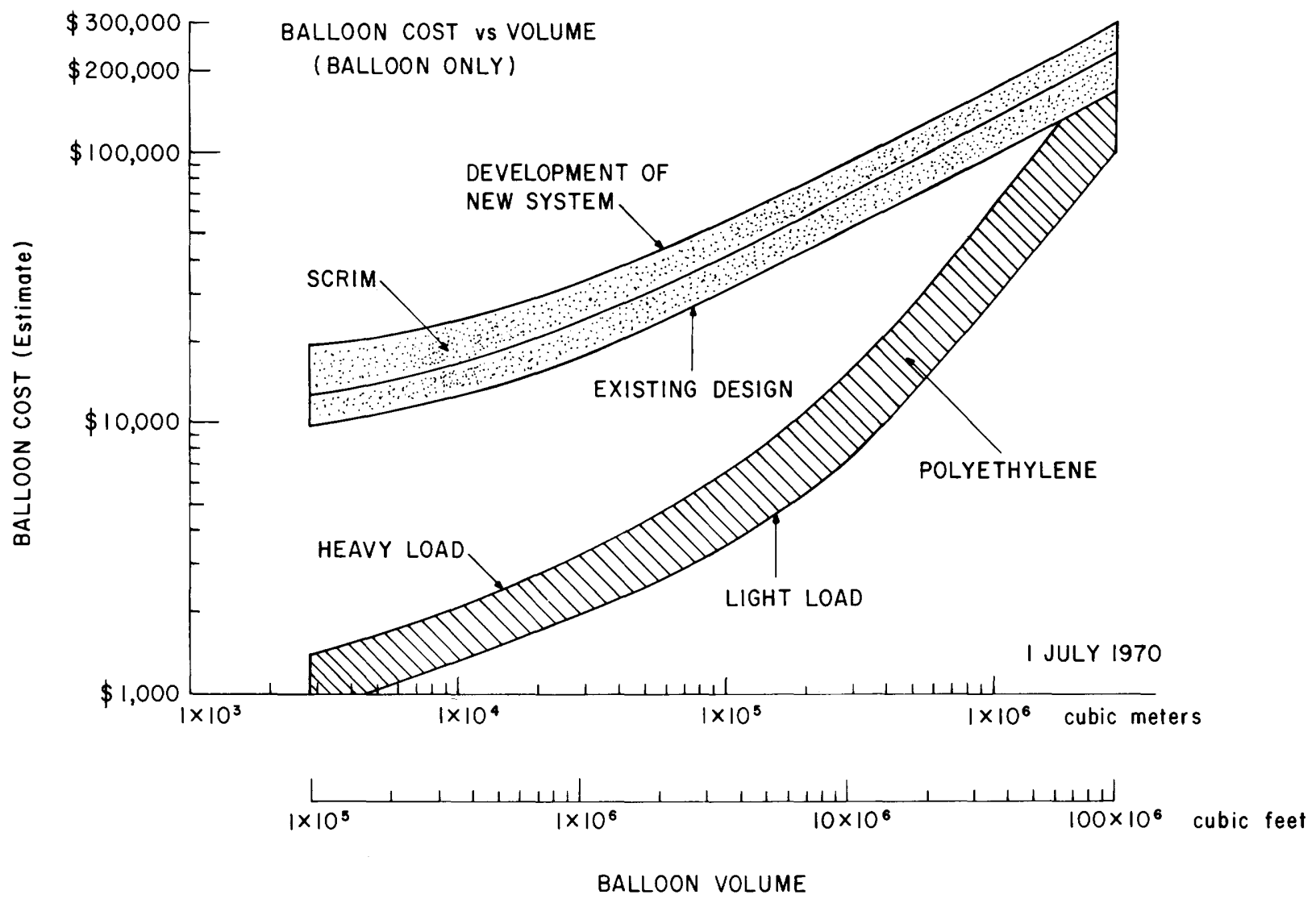

Figure 5.-Cost estimates for polyethylene and scrim free balloons. 


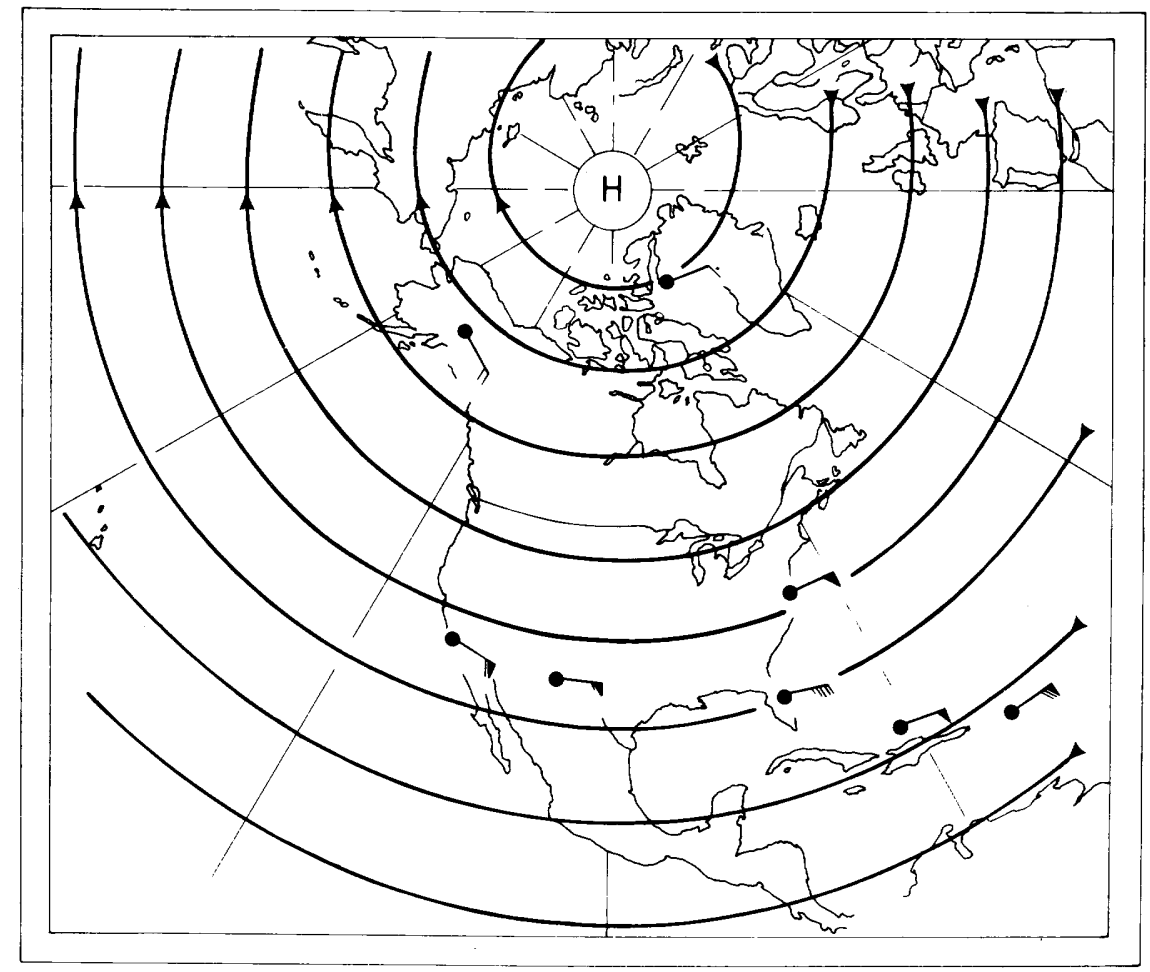

FIGURE 6.-Typical stratospheric wind flow at $37 \mathrm{~km}(120,000 \mathrm{ft})$ during midsummer.

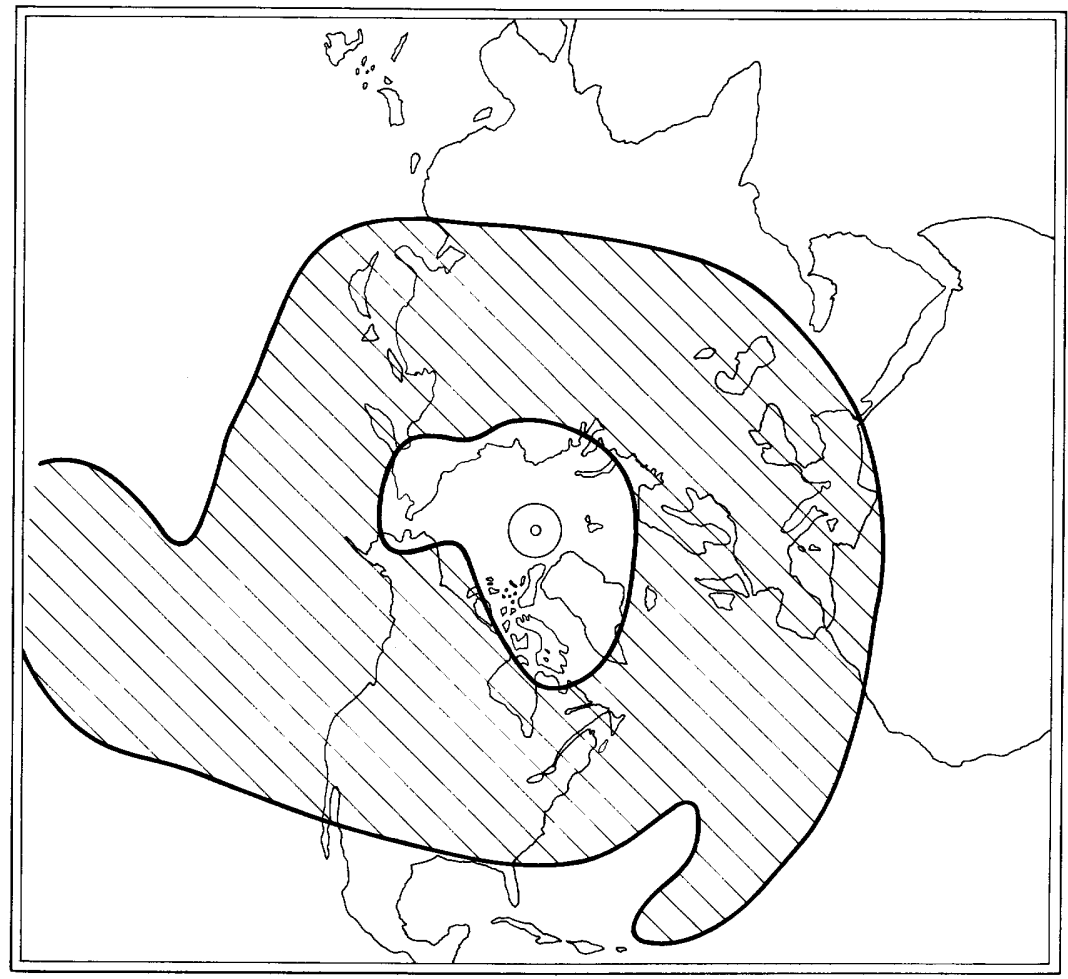

FigURE 7.-First approximation of areas in the Northern Hemisphere where balloon hovering and boomerang drifts are feasible during summer within the altitude range 14 to $22 \mathrm{~km}$. 

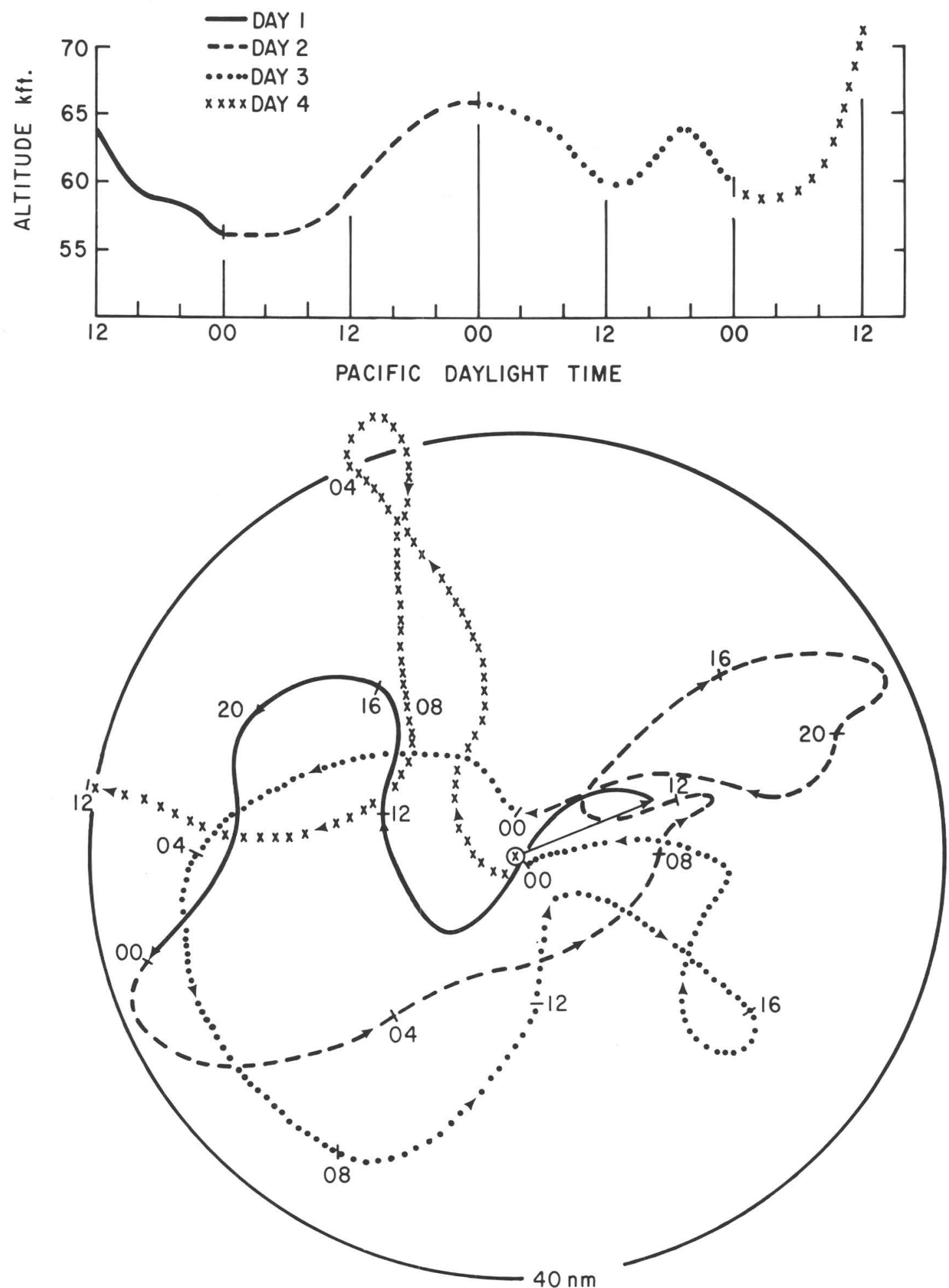

Figure 8.-Hovering balloon flight C70-18 launched from Chico, Calif., August 17, 1970. Flight duration, 72 hours. 


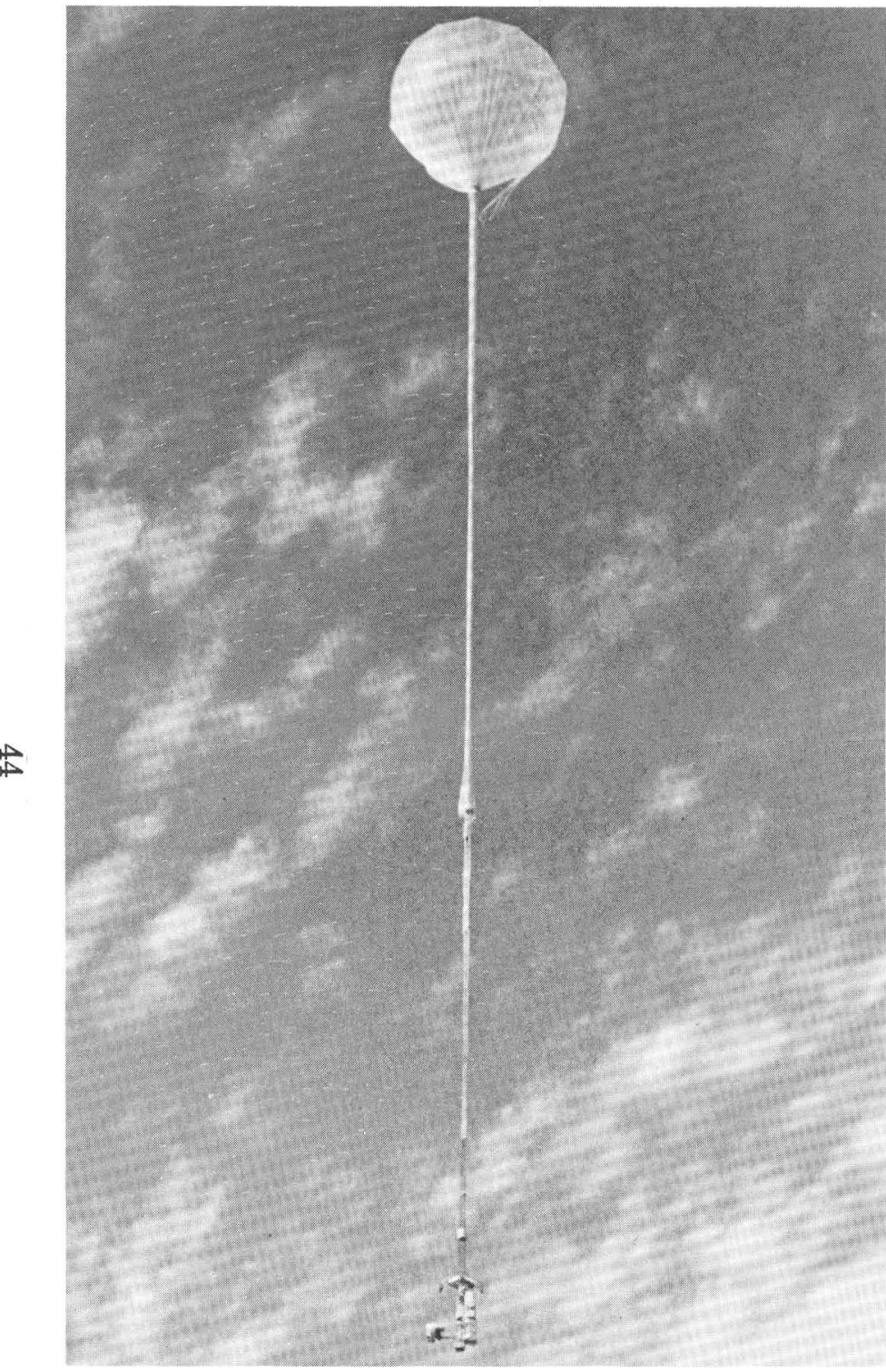

FIGURE 9.-Project Stratoscope II carrying a 3-ton optical telescope to an altitude of $24,400 \mathrm{~m}(80,000 \mathrm{ft})$. Its observations yielded much valuable astronomical data.

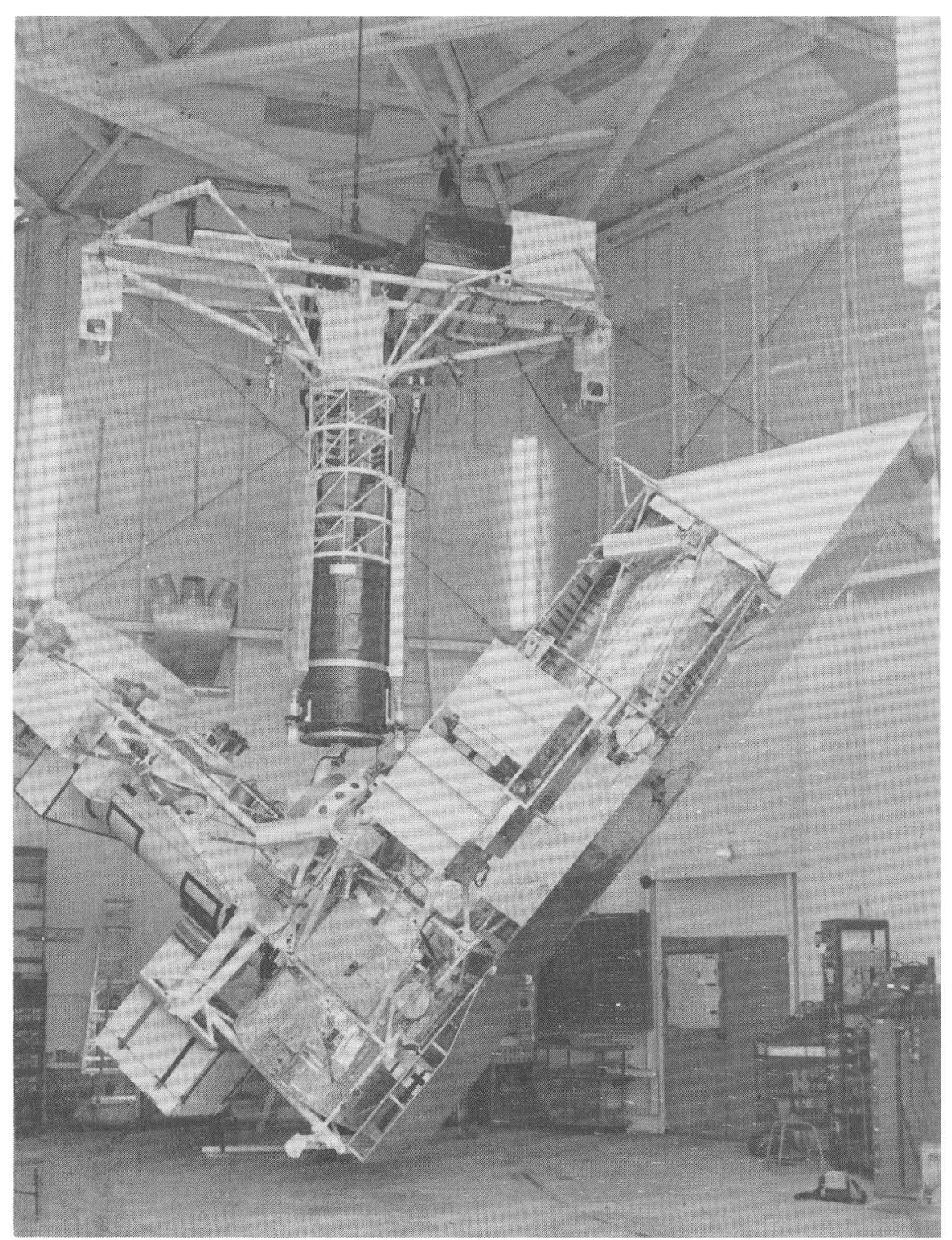

Figure 10.-The Stratoscope II telescope with guidance package and highresolution camera equipment. 


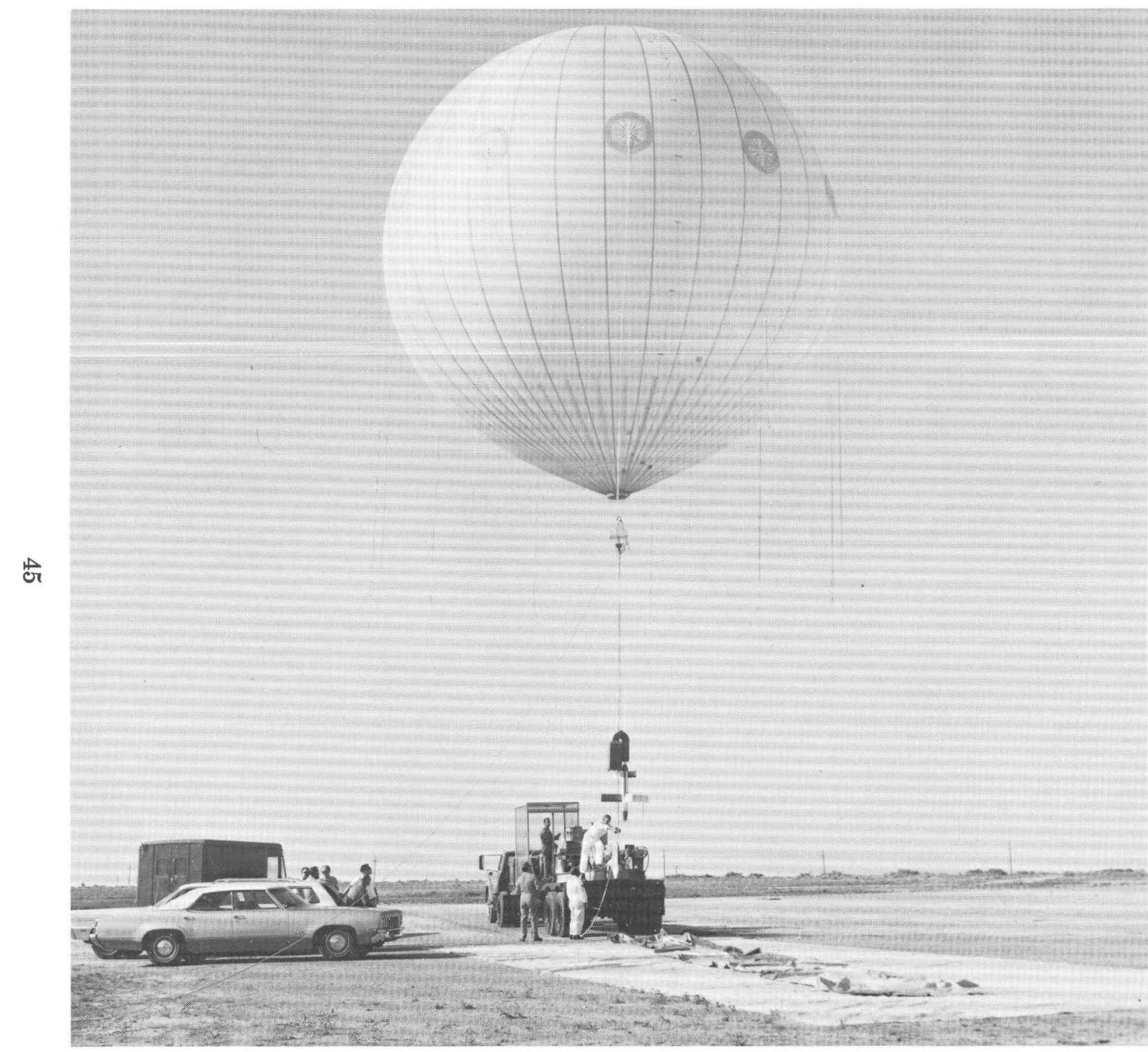

FIGURE 11.-A $710-\mathrm{m}^{3}$ spherical tethered balloon being prepared for launch at the White Sands Missile Range, N. Mex.

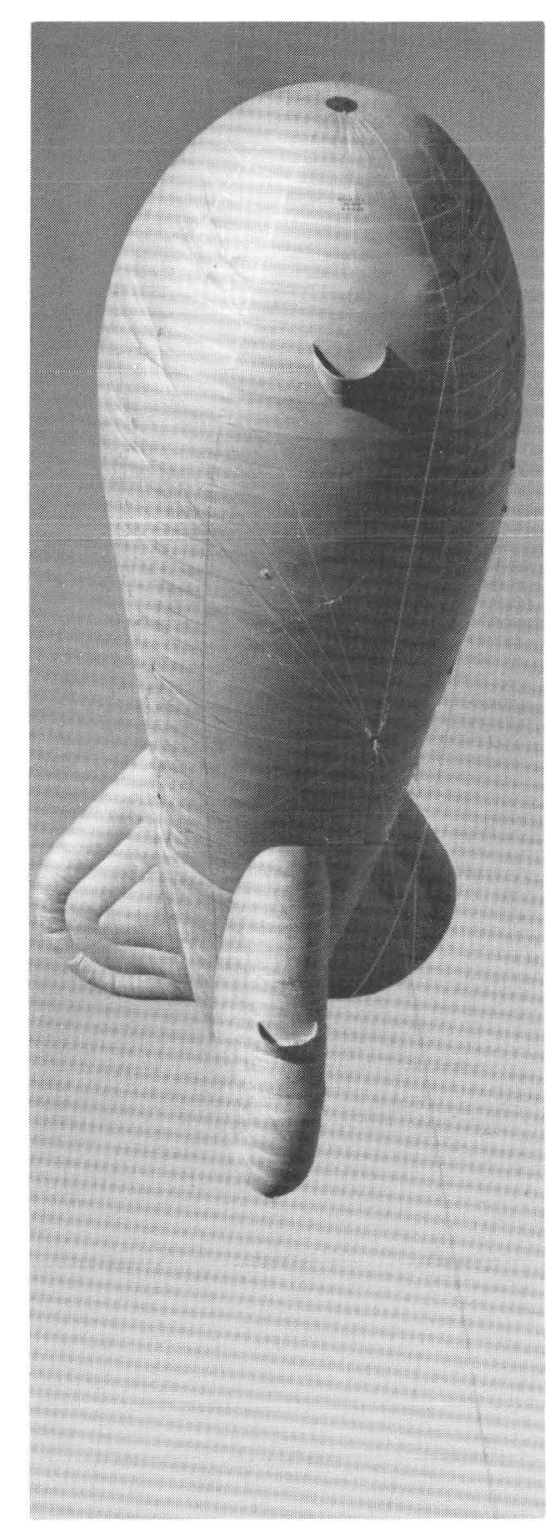

FIGURE 12.-Single-hull British Ashape kite balloon with a volume of $2,800 \mathrm{~m}^{3}$. 


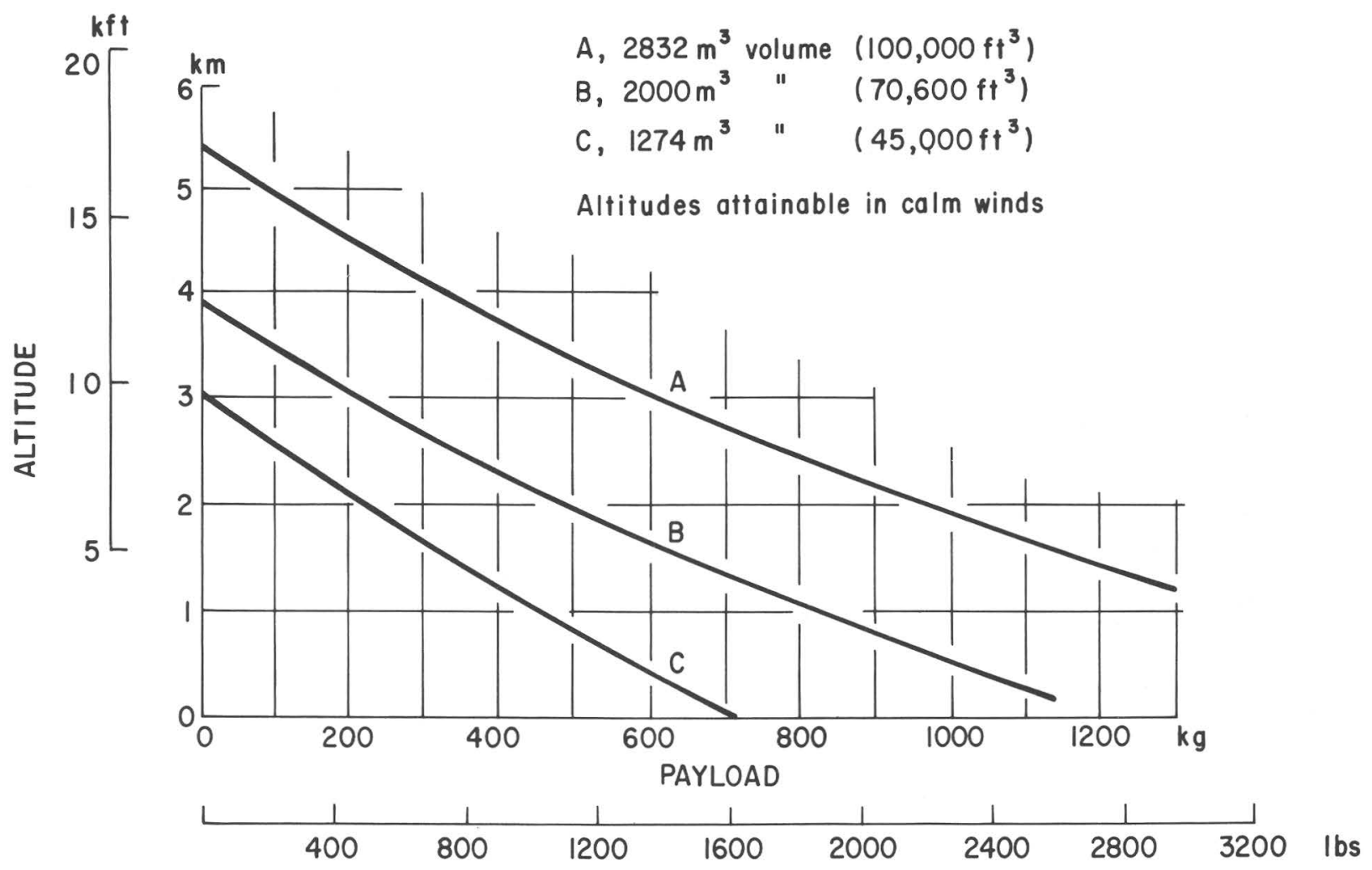

FigURE 13.-Payload versus altitude for British barrage balloons. 


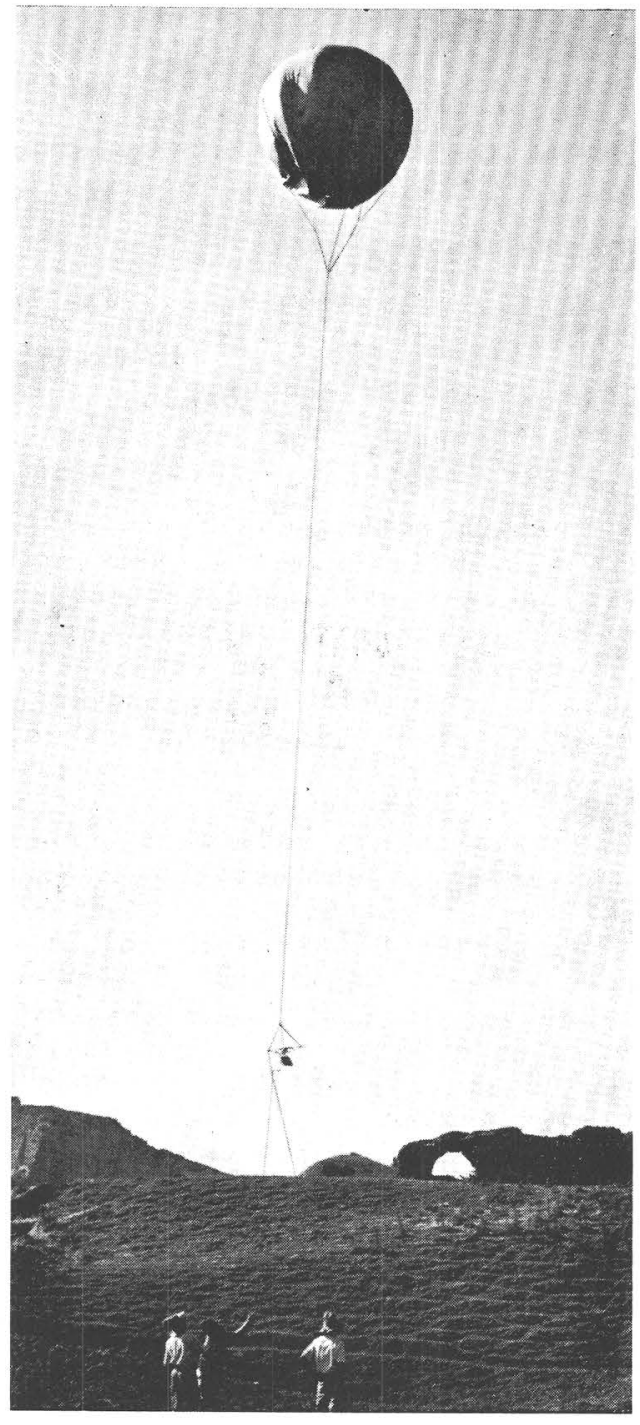

Figure 14.-Walking the balloon and aerial camera to the target area (Turkey).

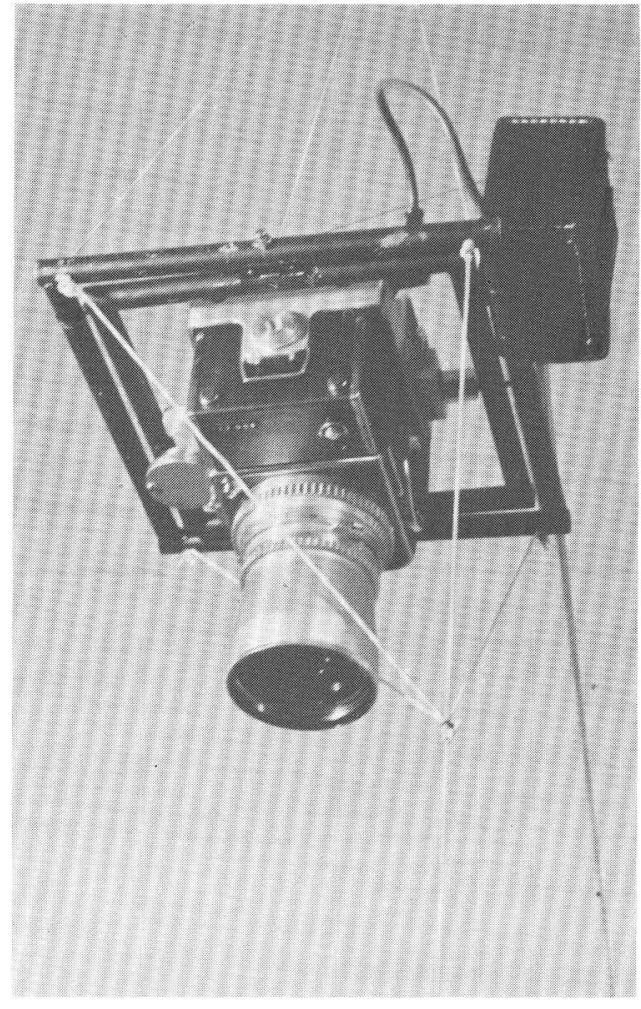

FIGURE 15.-The radio-controlled Hasselblad EL 500 camera hung in its gimbal as seen from below. 


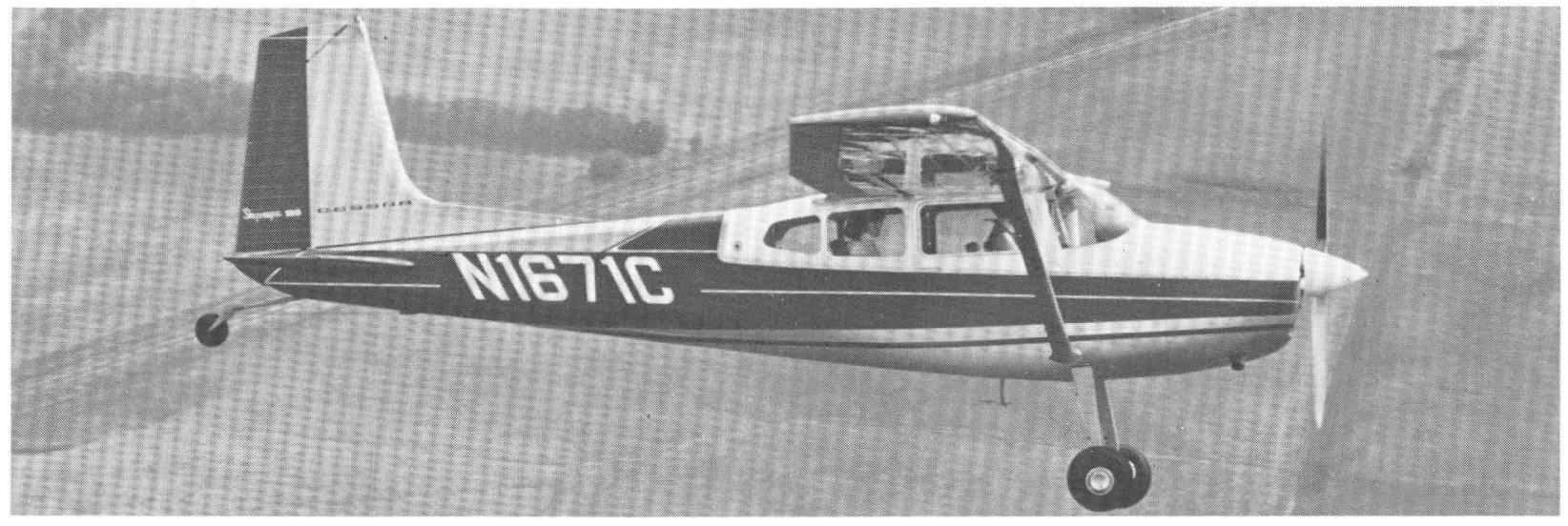

FiguRE 16.-Cessna 180 Skywagon.

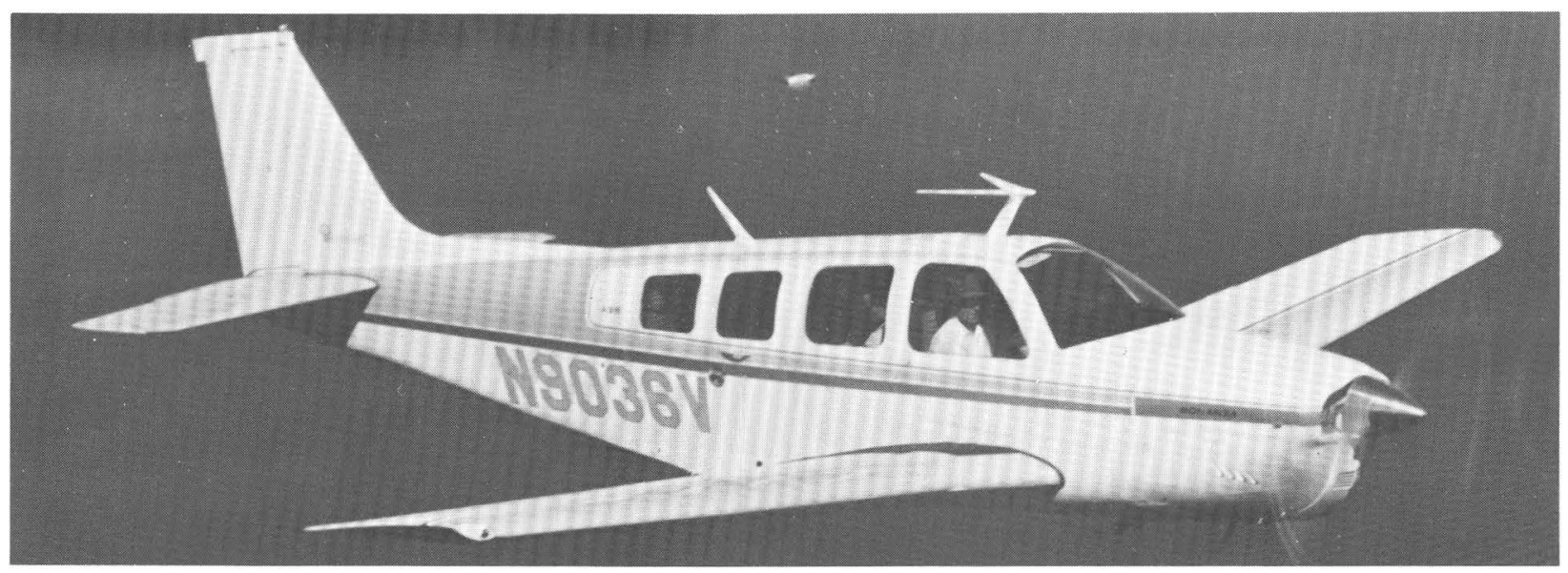

FigURE 17.-Beecheraft Bonanza A36.

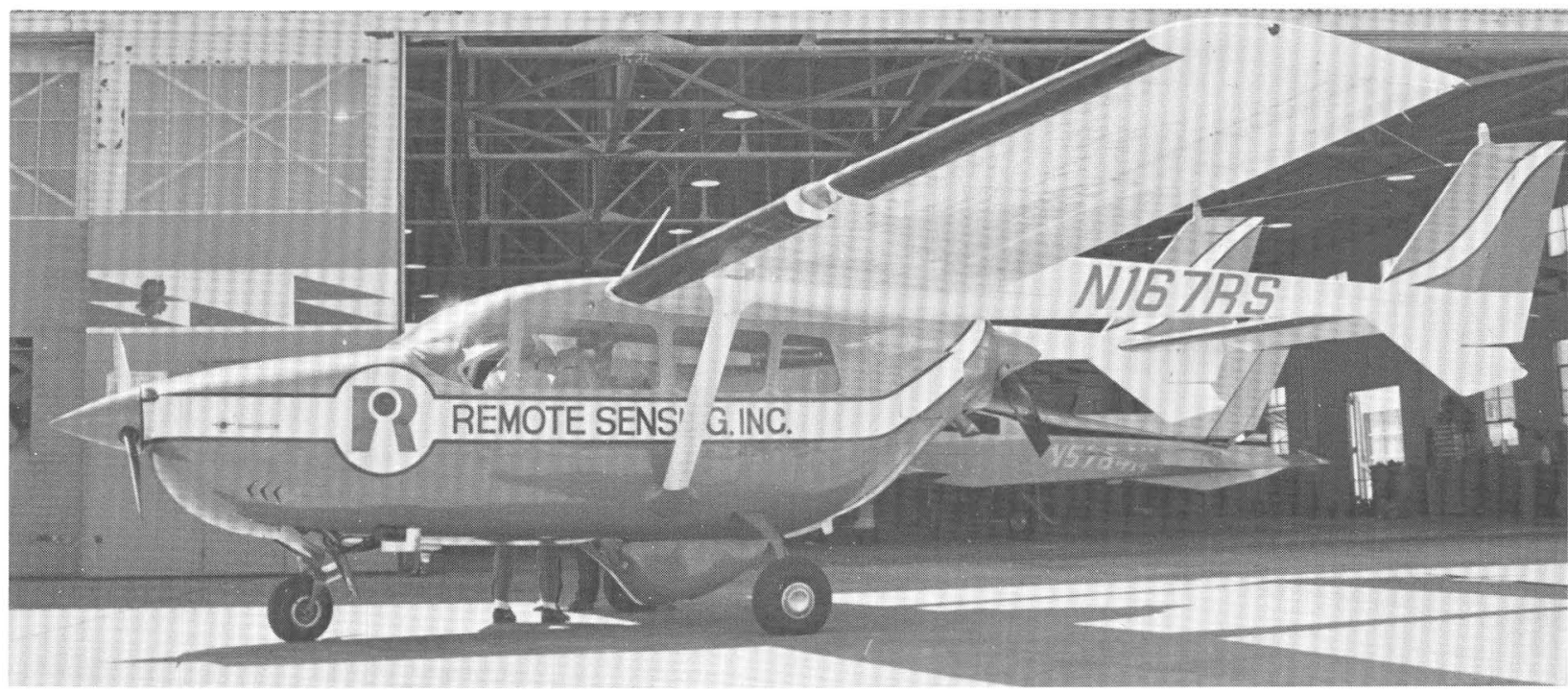

Figure 18.-Cessna 337 Turbo-System Super Skymaster. 


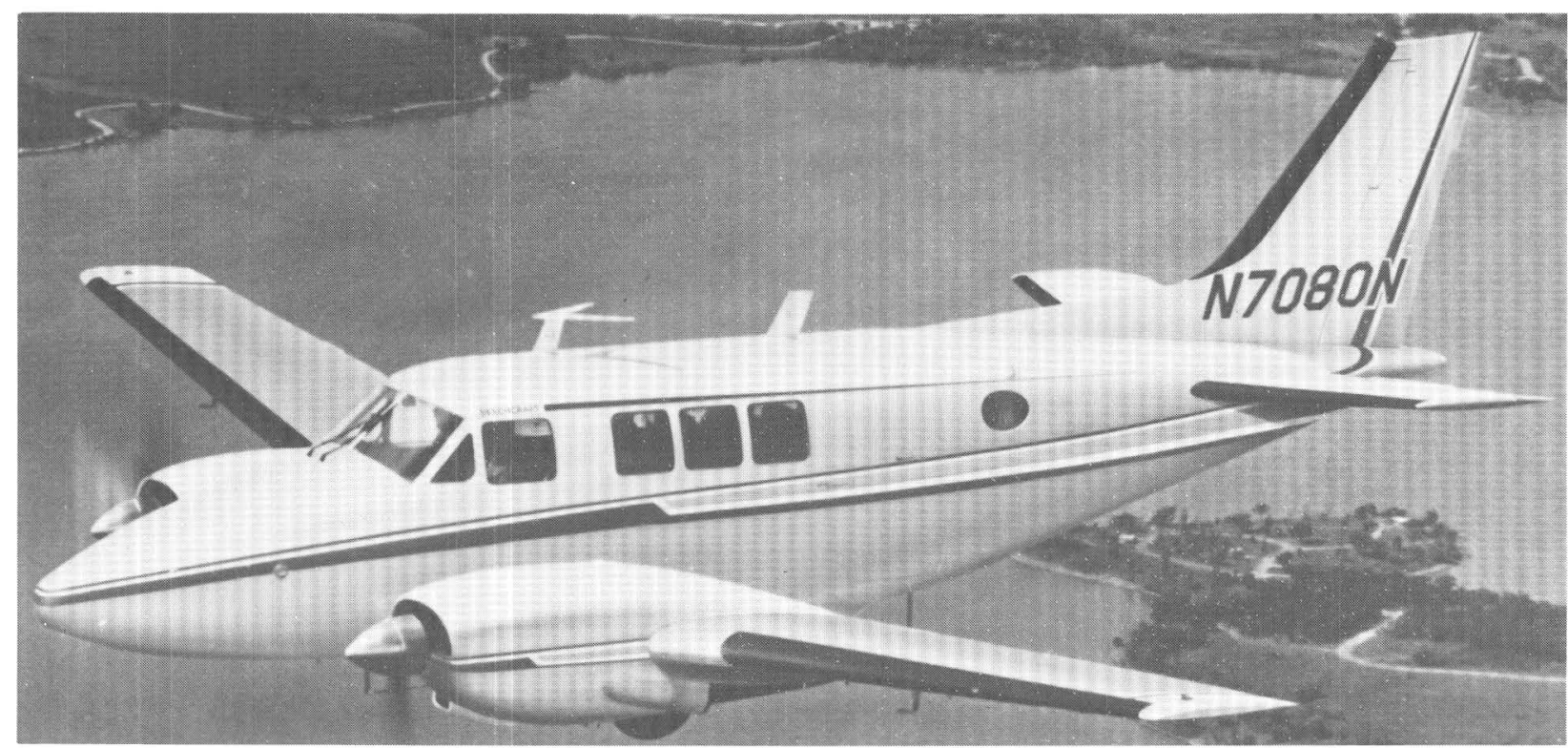

Figure 19.-Beecheraft Queen Air B80.

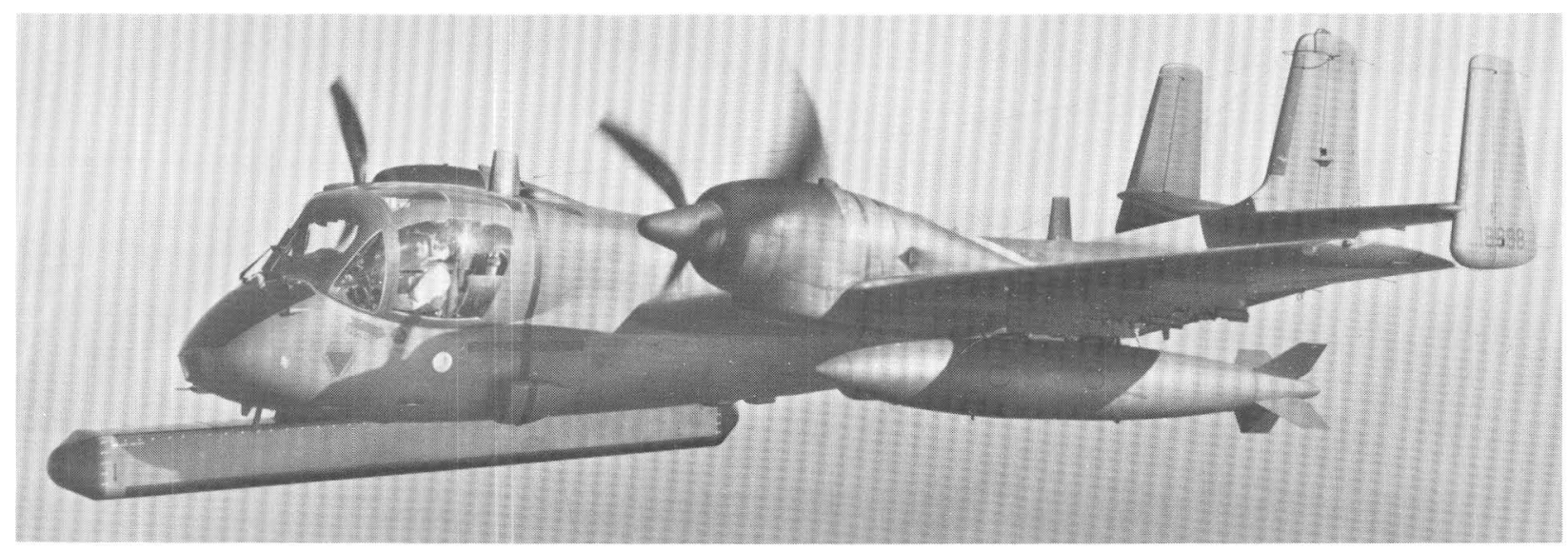

FIGURE 20.-The Grumman OV-1 Mohawk observation aircraft. 


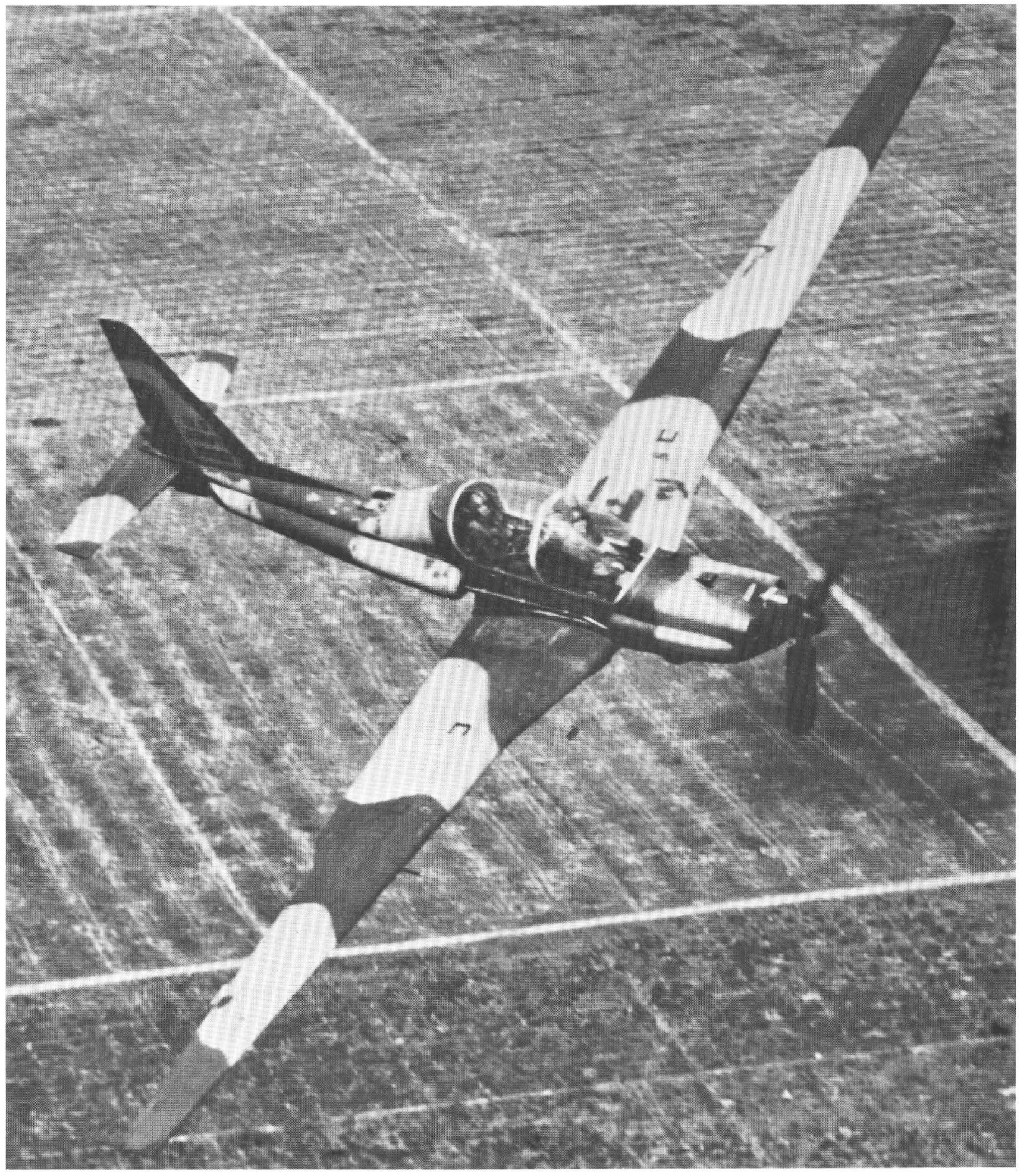

FIGURE 21.-Lockheed YO-3A quiet reconnaissance aircraft. 


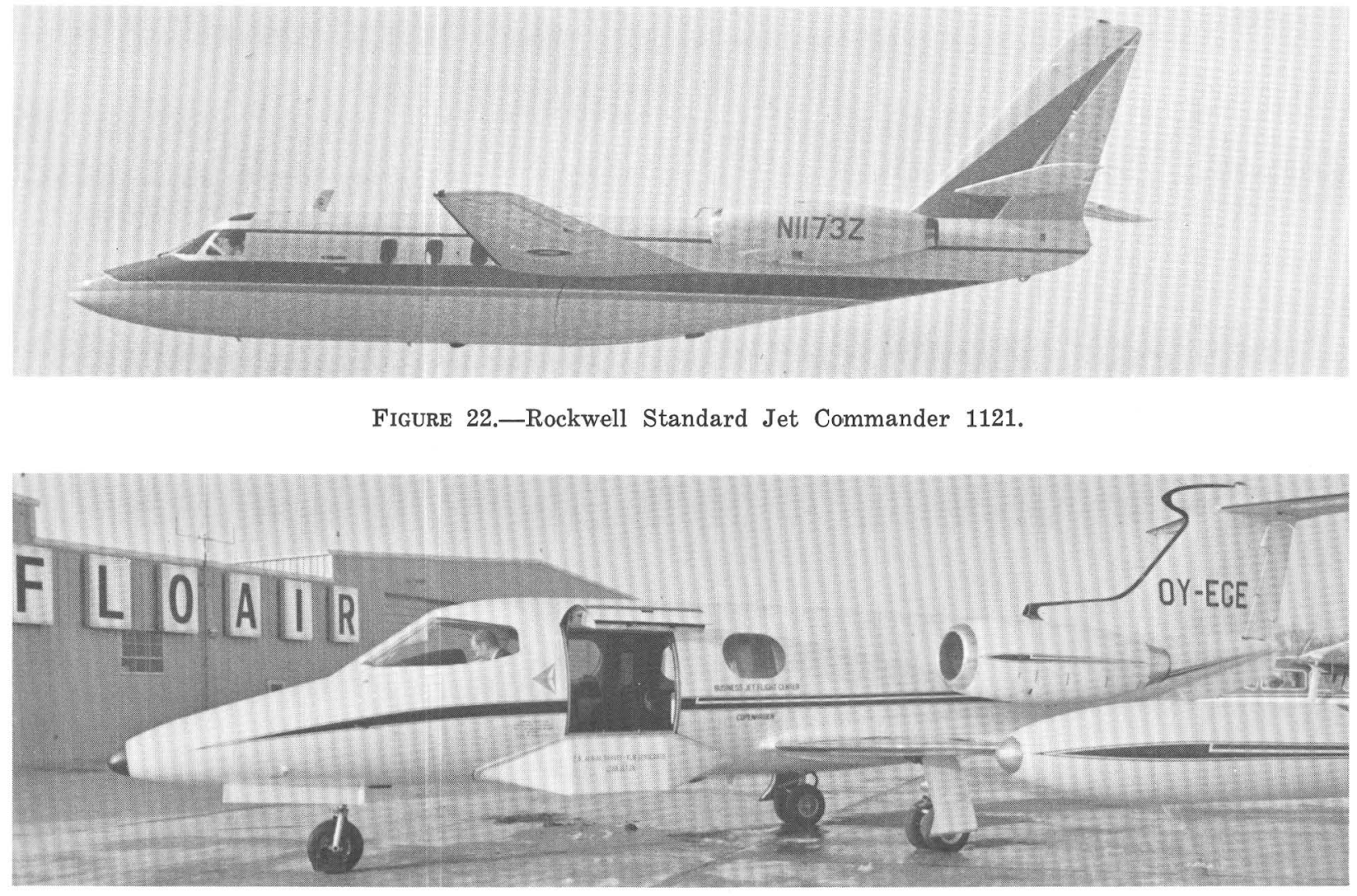

FIGURE 23.-Gates Learjet 24.

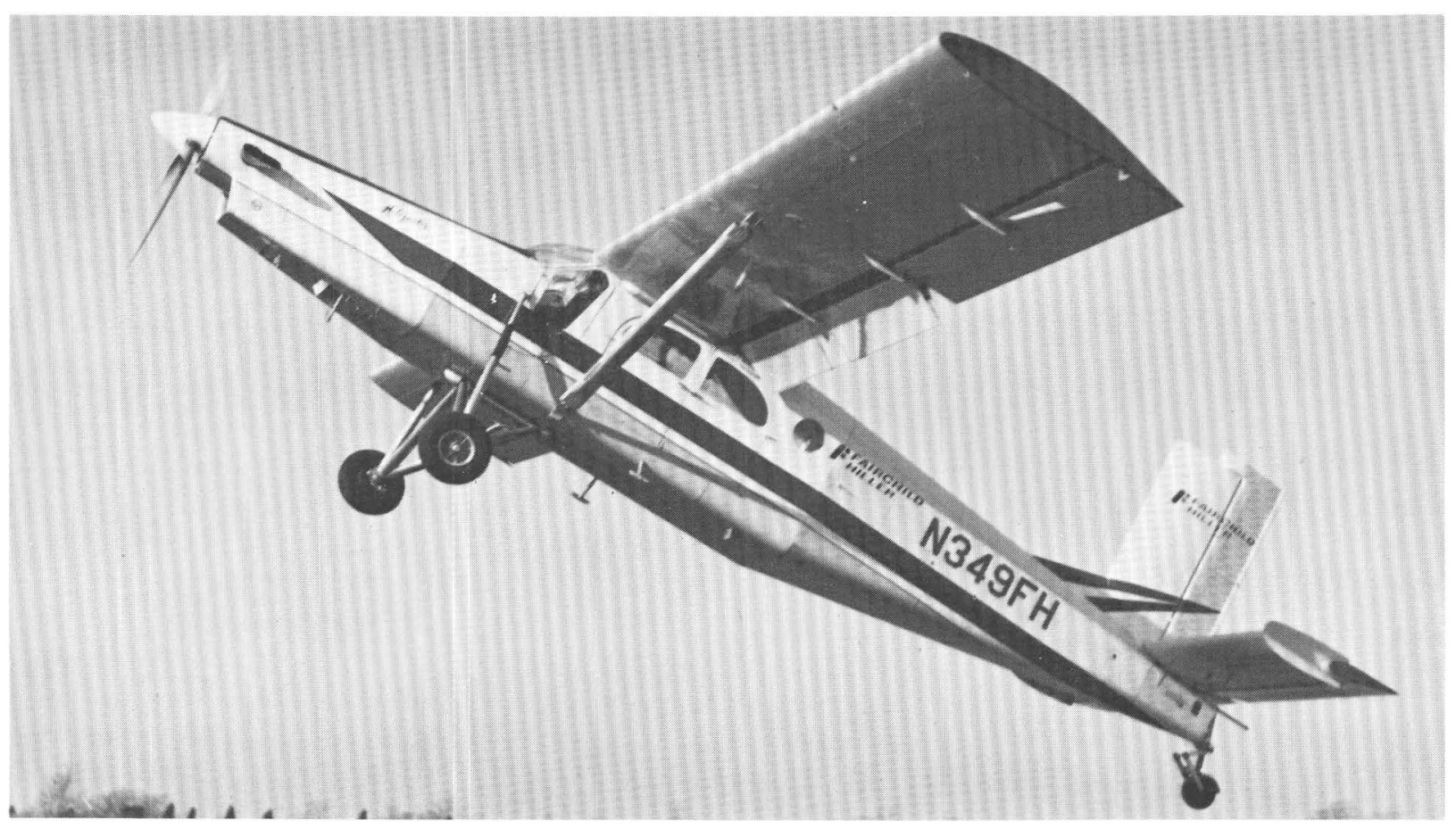

FIGURE 24.-Fairchild Hiller Porter. 


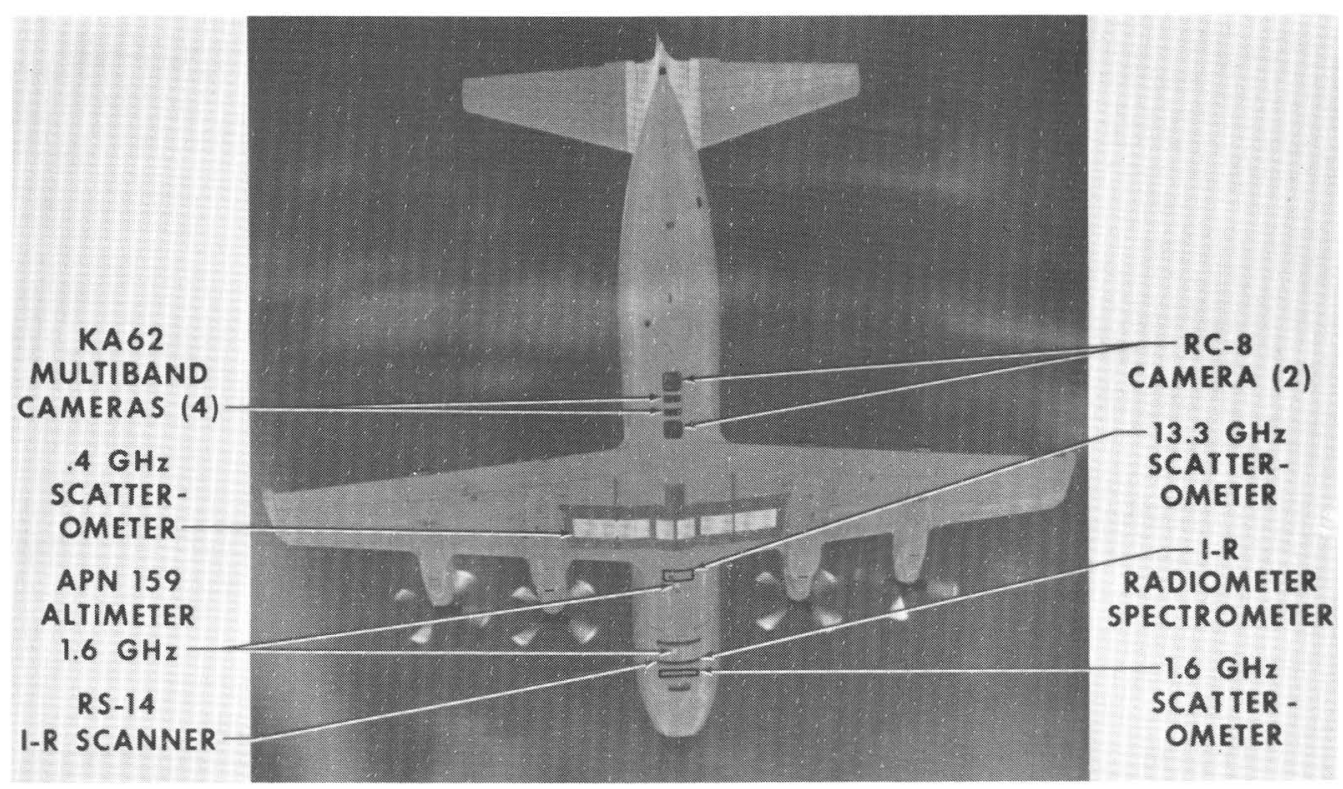

FiguRE 25.-NASA 927 Lockheed NP3A Orion flight configuration.

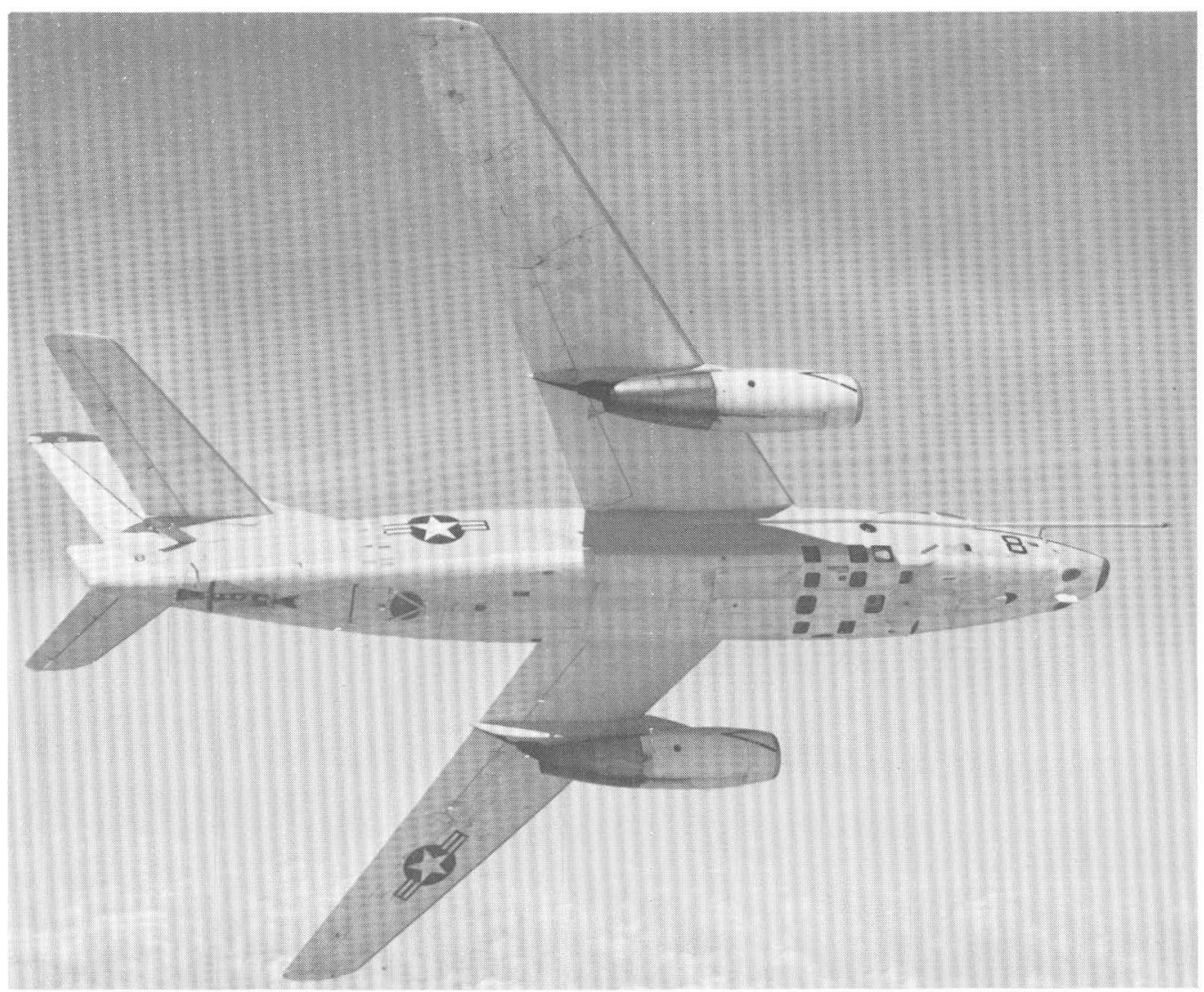

FIGURE 26.-Douglas Skywarrior RA-3B. 


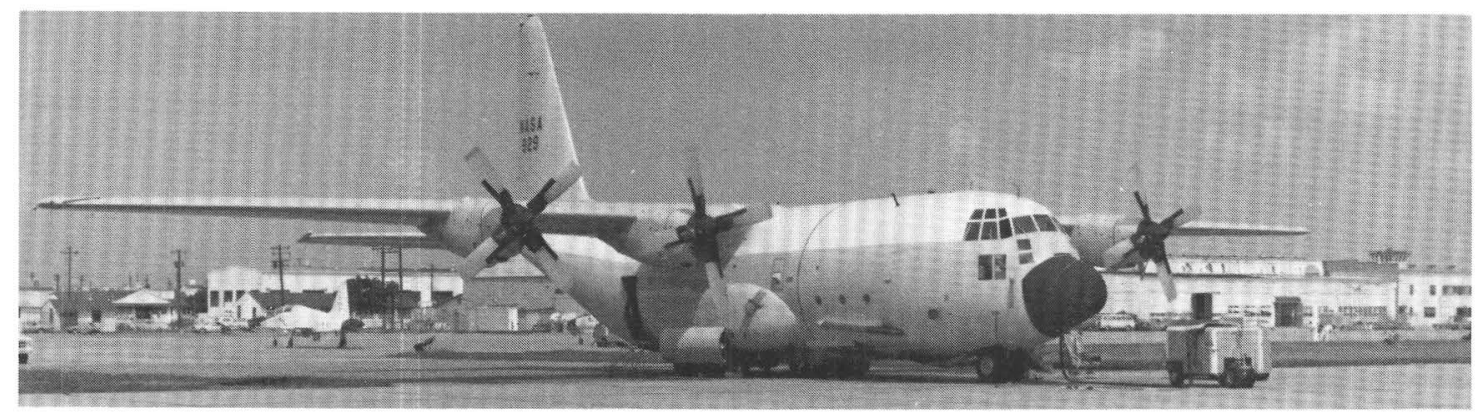

FIGURE 27.-Lockheed NC130B (RC130) Earth Resources Aircraft (NASA 929).

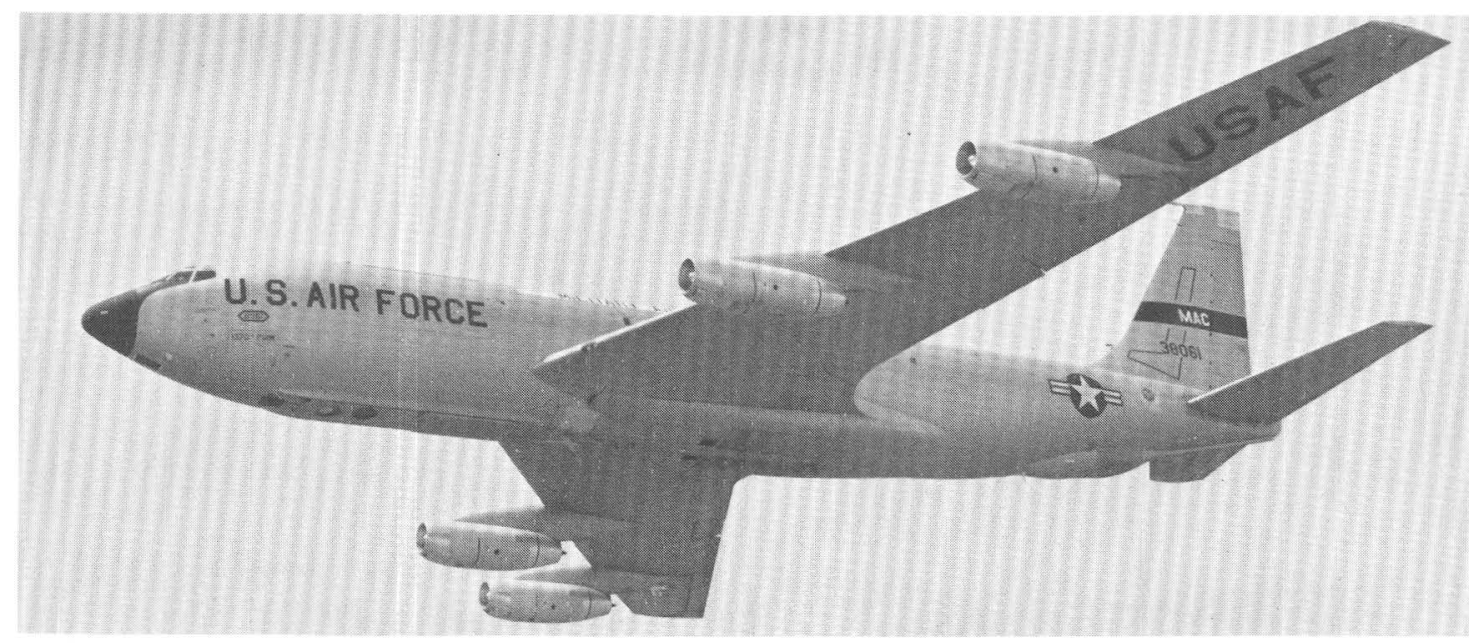

Figure 28.-Boeing RC135A.

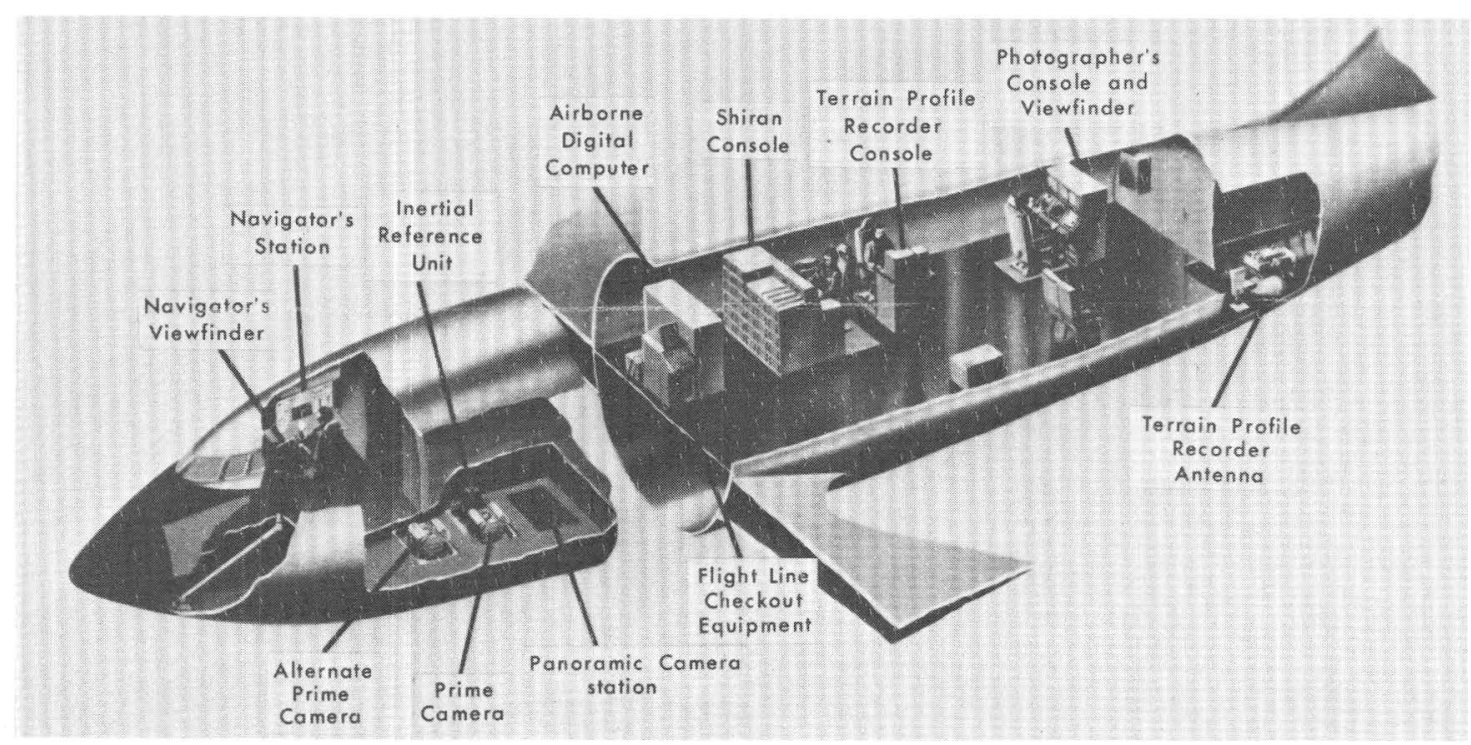

FIGURE 29.-Isometric view of Boeing RC135A showing the USQ-28 aerial electro-photomapping system. 


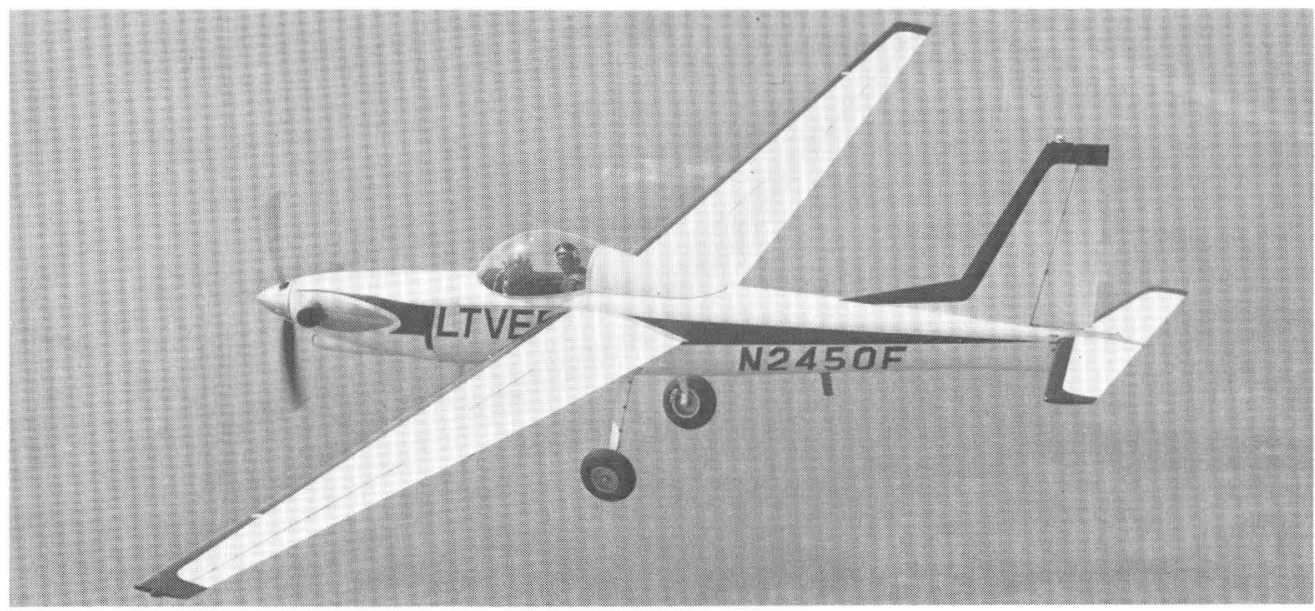

FIGURE 30.-E-Systems L450S reconnaissance aircraft in piloted configuration.

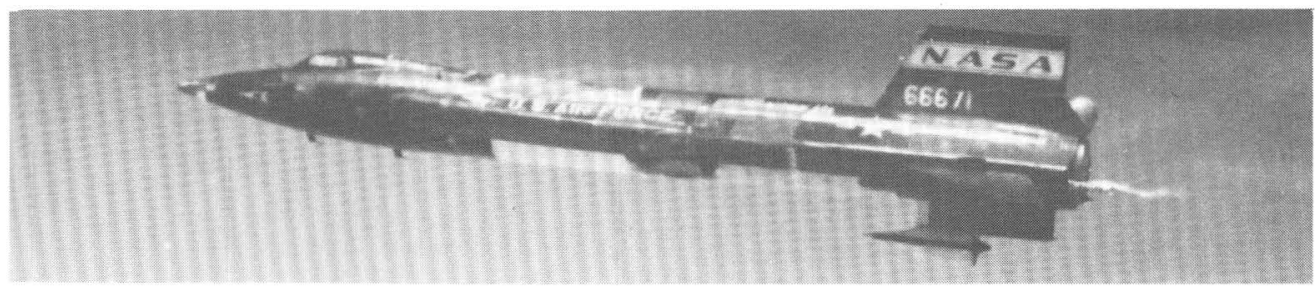

FIgURE 31.-North American Rockwell X15 research aircraft.

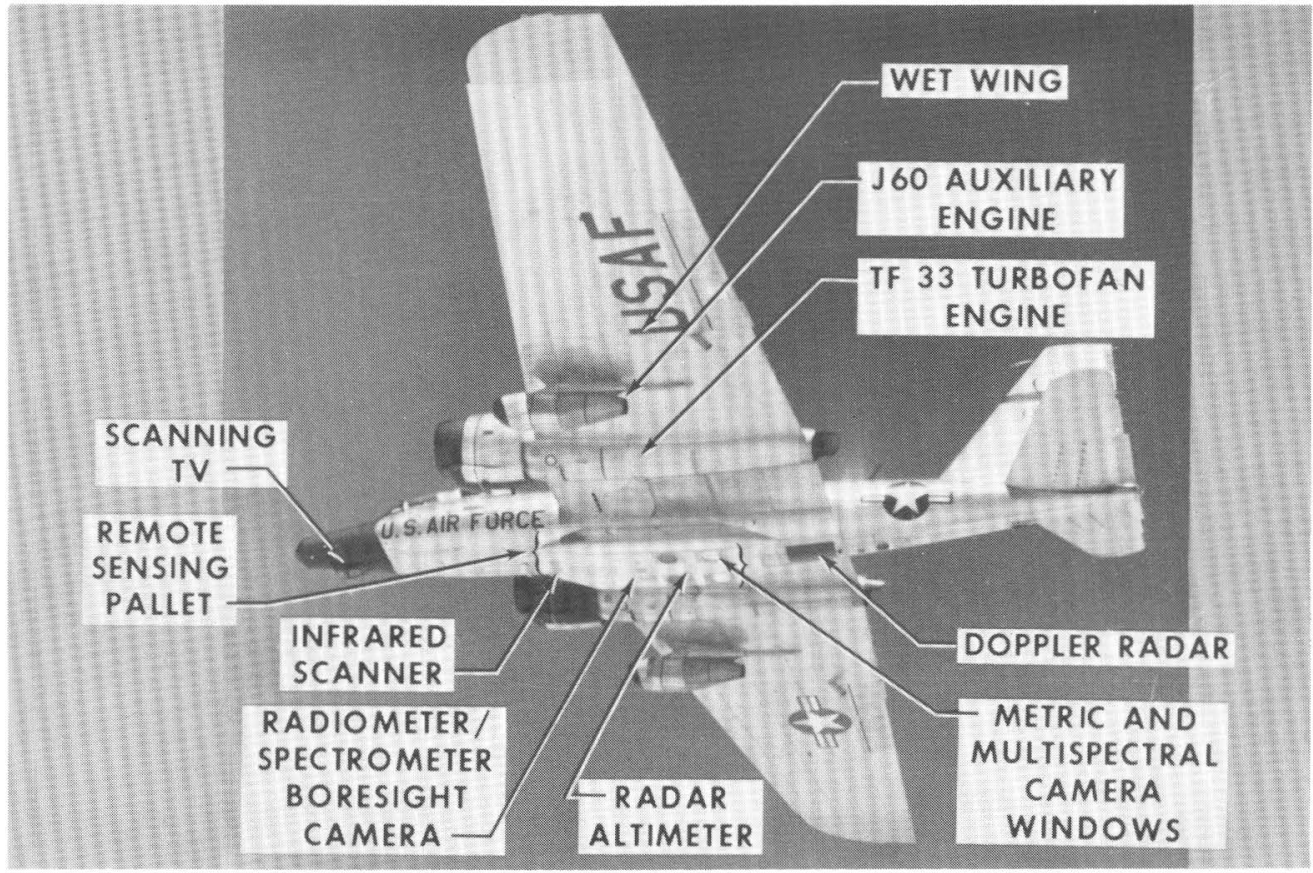

FIgURE 32.-General Dynamics/Martin RB57F. 


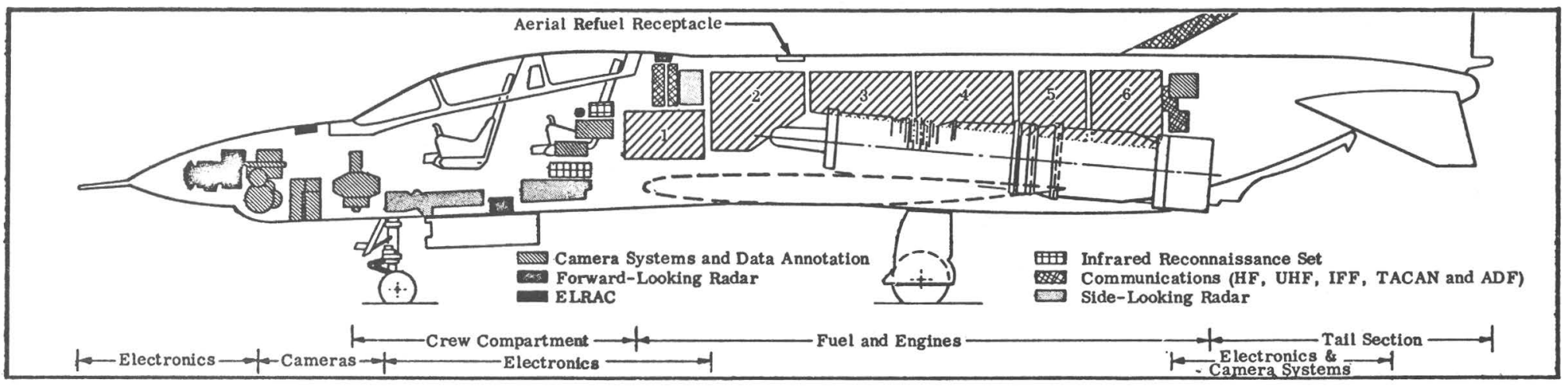

FIGURE 33.-McDonnell Douglas (Phantom II) RF-4C.

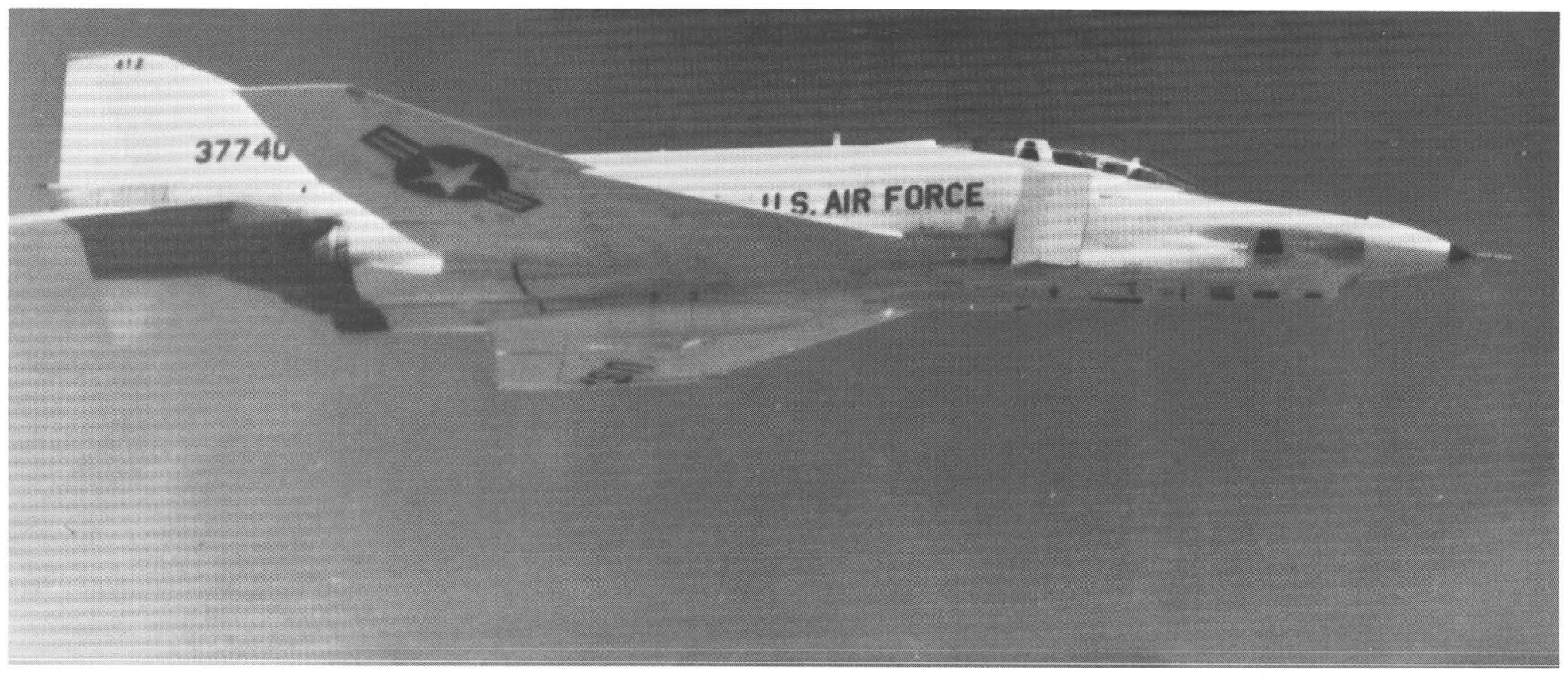




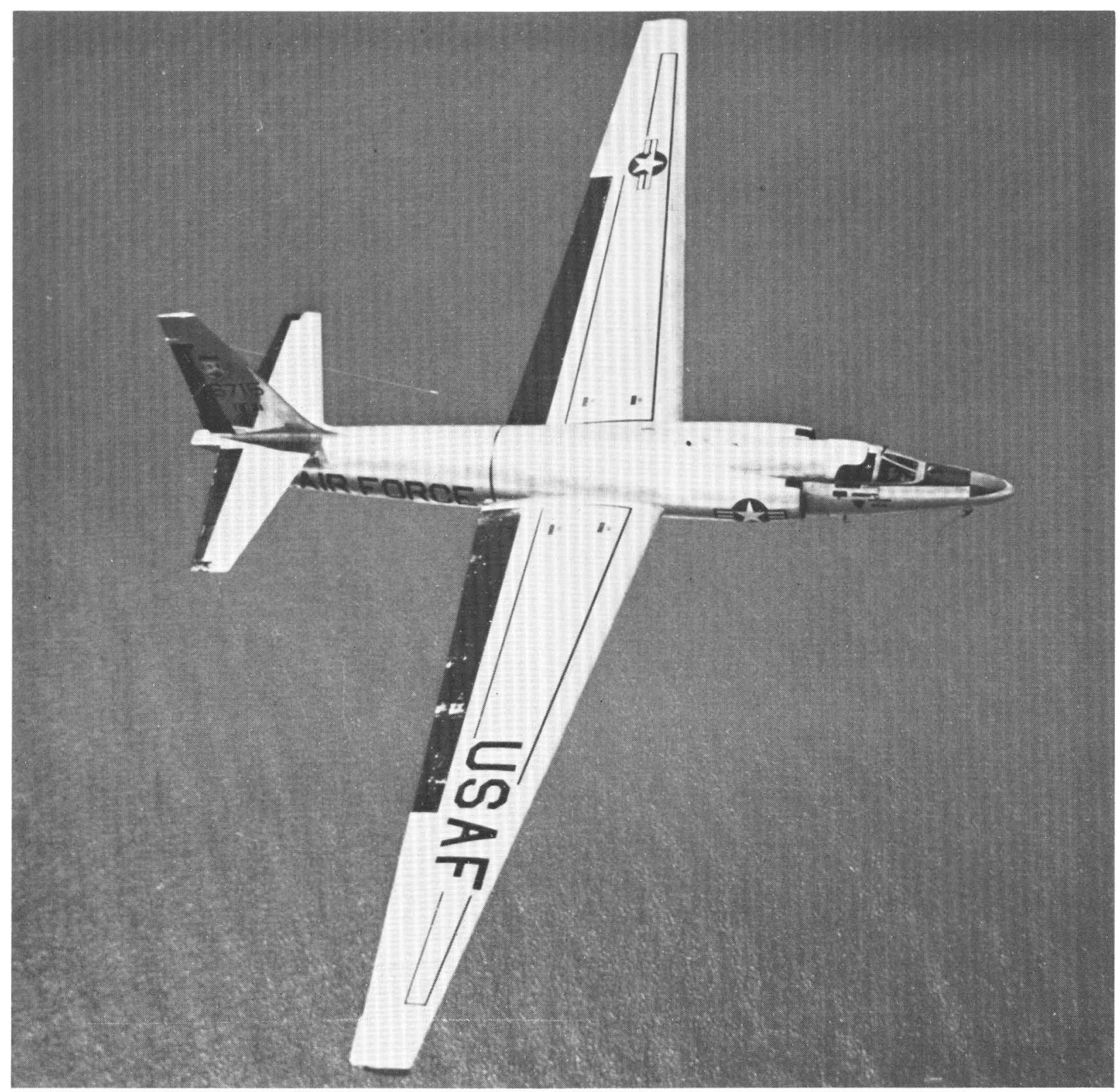

FIGURE 35.-Lockheed U-2.

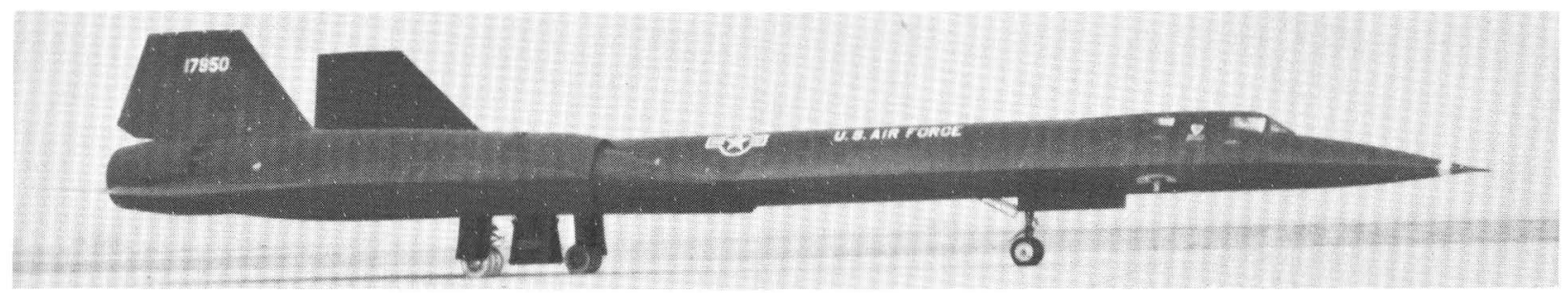

FIGURE 36.-Lockheed SR71A strategic reconnaissance aircraft. 


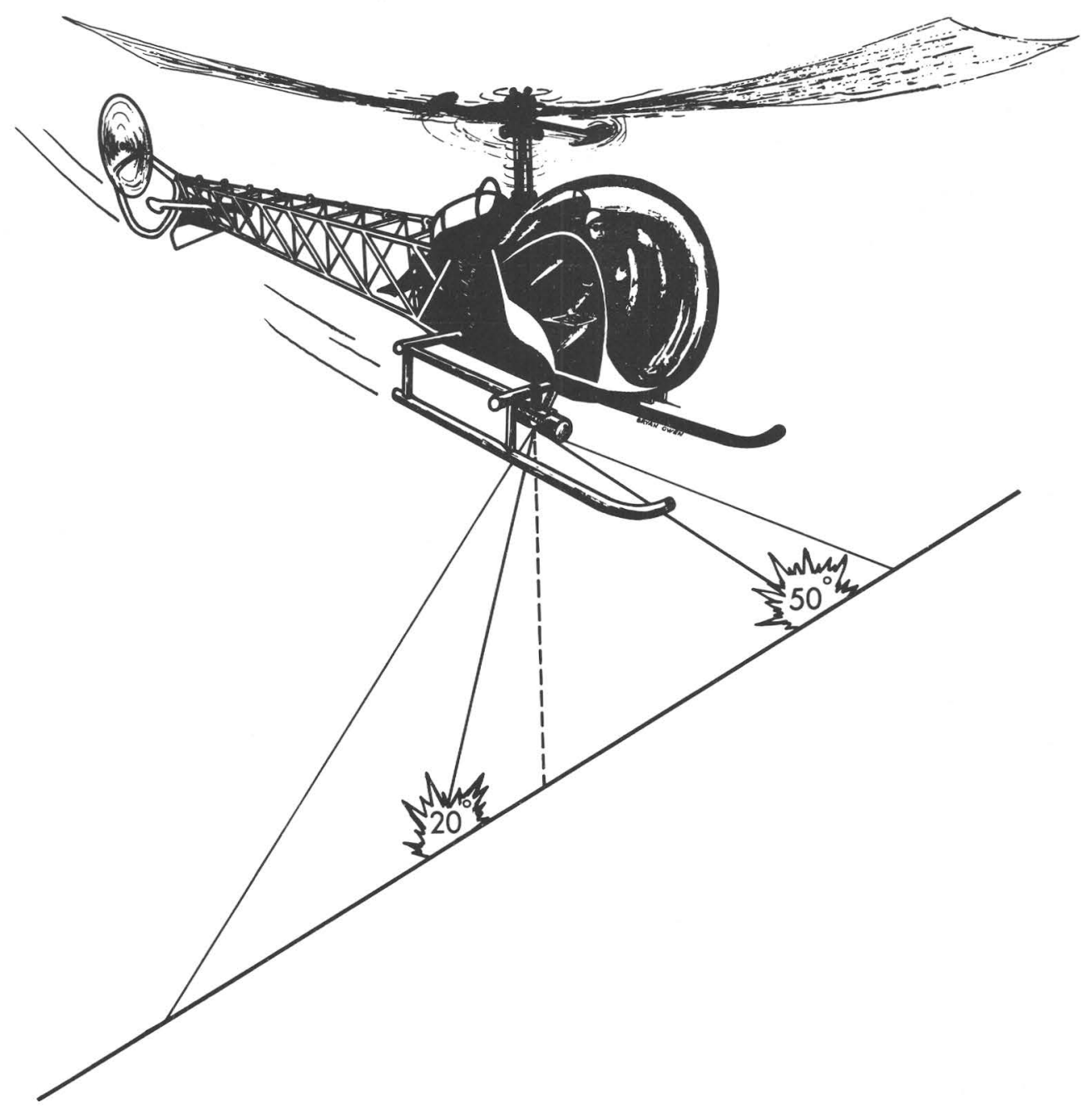

FigURe 37.-USDA Forest Service Bell Helicopter fire spotter, Model 47G-3B-1.

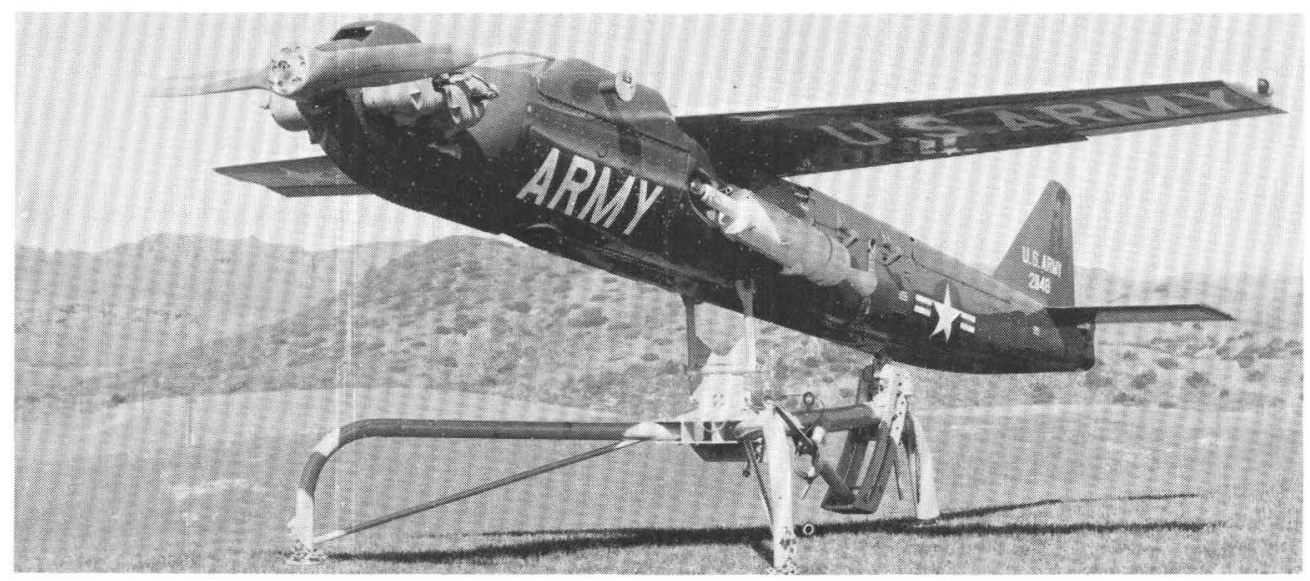

FIGURE 38.-Northrop Falconer surveillance drone. 


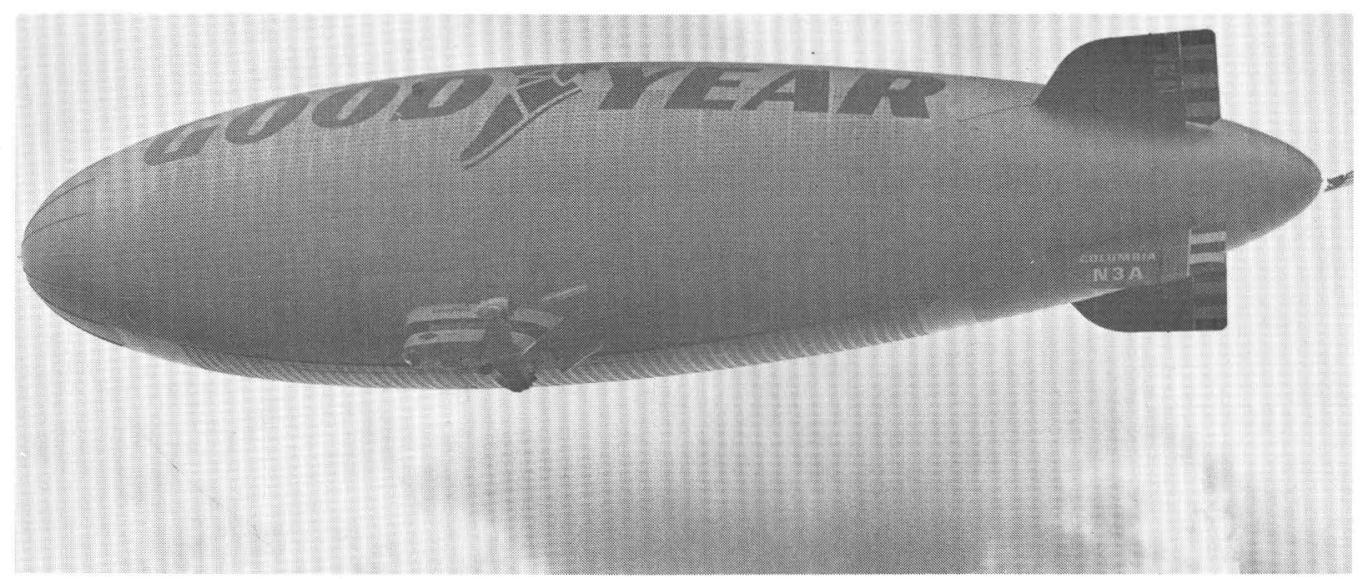

FigURE 39.-Goodyear blimp Columbia.

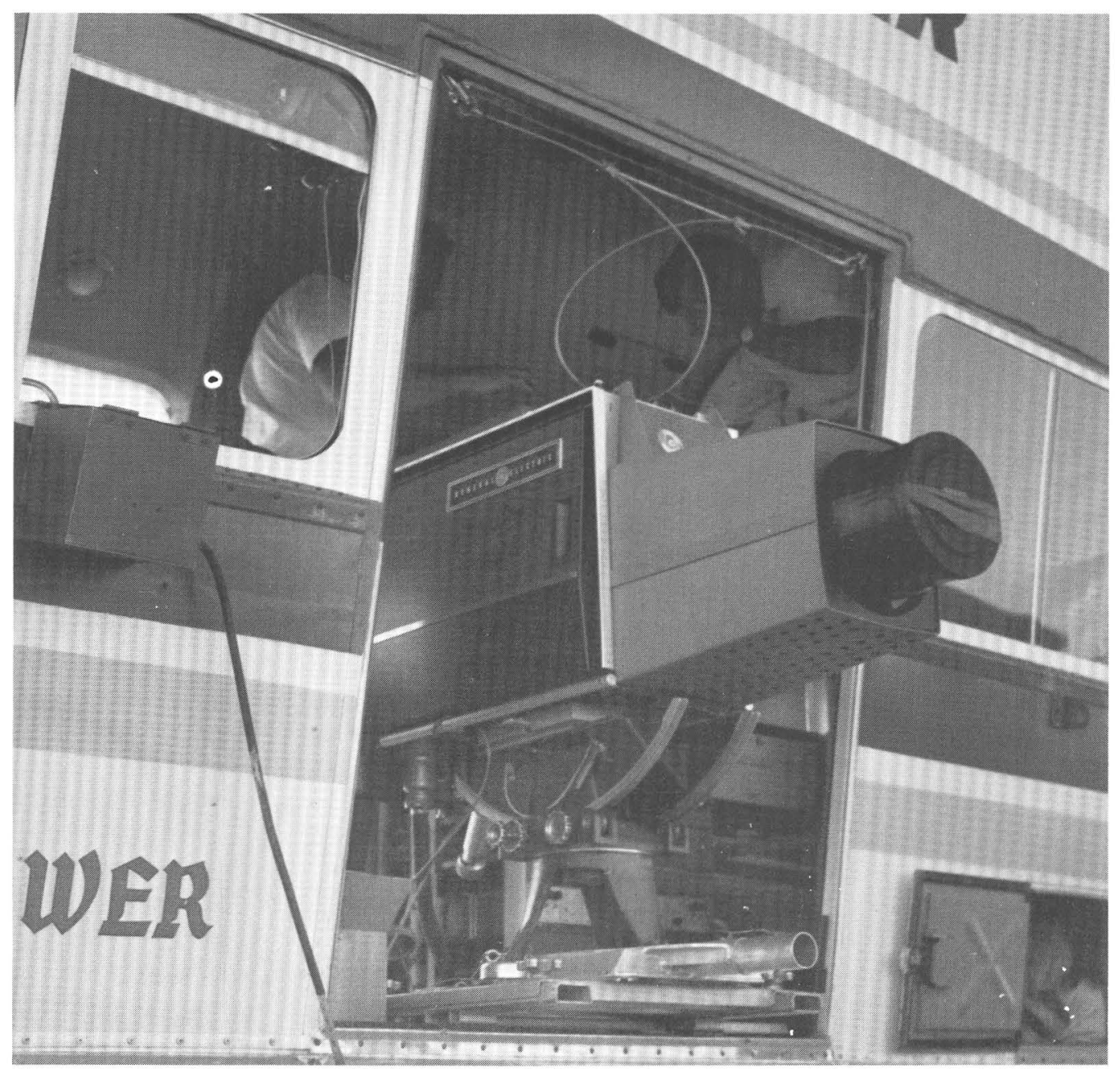

Figure 40.-Television camera mounted on blimp Mayflower. 


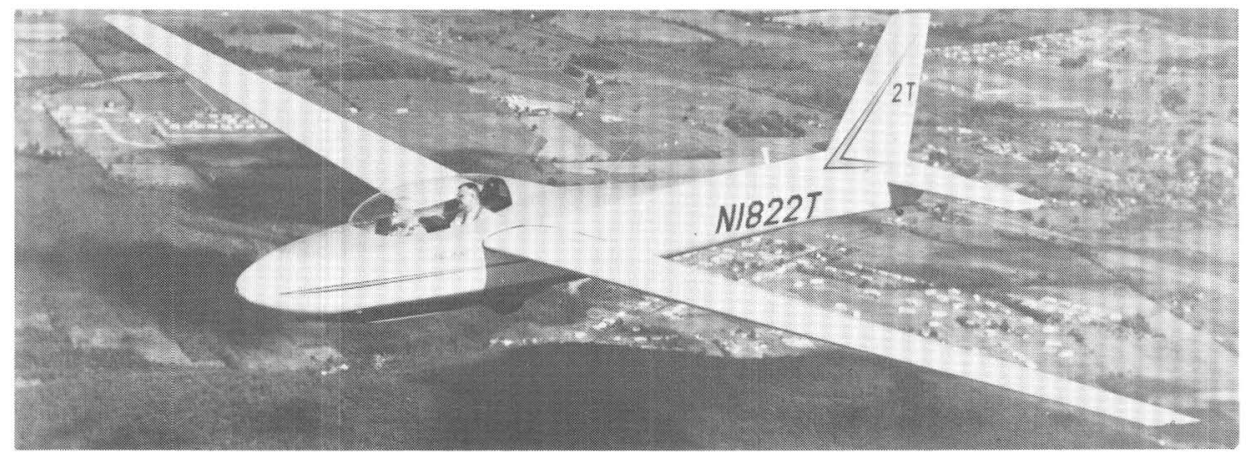

FIGURE 41.-Schweizer sailplane SGS 2-32.

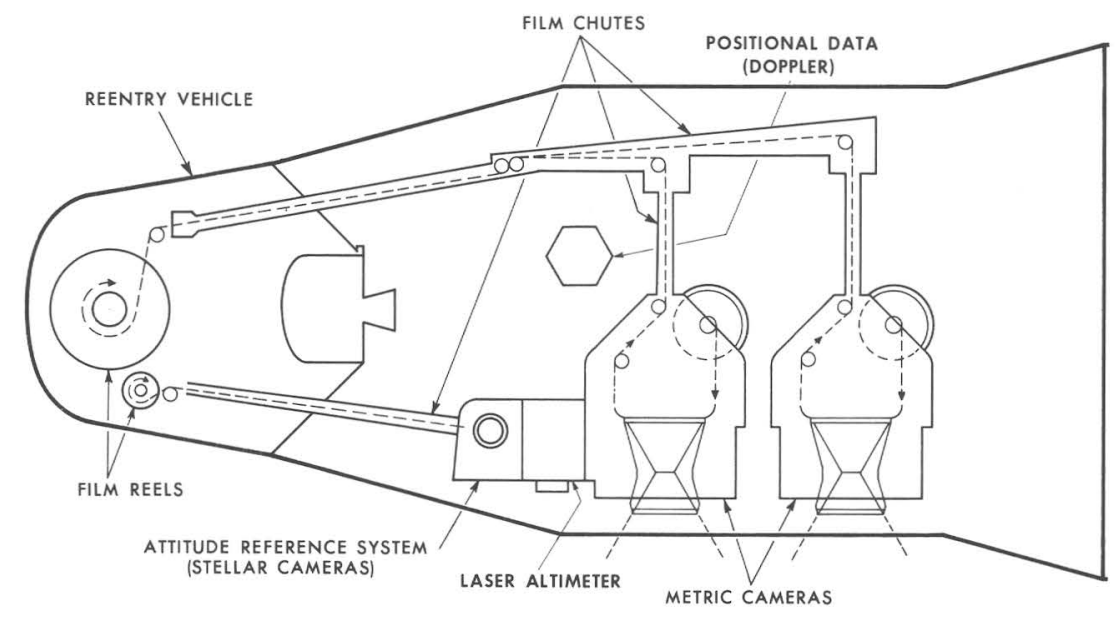

FIGURE 42.-Sketch of proposed film-return Earth-sensing space vehicle (USGS).

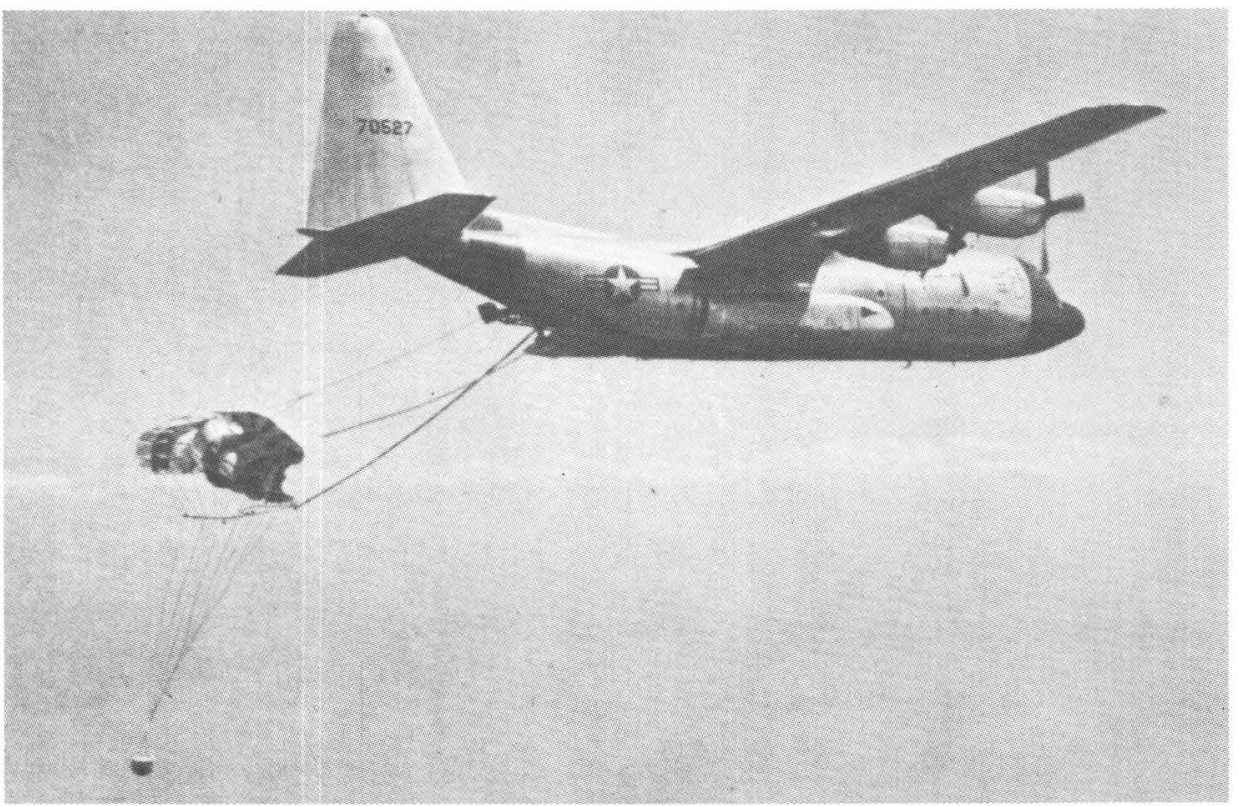

FIGURE 43.-Aircraft recovering a capsule such as might contain film from an Earth-sensing spacecraft. 


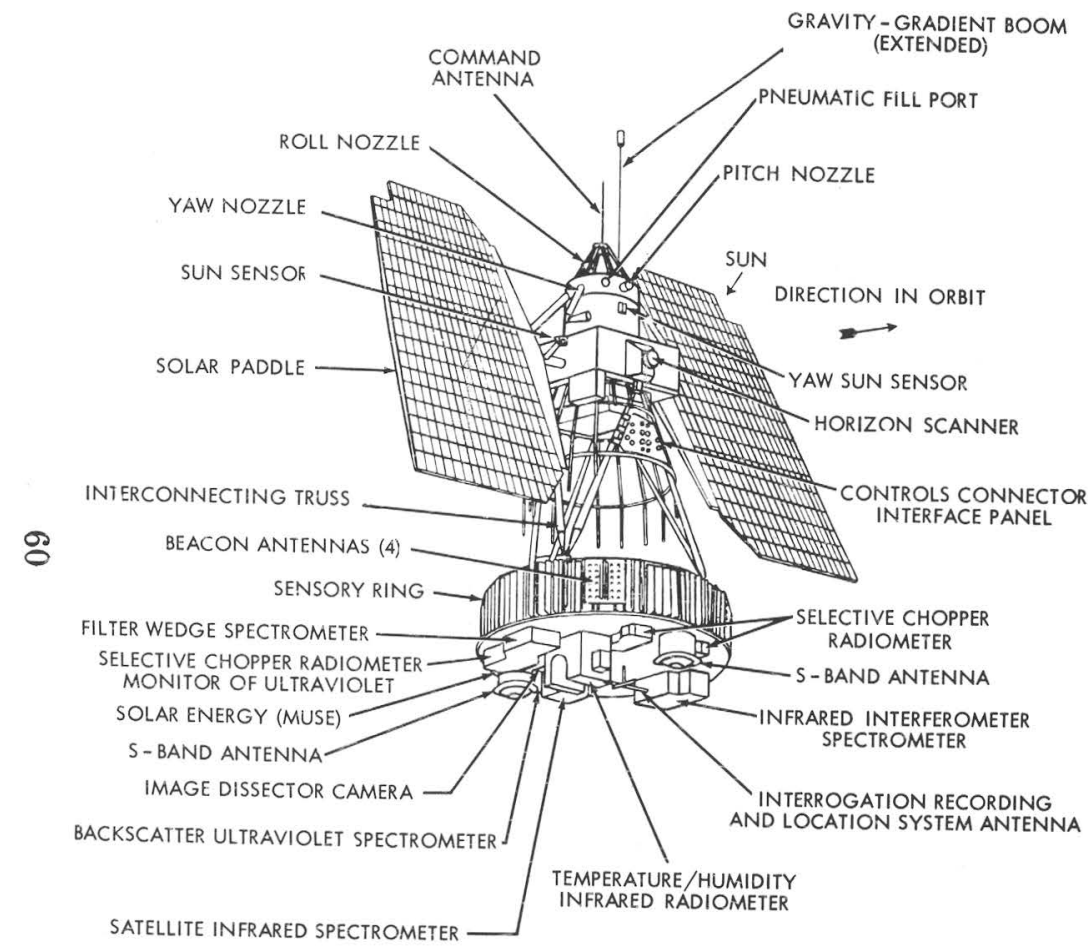

FIGURE 44.-Nimbus D satellite (sketch).

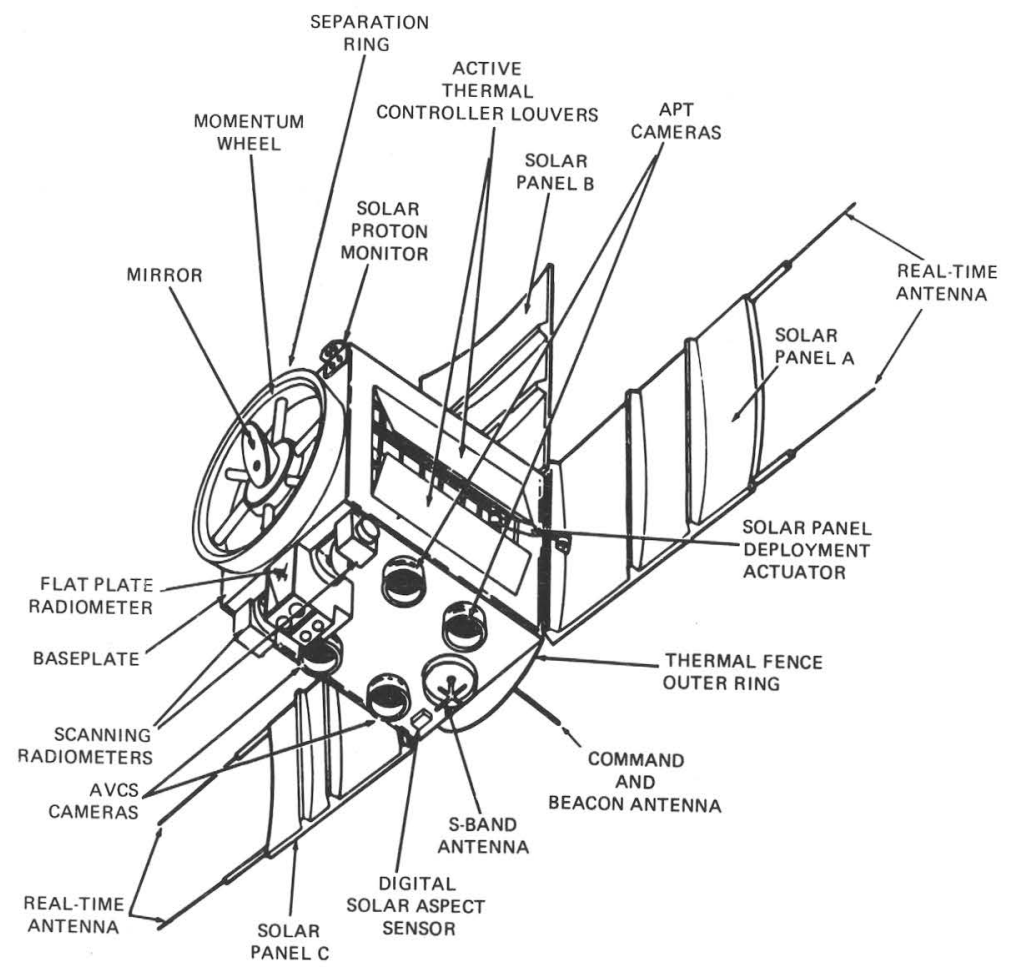

FIGURE 45.-TIROS M spacecraft. 


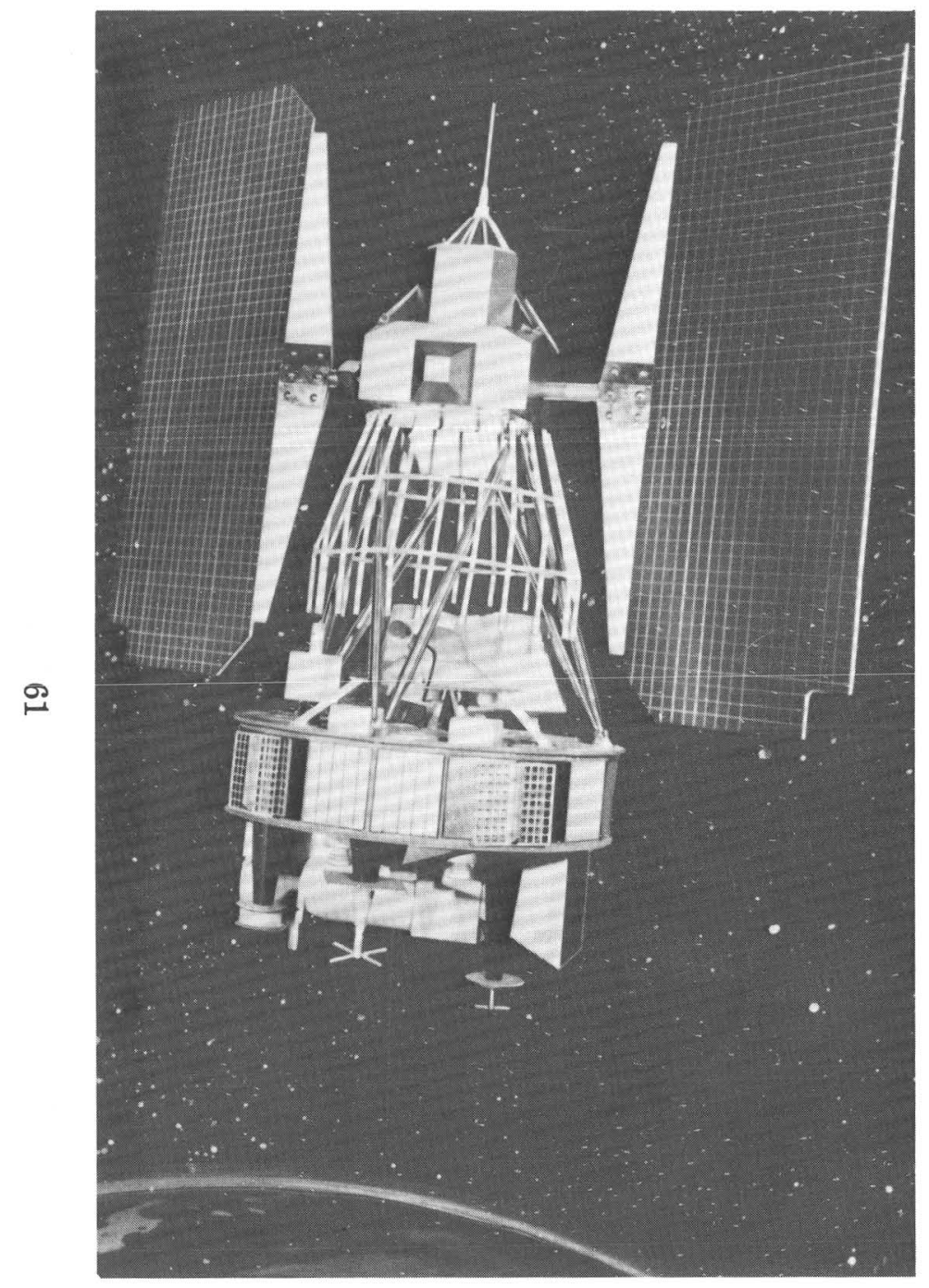

FIGURE 46.-Earth Resources Technology Satellite (ERTS).

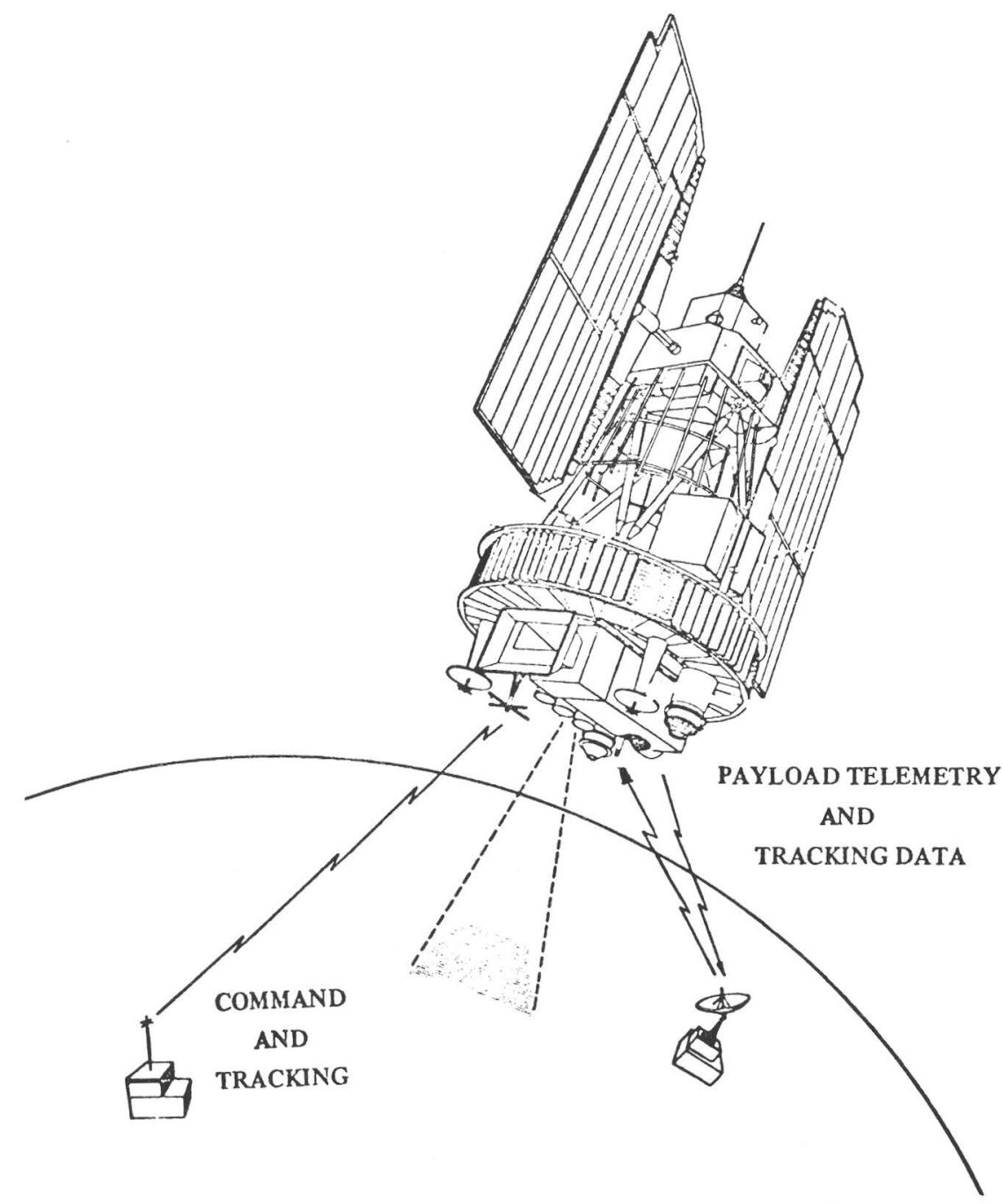

FIGURE 47.--Sketch of ERTS system. 


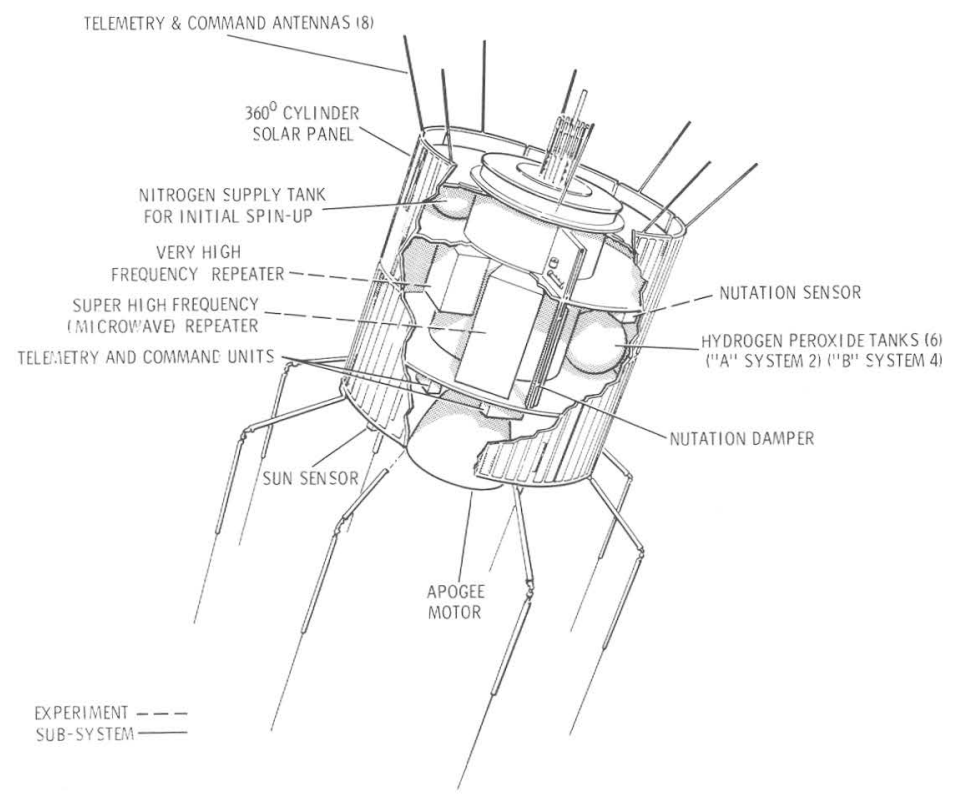

FigURE 48.-ATS-B systems and interior experiments.

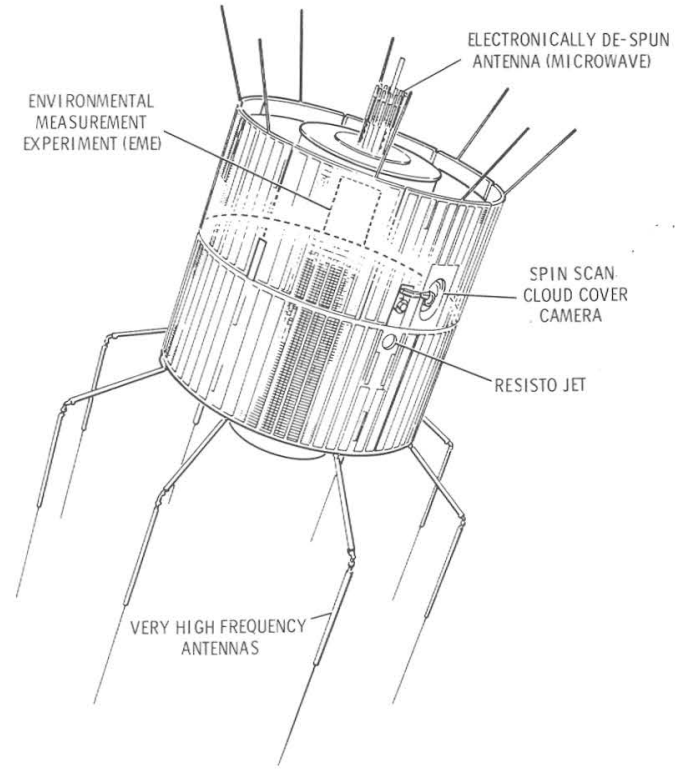

FIGURE 49.-ATS-B exterior experiments.

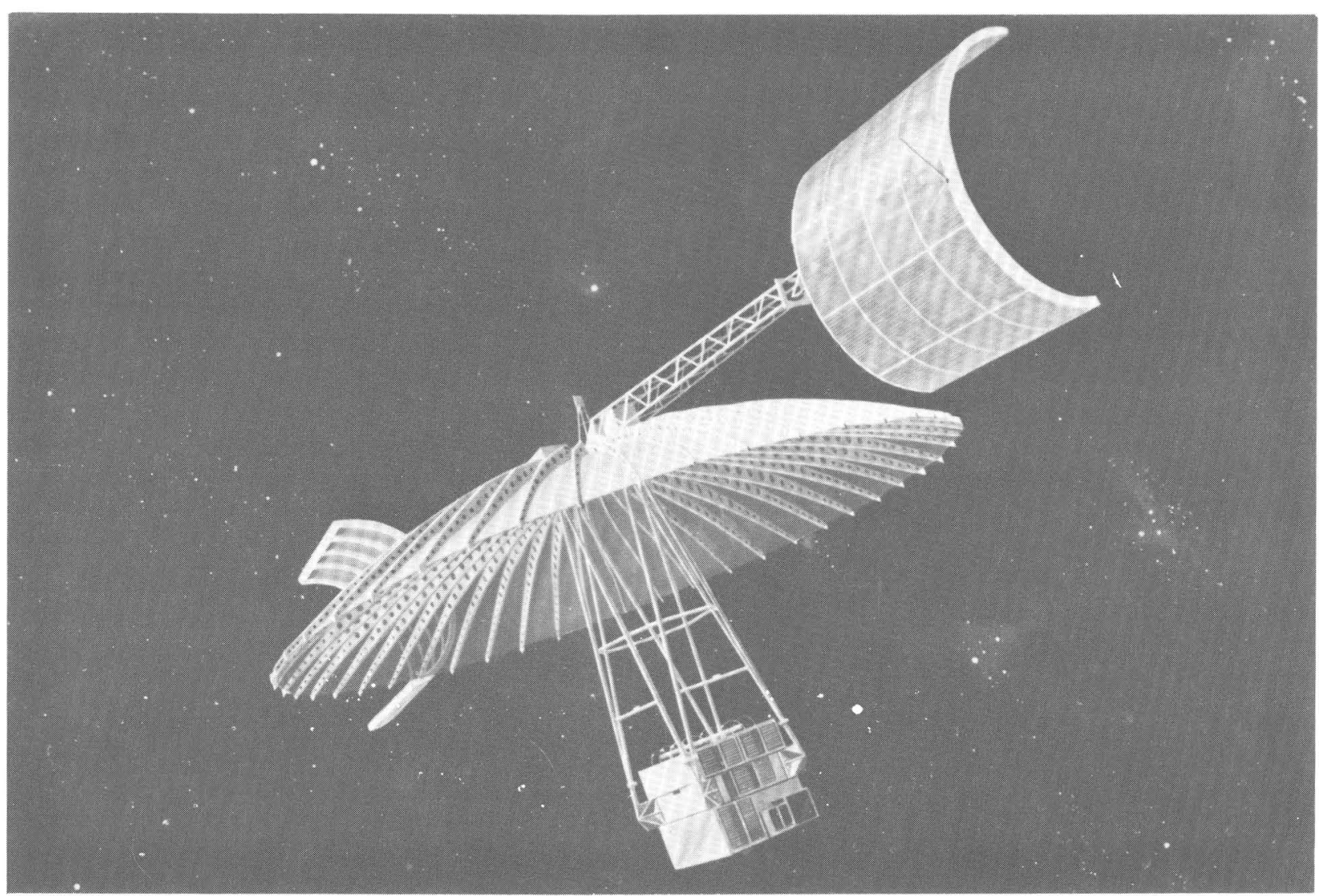

FigURE 50.-Concept of ATS-F\&G. 


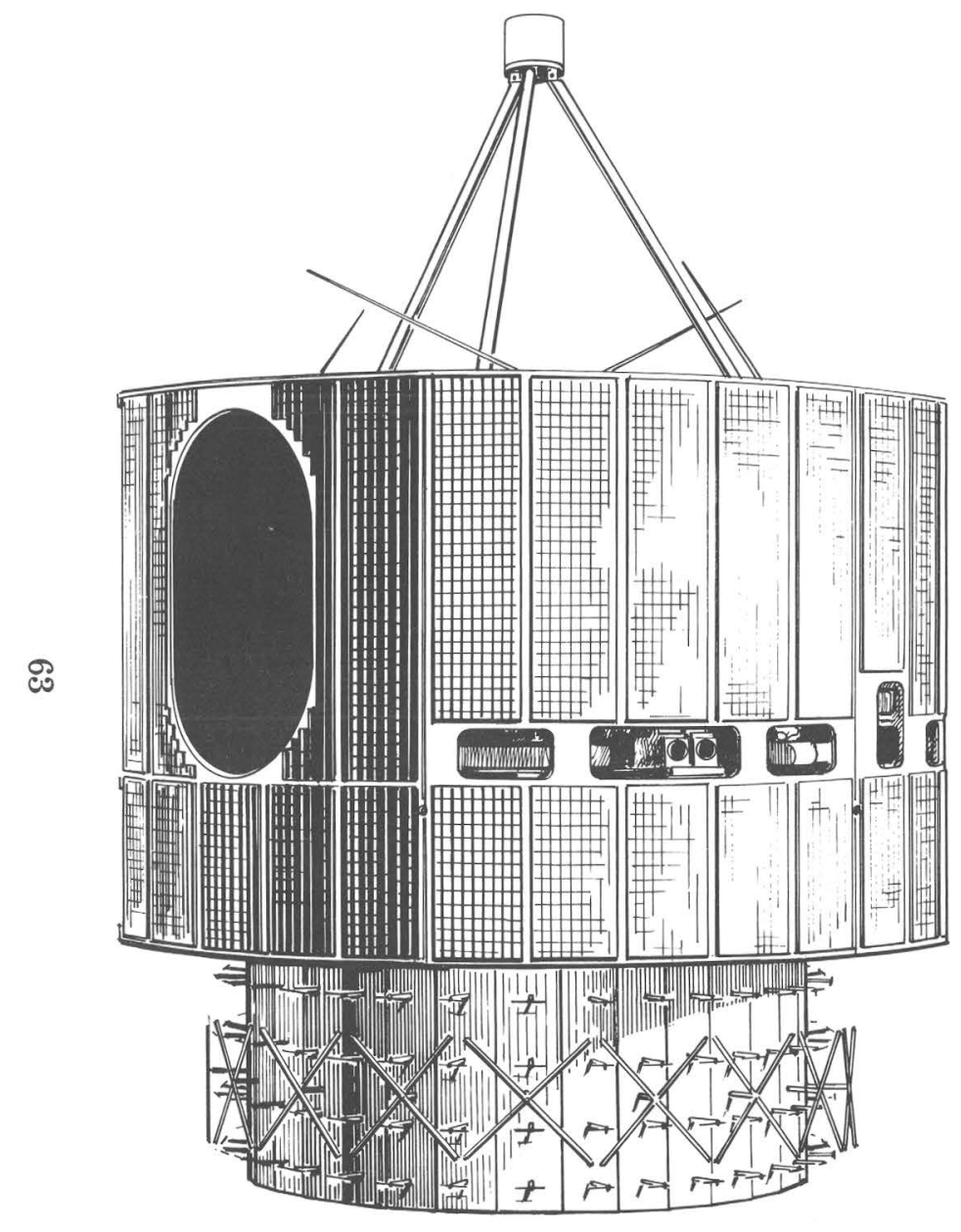

Figure 51.-Synchronous Meteorological Satellite (SMS).

\section{SATELLITE POSITIONS (SIX)}
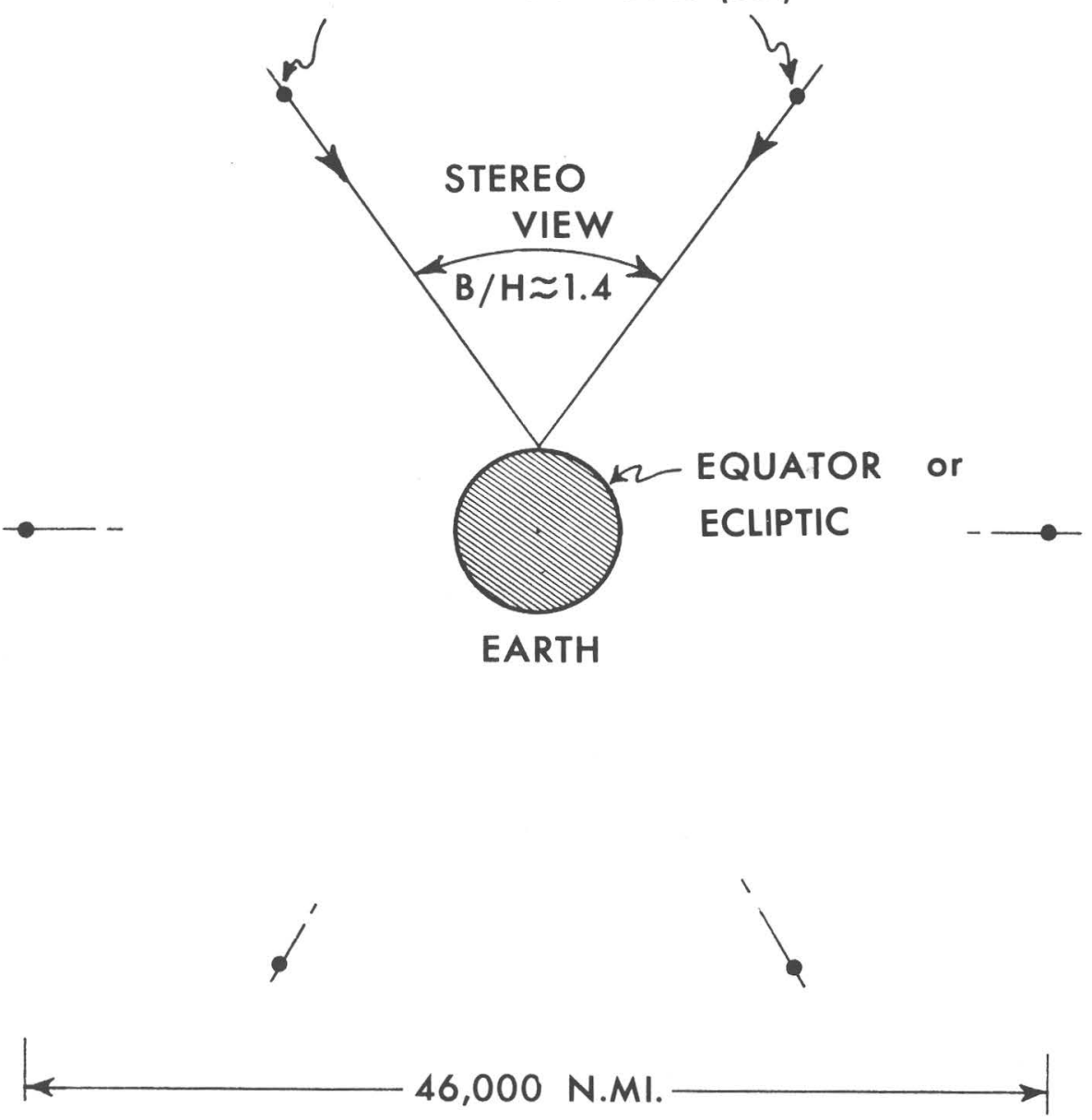

FIGURE 52.-Schematic drawing of a 6-satellite high-resolution geosynchronous Earth-sensing system. 


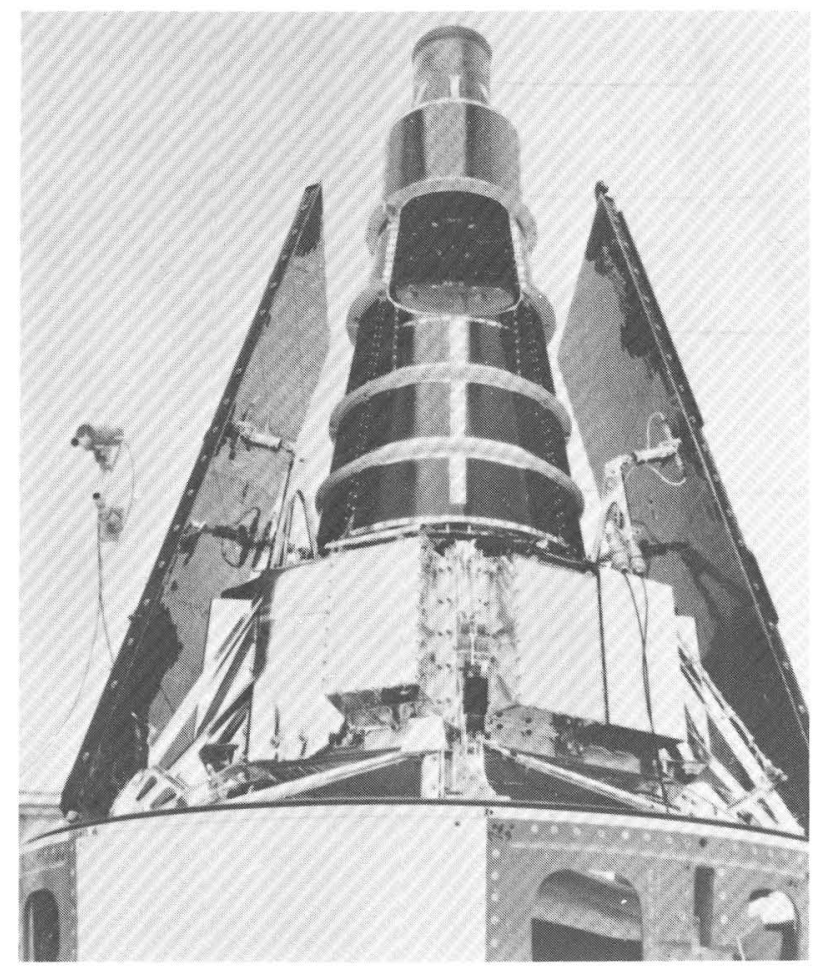

FigURE 53.-Ranger lunar probe.

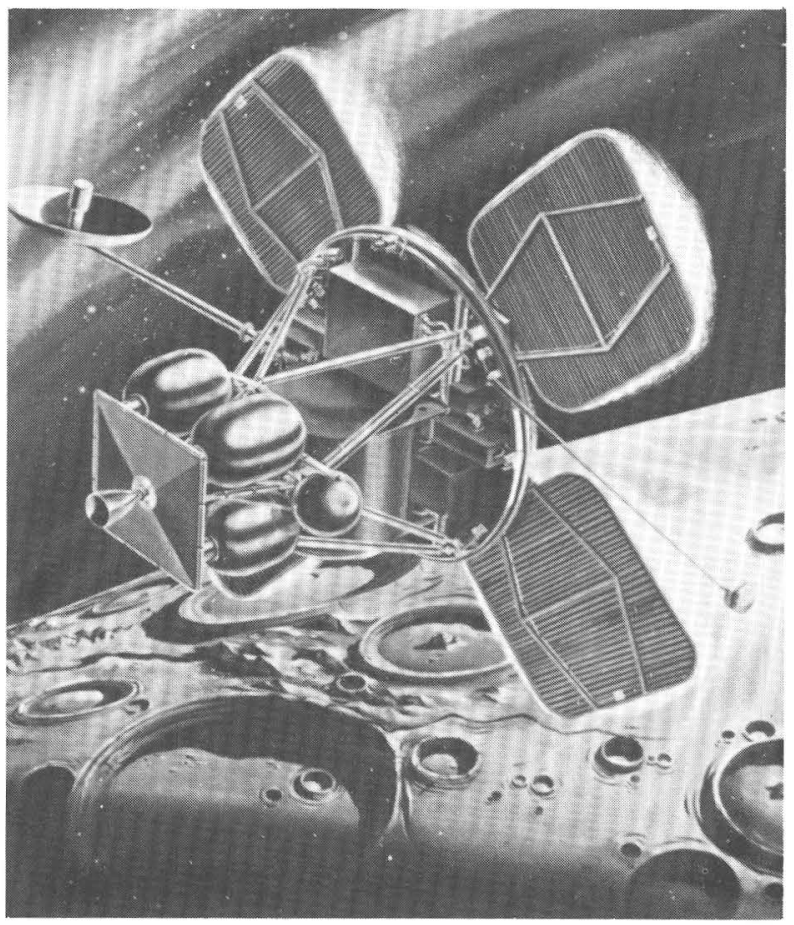

FigURE 54.-Lunar Orbiter spacecraft (artist's conception.)

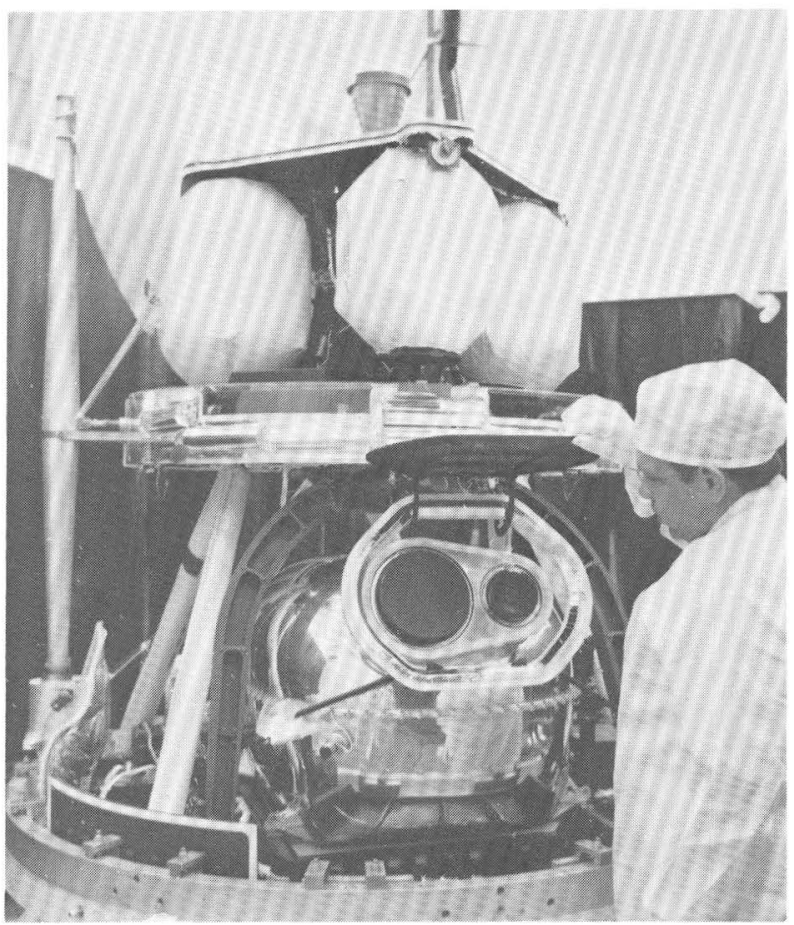

Figure 55.-Lunar Orbiter E, showing camera lens. 


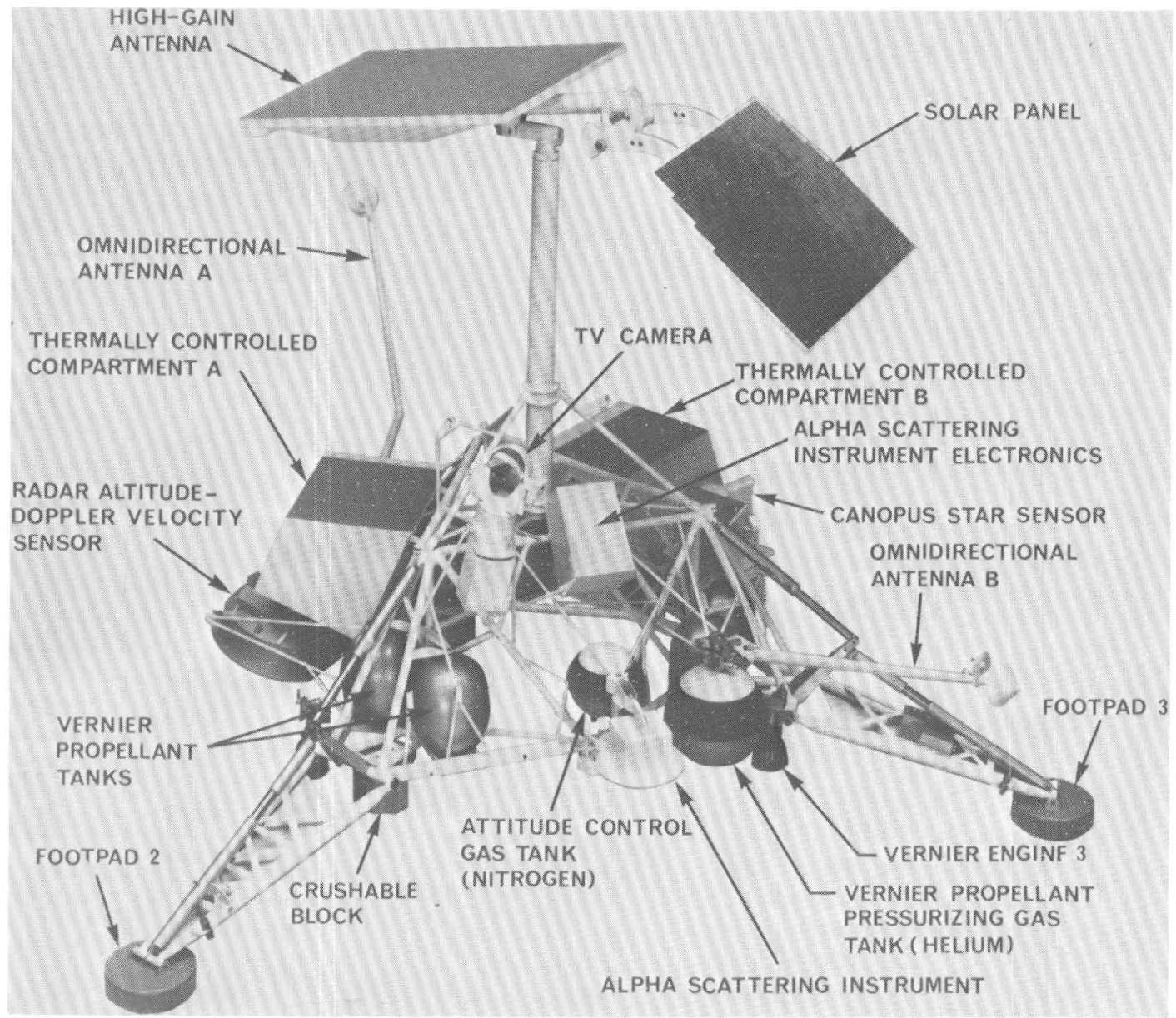

Figure 56.-Surveyor lunar lander.

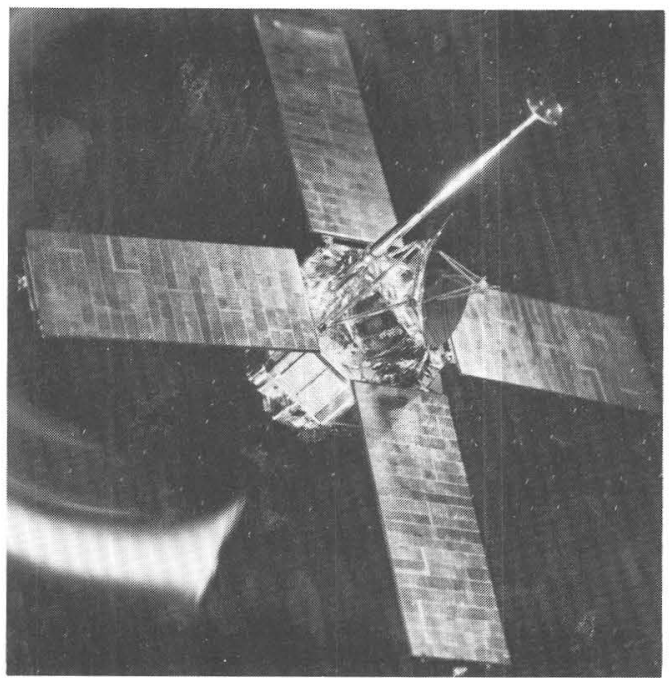

FigURE 57.-Mariner 4 spacecraft (flyby version).

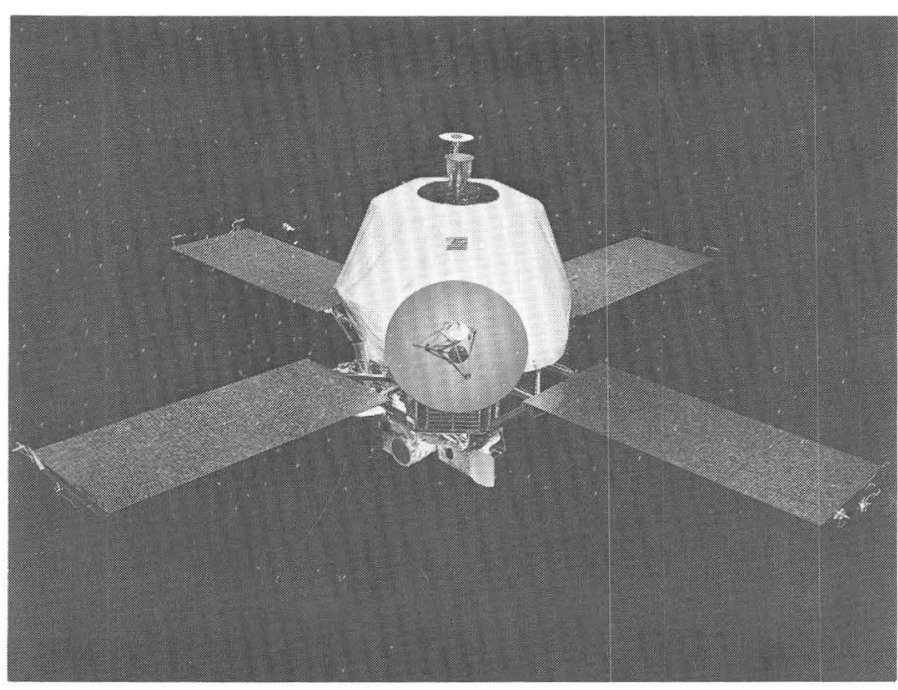

FiguRE 58.-Mariner 9 spacecraft (Mars Orbiter). 


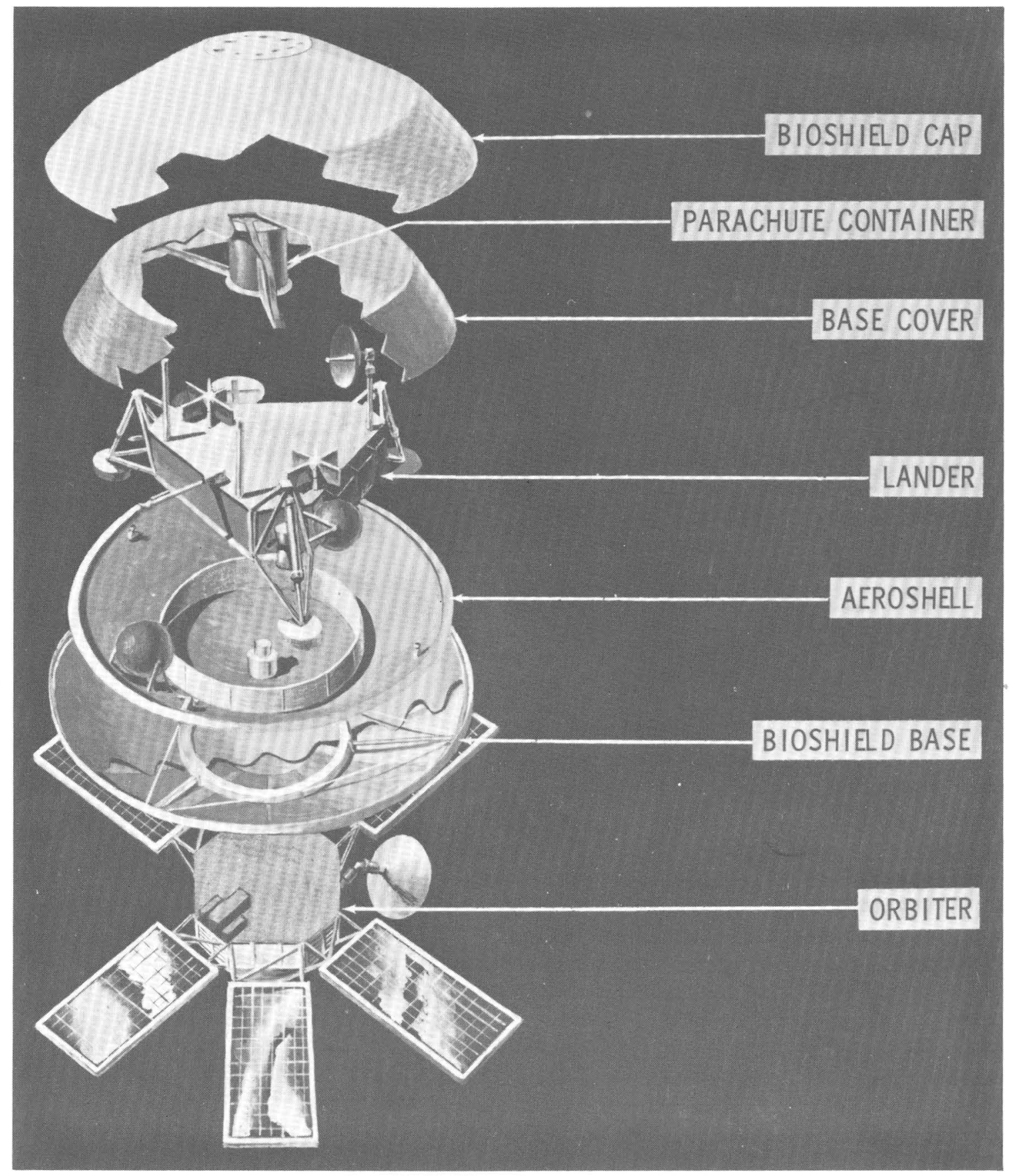

FIGURE 59.-Viking spacecraft. 


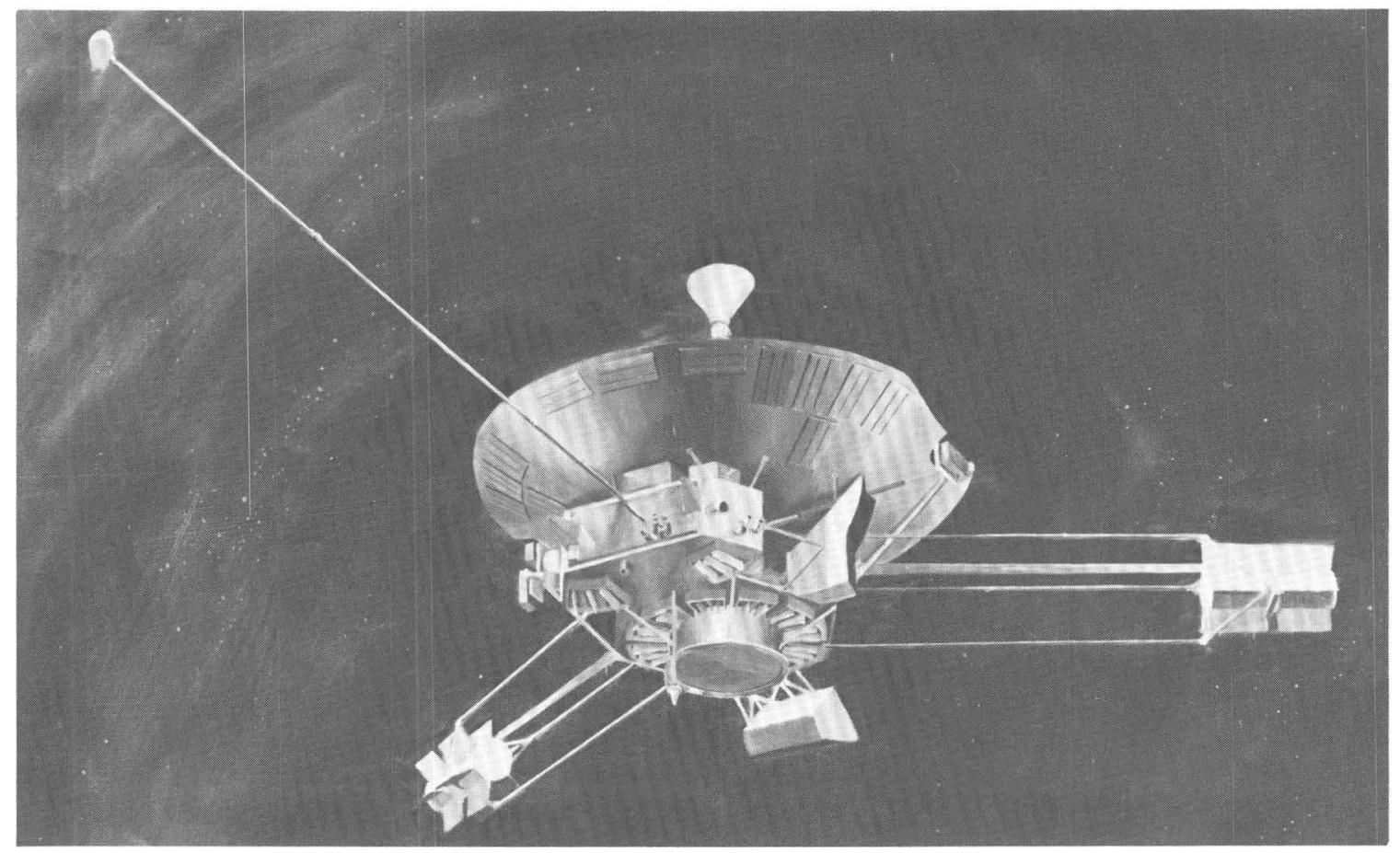

FiguRE 60.-Pioneer spacecraft.

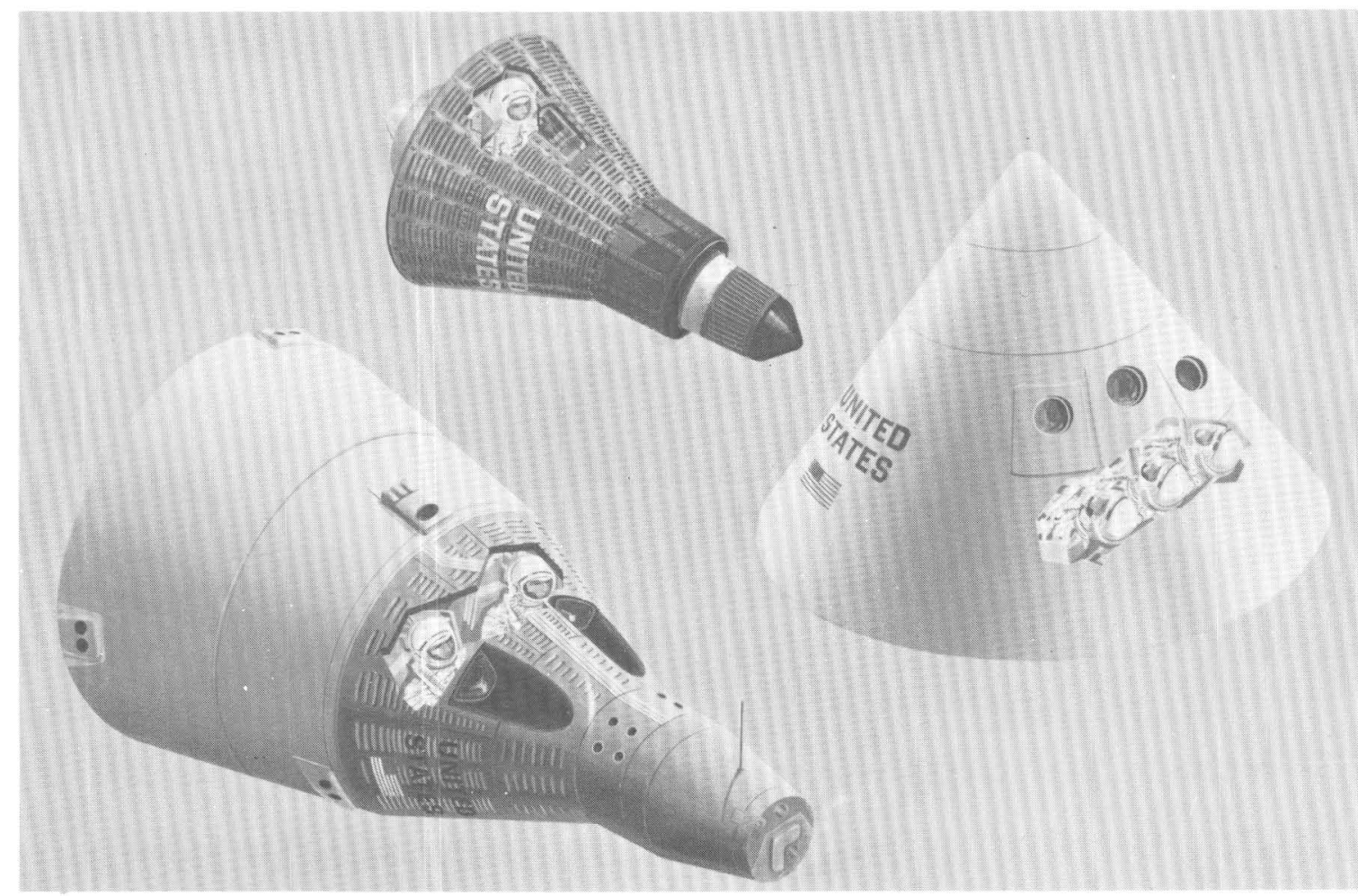

Figure 61.-Mercury, Gemini, and Apollo spacecraft. 


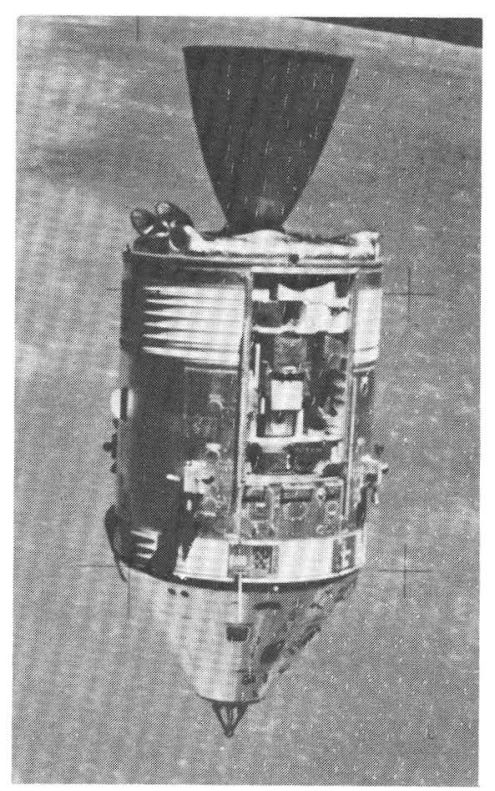

FIgURE 62.-Apollo service module, showing Scientific Instrument Module (SIM).

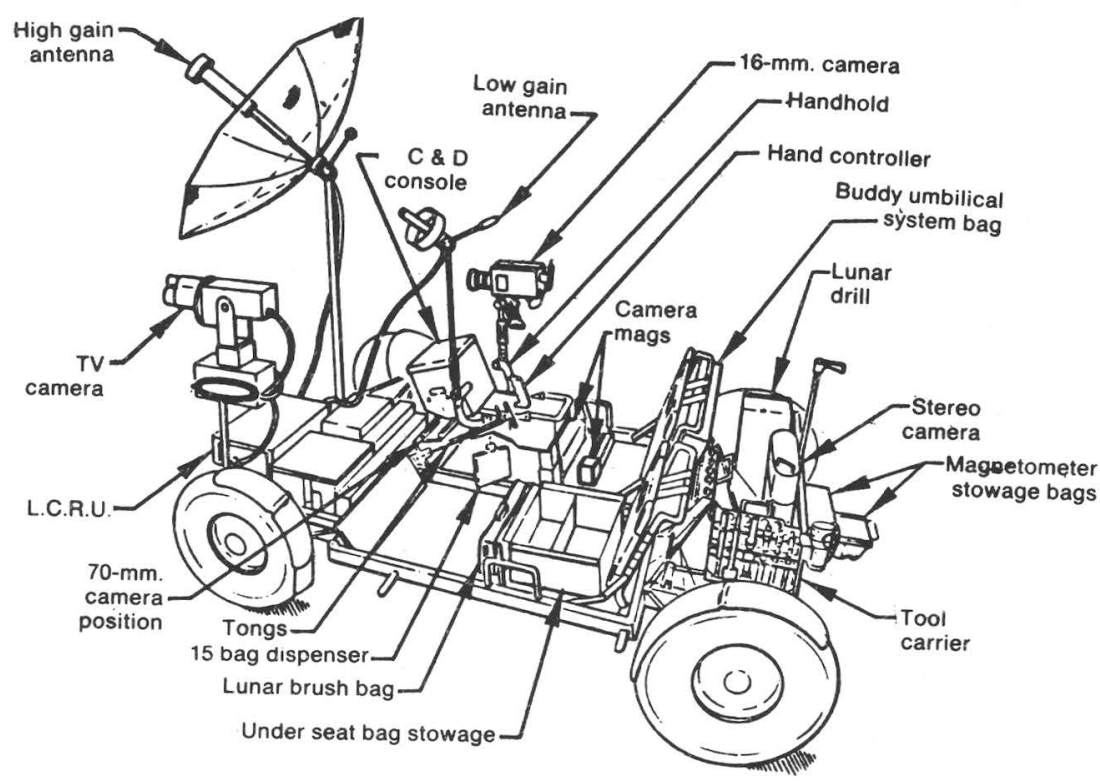

FigURE 64.-Sketch of Lunar Rover Vehicle, showing instruments.

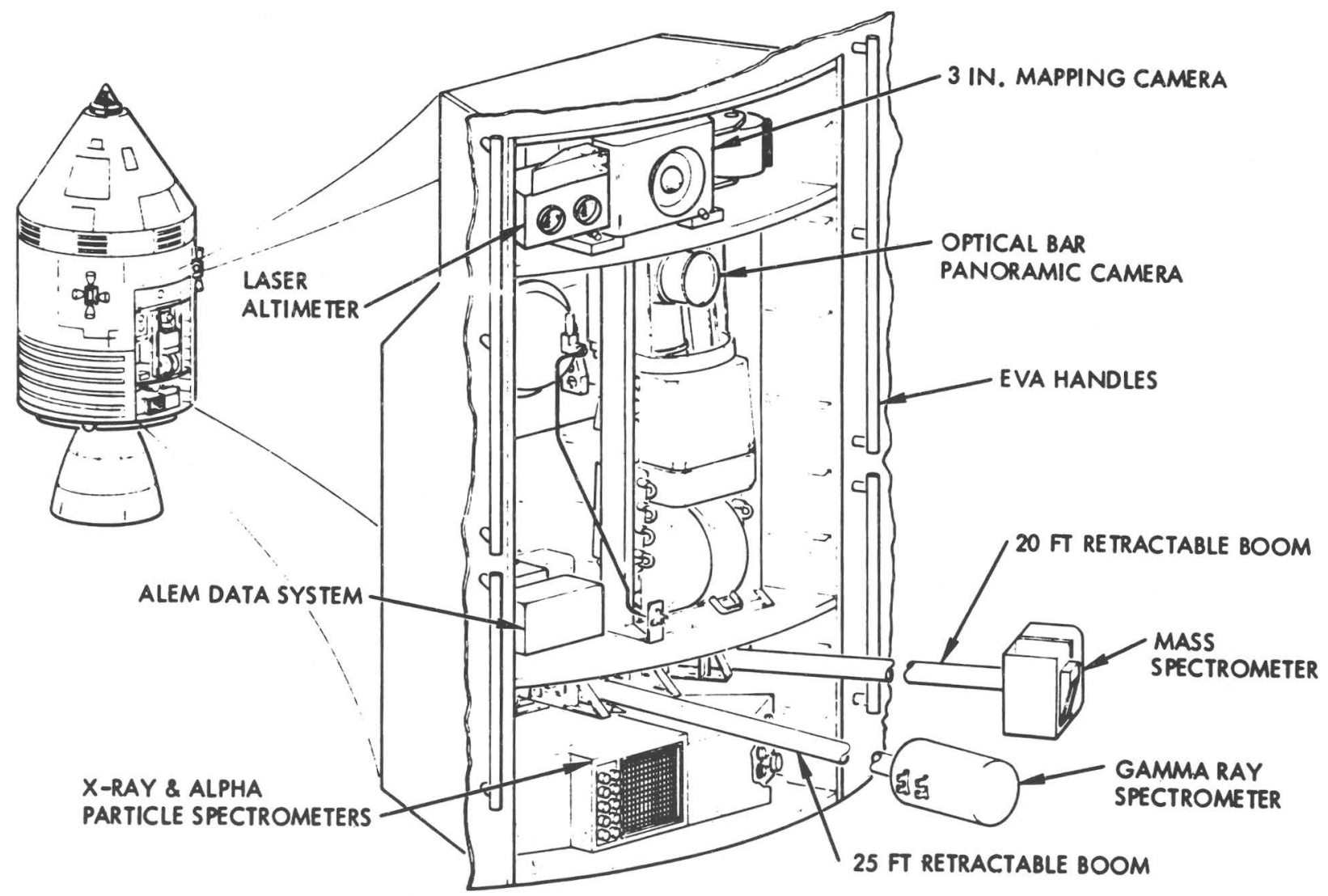

FIGURE 63.-Sketch of instruments carried in Apollo SIM bay. 


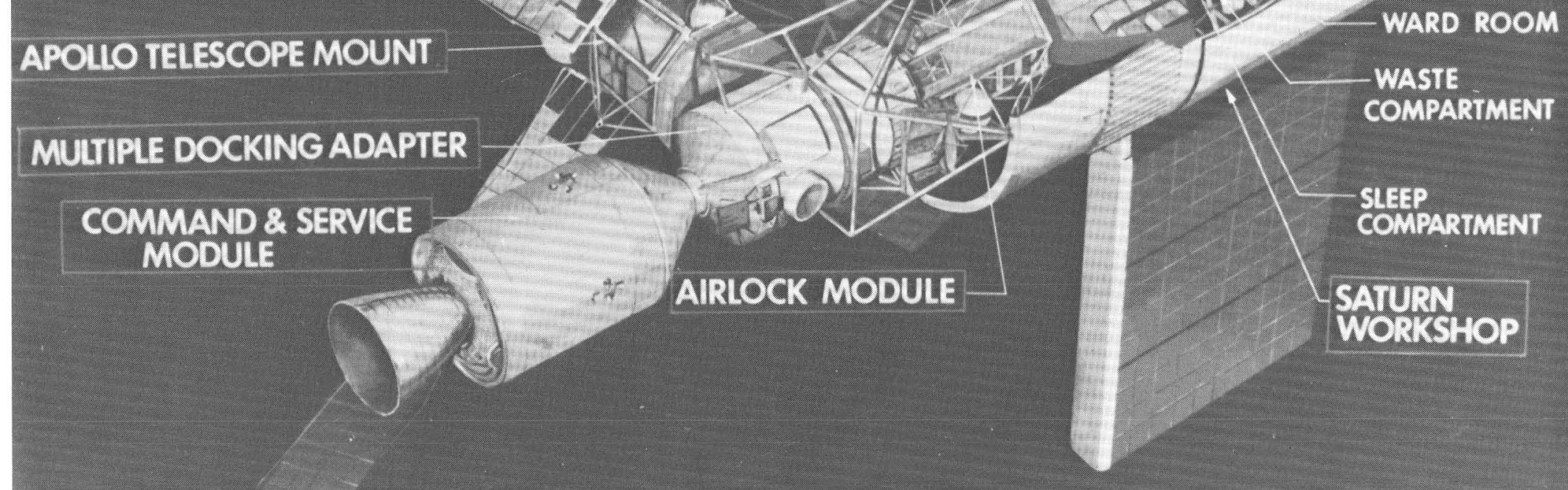




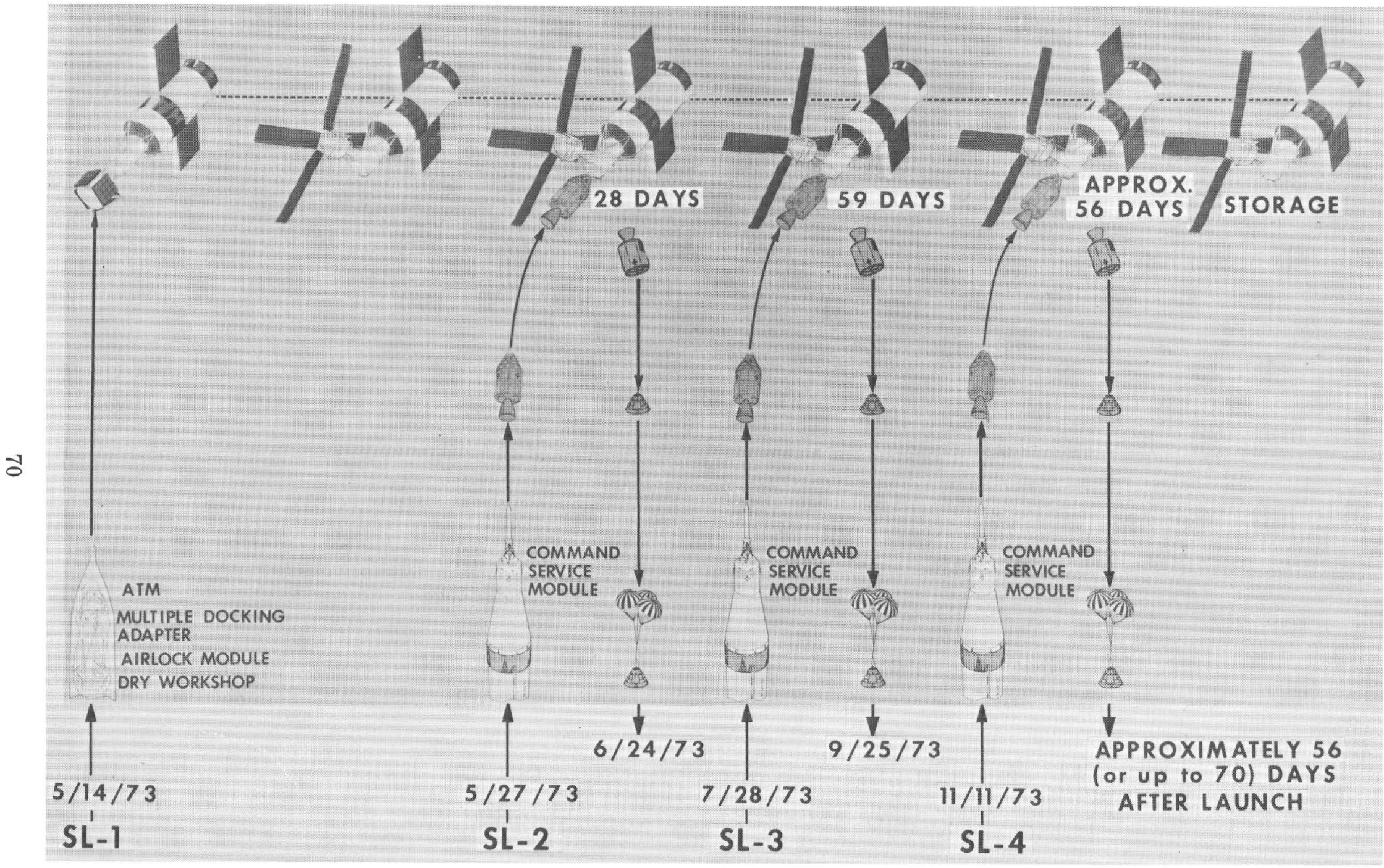

FIGURE 66.-Skylab-A, activation and operation-periods of occupancy. 


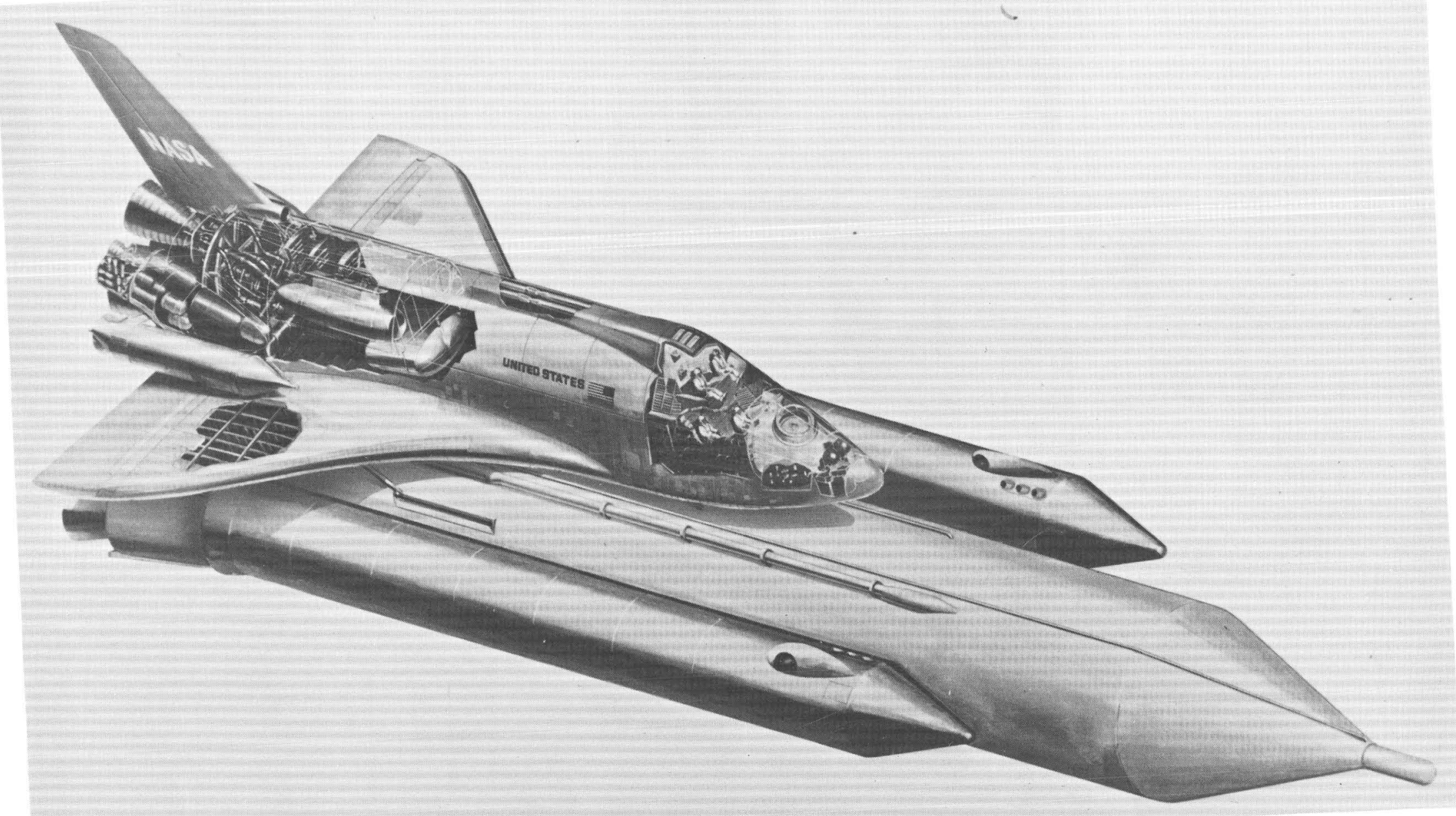

FIGURE 67.-Space Shuttle. 


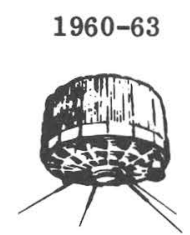

TIROS R\&D MISSION

TIROS I

- Television Feasibility

- Infrared Experiments

- Narrow and Wide-Angle Television

TIROS II

- Magnetic Torquing

- Narrow and Wide-Angle Television

TIROS III

- Limited Operational Use

- University of Wisconsin Radiometer

- NASA Radiometer

- Wide-Angle Television

TIROS IV through VI

- Limited Operational Use

- Wide-Angle Television

TIROS VII

- Limited Operational Use

- Ion Temperature Probe

- NASA Radiometer

- Wide-Angle Television

TIROS VIII

- First Use of APT Real-Time Television Readout

- Wide-Angle Television
1965-66

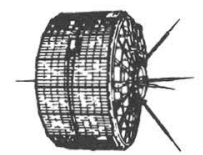

TIROS WHEEL

TIROS IX

- First Wheel Mode Spacecraft

- Near-Polar Sun-Synchronous Orbit For Daily Global Observation

- Forerunner of the TIROS Operational System

- Wide-Angle Television

TIROS X

- Interim Operational Satellite

- Wide-Angle Television

ESSA 1

- Operational Satellite

- Wide-Angle Television

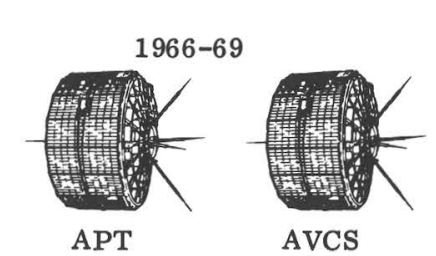

TIROS OPERATIONAL SYSTEM

ESSA 2, 4, 6 and 8

- APT Spacecraft For Real-Time Global Readout

ESSA $3,5,7$, and 9

- AVCS Spacecraft For - Daytime Global TV Observation

- Remote Sensing and Storage for U.S.

Readout

- S-Band Transmission From ESSA 7 and 9

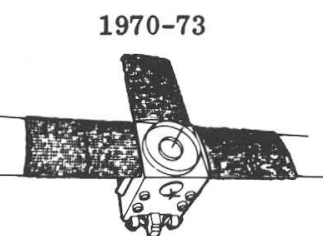

THE IMPROVED TIROS

\section{OPERATIONAL SYSTEM}

TIROS $\mathrm{M}$ and ITOS A, B, and C

- Daytime Global APT

Readout

- Daytime Global AVCS

$$
\text { Readout }
$$

- Day and Night Real-Time and Remote IR and

Visible Channel Scanning Radiometer

- Solar Proton Monitor

- Flat Plate Radiometer

- Earth-Stabilized

Platform With

Growth Capability

For Future Sensors

- ITOS 1 (formerly TIROS M) launched January 23, 1970

- NOAA 1 (formerly ITOS A) launched December 11, 1970

ITOS D, E, F, and G

- Scanning Radiometers and Very High Resolution Radiometers For Day and Night Real-Time and Remote IR and Visible DataGlobal Coverage

- Vertical Temperature Profile of Atmosphere

- Solar Proton Monitor 


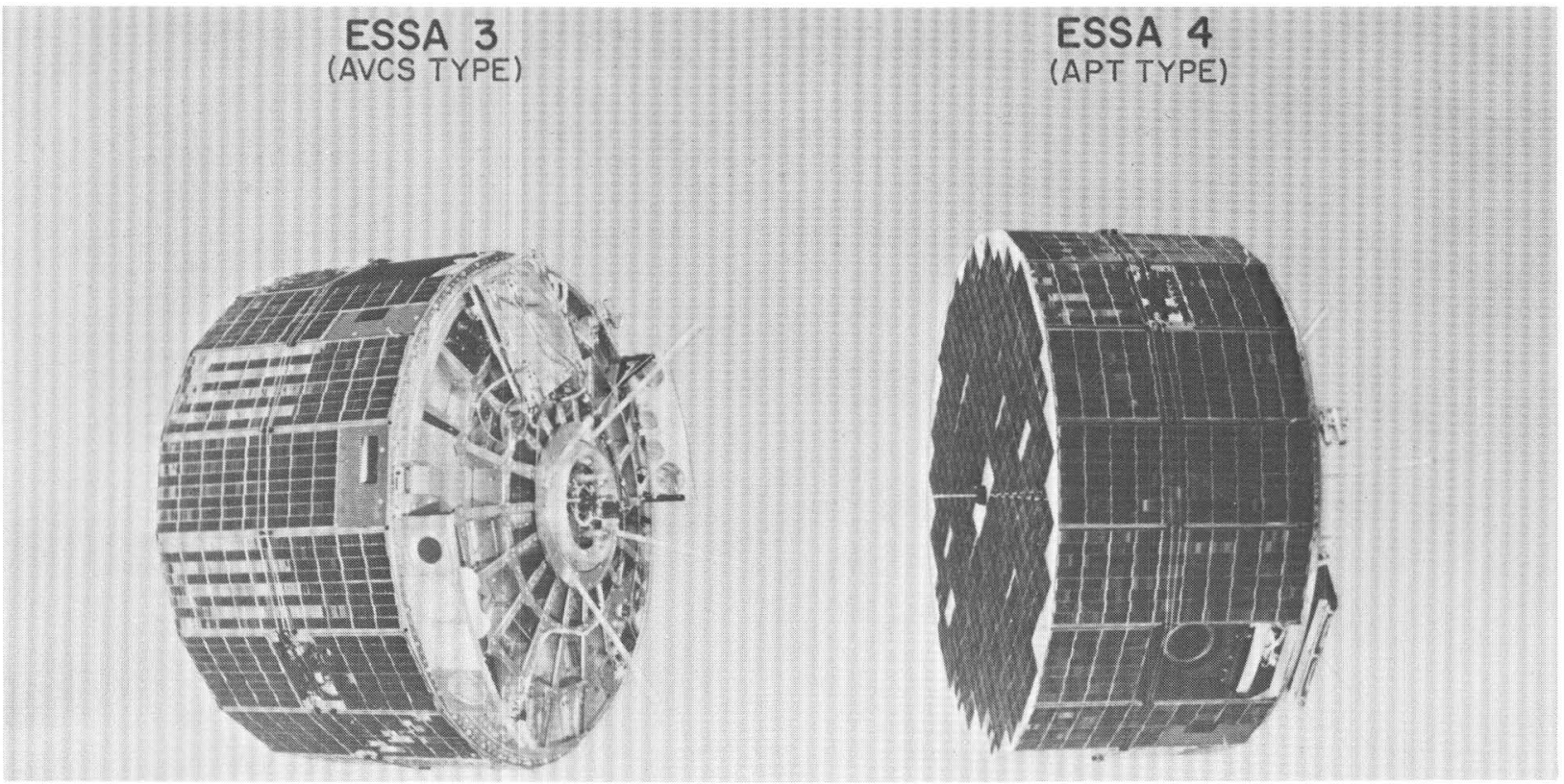

FigURE 69.-TIROS Operational Satellites (TOS).

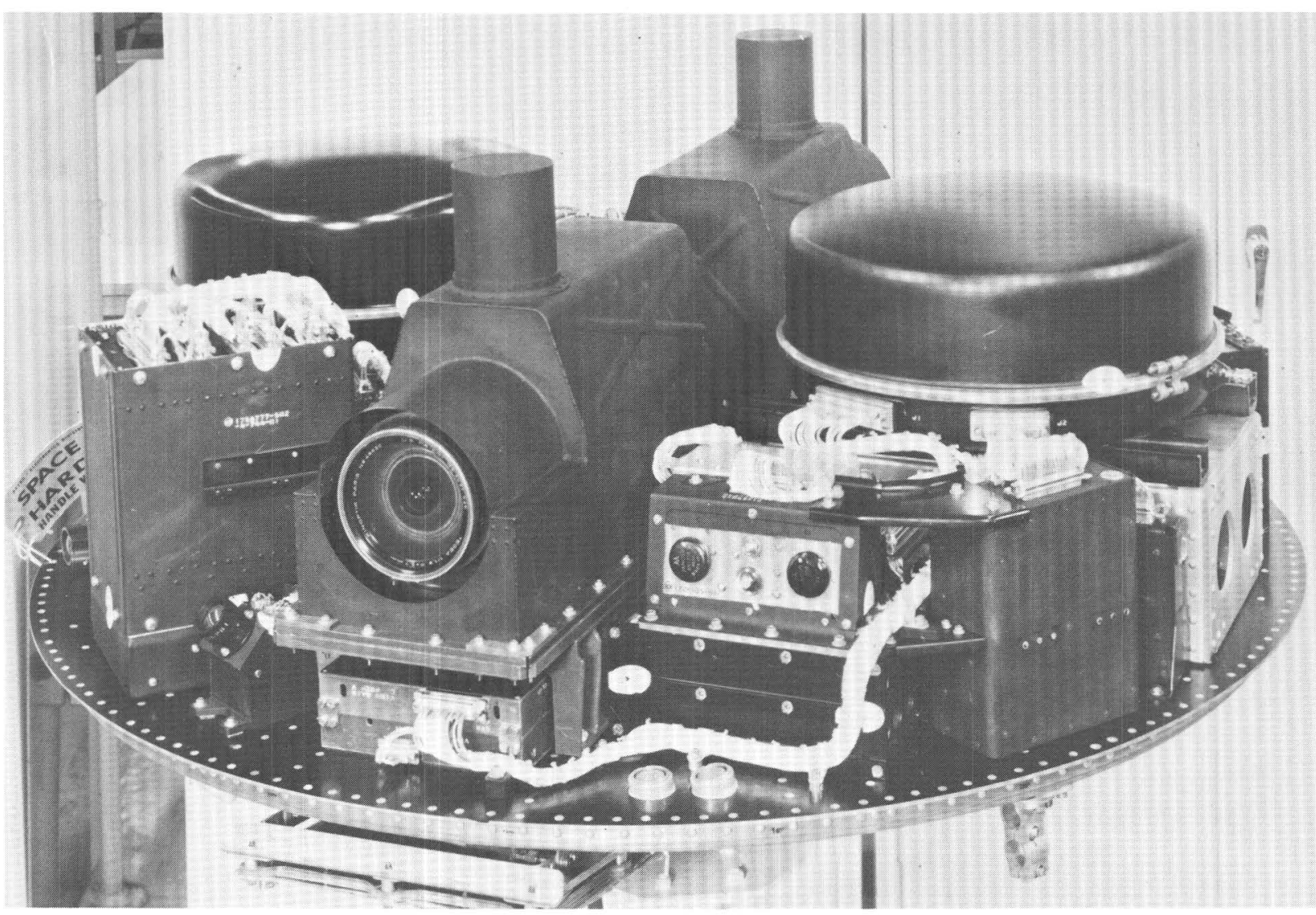

FIGURE 70.-Interior of the Environmental Survey Satellite, ESSA 3. 


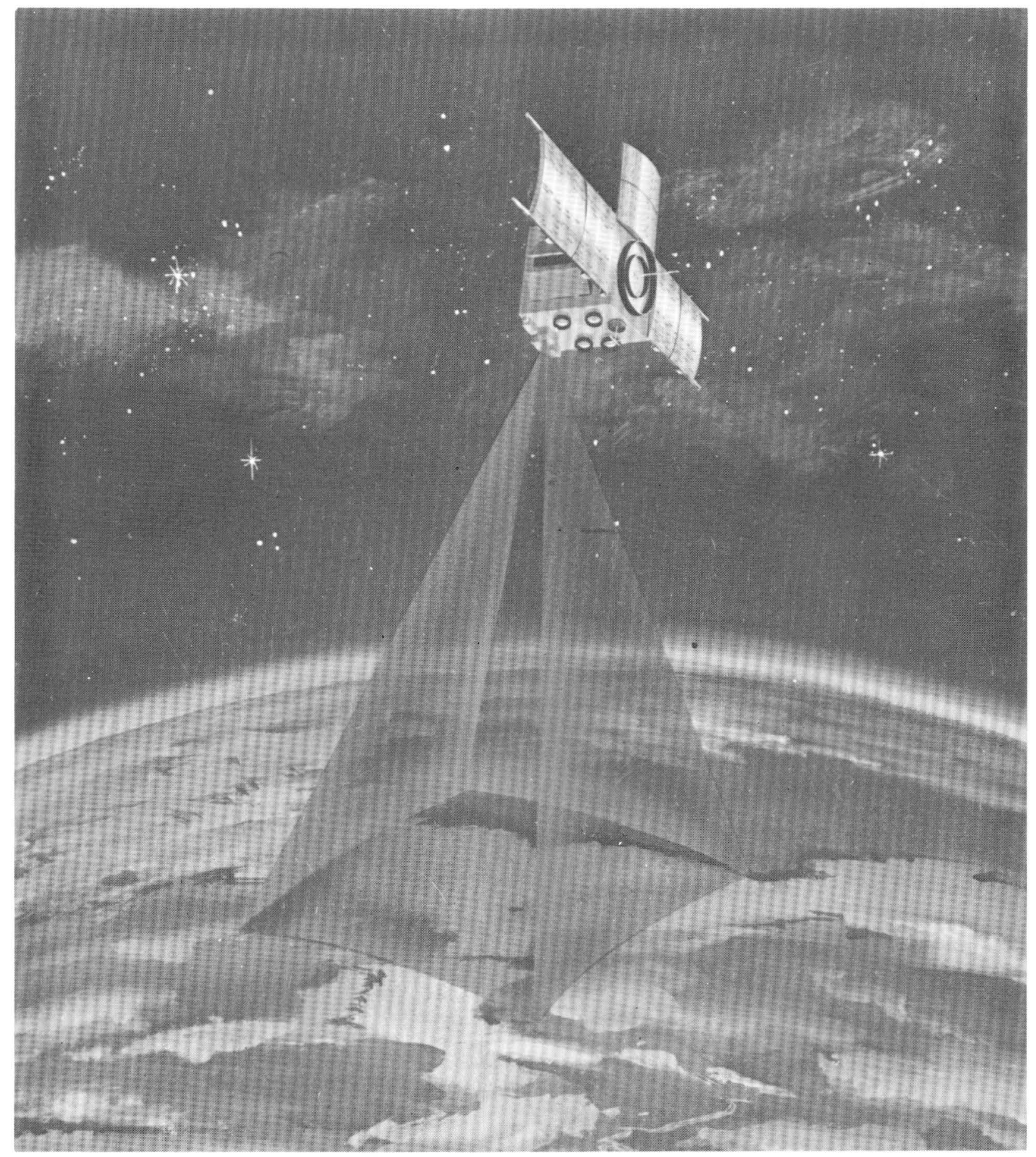

FIGURE 71.-NOAA Satellite ITOS. 


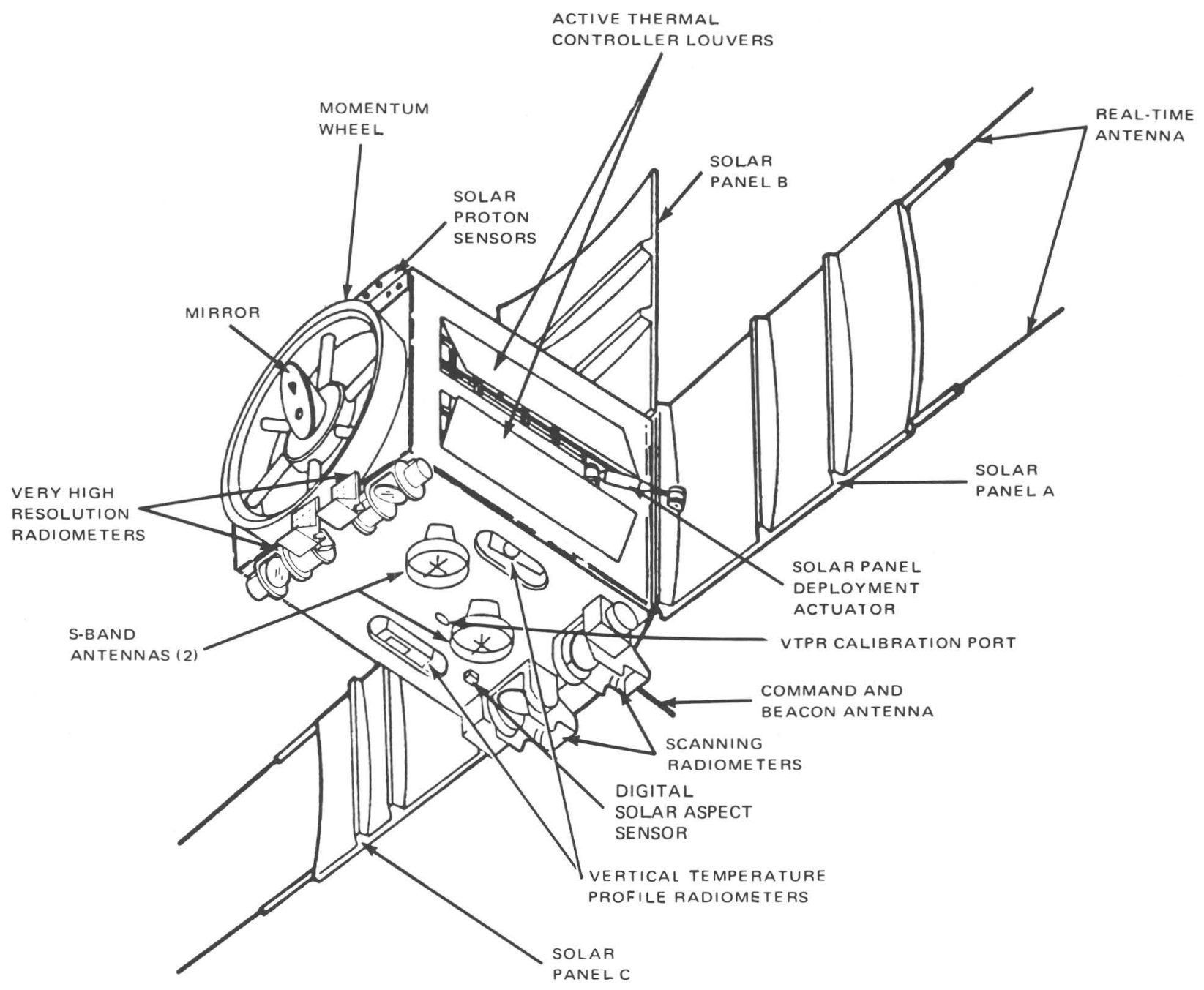

Figure 72.-NOAA Satellite ITOS-D. 
